\title{
(Re-)Programming of Subtype Specific Cardiomyocytes
}

Frauke Hausburg ${ }^{a b \S}$, Julia Jeannine Jung ${ }^{a b \S}$, Matti Hoch ${ }^{c}$, Markus Wolfien ${ }^{c}$, Arash Yavari ${ }^{\text {d }}{ }^{f}$, Christian $^{2}$ Rimmbach $^{\text {ab }}$ and Robert David ${ }^{a *}$

${ }^{a}$ Reference and Translation Center for Cardiac Stem Cell Therapy (RTC), Department of Cardiac Surgery, Rostock University Medical Center, Schillingallee 69, 18057 Rostock, Germany

${ }^{b}$ Department Life, Light and Matter of the Interdisciplinary Faculty at Rostock University, Albert-EinsteinStraße 25, 18059 Rostock, Germany

${ }^{c}$ Department of Systems Biology and Bioinformatics, University of Rostock, Ulmenstraße 69, 18057 Rostock, Germany

${ }^{d}$ Experimental Therapeutics, Radcliffe Department of Medicine, University of Oxford, UK

${ }^{\mathrm{e}}$ Division of Cardiovascular Medicine, Radcliffe Department of Medicine, University of Oxford, UK

fThe Wellcome Trust Centre for Human Genetics, Oxford, UK

$\S$ shared first authors

*Corresponding author:

$\begin{array}{ll} & \text { Robert David } \\ \text { E-mail address: } & \text { robert.david@med.uni-rostock.de } \\ \text { Fax number: } & +49-381-4946102 \\ \text { Postal address: } & \text { RTC, Department of Cardiac Surgery } \\ & \text { Rostock University Medical Center } \\ & \text { Schillingallee } 69 \\ & \text { 18057 Rostock } \\ & \text { Germany }\end{array}$




\begin{abstract}
Adult cardiomyocytes (CMs) possess a highly restricted intrinsic regenerative potential -a major barrier to the effective treatment of a range of chronic degenerative cardiac disorders characterised by cellular loss and/or irreversible dysfunction and which underlies the majority of deaths in developed countries. Both stem cell programming and direct cell reprogramming hold promise as novel, potentially curative approaches to address this therapeutic challenge. The advent of induced pluripotent stem cells (iPSCs) has introduced a second pluripotent stem cell source besides embryonic stem cells (ESCs), enabling even autologous cardiomyocyte production. In addition, the recent achievement of directly reprogramming somatic cells into cardiomyocytes is likely to become of great importance. In either case, different clinical scenarios will require the generation of highly pure, specific cardiac cellular-subtypes. In this review, we discuss these themes as related to the cardiovascular stem cell and programming field, including a focus on the emergent topic of pacemaker cell generation for the development of biological pacemakers and in vitro drug testing.
\end{abstract}

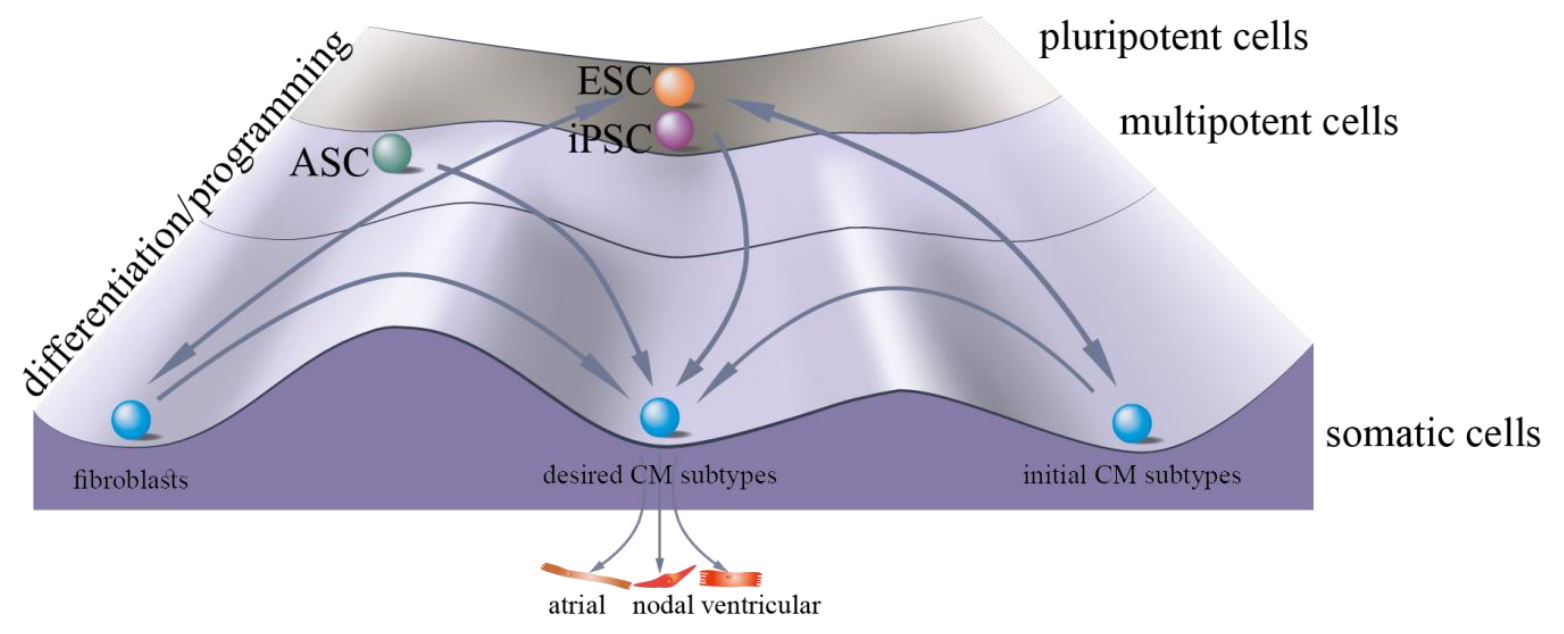

\title{
Keywords
}

ESC; iPSC; cardiovascular development; subtype differentiation; system-based data analysis; nodal cells; pacemaker 


\section{List of abbreviations}

\begin{tabular}{|c|c|}
\hline ADSC & adipose tissue-derived mesenchymal stem cell \\
\hline Alcam & activated leukocyte cell adhesion molecule \\
\hline AMI & acute myocardial infarction \\
\hline ANF & natriuretic factor \\
\hline AP & action potential \\
\hline ASC & adult stem cell \\
\hline AV & atrioventricular \\
\hline AVB & atrioventricular bundle \\
\hline AVN & atrioventricular node \\
\hline BB & bundle branch \\
\hline BCT & bioartificial cardiac tissue \\
\hline bHLH & basic helix-loop-helix \\
\hline Bry & Brachyury \\
\hline CABG & coronary artery bypass graft \\
\hline $\mathrm{Ca}_{\mathrm{v}} 1.3$ & calcium voltage-gated channel subunit alpha1 D \\
\hline $\mathrm{Ca}_{\mathrm{v}} 3.1$ & calcium voltage-gated channel subunit alpha1 G \\
\hline CCS & cardiac conduction system \\
\hline CF & cardiac fibroblast \\
\hline CHD & congenital heart disease \\
\hline CM & cardiomyocyte \\
\hline CMPC & cardiomyocyte progenitor cell \\
\hline CMVEC & cardiac microvascular endothelial cell \\
\hline CPC & cardiac progenitor cell \\
\hline CS & conduction system \\
\hline CV & cardiovascular \\
\hline CVD & cardiovascular disease \\
\hline Cx30.2 & connexin30.2 \\
\hline Cx40 & connexin40 \\
\hline Cx43 & connexin43 \\
\hline Cx45 & connexin45 \\
\hline ECG & electrocardiogram \\
\hline EMILIN2 & elastin microfibril interface 2 \\
\hline EPC & endothelial progenitor cell \\
\hline EPCS & electric-pulse current stimulation \\
\hline ESC & embryonic stem cell \\
\hline FDA & Food and Drug Administration \\
\hline FGF & fibroblast growth factor \\
\hline
\end{tabular}




\begin{tabular}{|c|c|}
\hline FHF & first (primary) heart field \\
\hline GF & growth factor \\
\hline GFP & green fluorescence protein \\
\hline GO & gene ontology \\
\hline HCN4 & hyperpolarization-activated cyclic nucleotide-gated cation channel 4 \\
\hline hPSCreg & Human Pluripotent Stem Cell registry \\
\hline HTS & high-throughput sequencing \\
\hline iCM & induced cardiomyocyte \\
\hline iPSC & induced pluripotent stem cell \\
\hline iSAB & induced sino-atrial body \\
\hline Is|1 & ISL LIM homeobox 1 \\
\hline JNK & c-Jun N-terminal kinase \\
\hline LVEF & left ventricular ejection fraction \\
\hline MAPK & mitogen-activated protein kinase \\
\hline MB & molecular beacons \\
\hline MEA & multi-electrode-array \\
\hline Mlc2v & myosin, light polypeptide 2 , regulatory, cardiac, slow \\
\hline MSC & mesenchymal stem cell \\
\hline MYH6 & myosin, heavy chain 6 , cardiac muscle, alpha \\
\hline Myh7 & myosin, heavy polypeptide 7 , cardiac muscle, beta \\
\hline $\mathrm{Na}_{\mathrm{v}} 1.5$ & sodium voltage-gated channel alpha subunit 5 \\
\hline Nkx2-5 & NK2 homeobox 5 \\
\hline Nppa & natriuretic peptide $A$ \\
\hline ODE & ordinary differential equation \\
\hline PA & polyacrylate \\
\hline PDMS & polydimethylsiloxane \\
\hline PLGA & polylactide-co-glycolide \\
\hline PMC & pacemaker cell \\
\hline PPT & protein-protein interaction \\
\hline PSC & pluripotent stem cell \\
\hline Rarg & retinoic acid receptor, gamma \\
\hline ROCK & rho-associated, coiled-coil containing protein kinase \\
\hline Rxra & retinoid $X$ receptor, alpha \\
\hline SA & sino-atrial \\
\hline SAN & sinoatrial node \\
\hline SCD & sudden cardiac death \\
\hline SCN5A & sodium channel, voltage-gated, type $V$, alpha subunit \\
\hline SHF & second heart field \\
\hline Shox2 & short stature homeobox 2 \\
\hline SIRPA & signal-reduced protein alpha \\
\hline
\end{tabular}




\begin{tabular}{|l|l|}
\hline SSS & sick sinus syndrome \\
\hline Tbx18 & T-box 18 \\
\hline Tbx3 & T-box 3 \\
\hline TF & transcription factor \\
\hline THF & tertiary heart field \\
\hline VCAM1 & vascular cell adhesion molecule 1 \\
\hline VCS & ventricular conduction system \\
\hline VEGF & vascular endothelial growth factor \\
\hline wt & wild-type \\
\hline
\end{tabular}




\section{Introduction}

The advent of regenerative medicine has opened up new perspectives for so far insoluble clinical problems. Recent progress in understanding the biology of stem cell pluripotency and endogenous repair mechanisms has fostered a deeper understanding of its remarkable therapeutic potential for tissue repair or replacement. Such novel approaches are urgently required to effectively treat the growing burden of disorders characterized by irreversibly damaged or diseased tissue resulting in loss of organ/tissue function associated with a rapidly ageing population. Furthermore, through the production of autologous pluripotent stem cells, regenerative strategies hold promise in providing truly patientspecific therapies for structural and functional repair in disease.

Cardiovascular disease (CVD) is the leading cause of death worldwide (accounting for $31.3 \%$ in 2015) and is projected to rise further (WHO 2017). CVD encompasses a range of chronic disease states, including ischemic, rheumatic and hypertensive heart disease, in addition to extra-cardiac disorders such as stroke. Heart failure represents the final common phenotype resulting from a diverse range of inherited and acquired cardiac insults and affects $\sim 26$ million individuals worldwide [1]. Individuals with severe heart failure have a dismal prognosis with a worse 5-year adjusted mortality than many cancers [2]. To date, allogeneic heart transplantation remains the only available treatment option for patients with end-stage heart failure who are symptomatic despite optimal medical and device (cardiac resynchronization) therapy [3,4]. Despite advances in surgical technique, perioperative management and immunomodulation, a major limitation to its wider application is donor organ scarcity: in Europe in 2015, only 604 donor organs were successfully engrafted, while 1140 patients are on the active Eurotransplant waiting list [5]. An additional 209 recipients died before they could undergo heart transplantation [5]. Even for those transplanted, while symptomatic improvement and survival are in general markedly improved, outcomes (median 11 year survival) are limited by long-term complications, in part associated with immunosuppression, including malignancy, infection, renal dysfunction and allograft vasculopathy [6]. In view of such limitations, highly innovative approaches are under exploration with the ultimate goal of establishing safe, durable cellular replacement and repair of injured or diseased myocardium, in addition to in vitro disease modelling and drug development applications [7-9]. A key requirement for these approaches is to ensure highly reliable and robust generation of fully functional cardiomyocytes with physiological properties as close as possible to their natural counterparts. Partially or terminally differentiated cells offer a relevant alternative to somatic stem cell transplantation, given that the latter are still a matter of controversial debate regarding their moderate therapeutic outcomes $[10,11]$. Pluripotent stem cells (PSC) and their derivatives offer an attractive source for both cell replacement and studying key cellular and molecular processes involved in cardiovascular disease. Equally, resident cells (e.g. fibroblasts) may also represent a readily accessible source of cells to study cell fate transition not only within, but even across, germ layers. 


\section{Tissue regeneration and repair for cardiovascular disease}

Normal cardiac function and physiological homeostasis is achieved through the complex interaction of a diverse range of cell types broadly constituting myocyte, vascular and stromal compartments. Even amongst specific cell types, such as cardiomyocytes (CM), there exist different phenotypes (e.g. sinoatrial, atrial, nodal, Purkinje and ventricular). Disease processes do not affect all these cell types uniformly, with relatively greater impact on specific tissue components such as fibrosis or vascular insufficiency.

The human heart does exhibit some regenerative potential, albeit very low, with an annual cardiomyocyte turnover rate of $1 \%$ at age 25 years, reducing further to $0.45 \%$ by 75 years [12]. As a corollary, adult human cardiomyocytes are long-lived cells, such that less than $50 \%$ will be replaced over a life-span of 75 years. In contrast, the proportion of $\mathrm{CM}$ situated in mitosis and cytokinesis is highest in infancy and contributes to developmental growth, suggesting significant cardiac regenerative potential in children and adolescents [13]. Other studies, including data from animal models, have highlighted that $\mathrm{CMs}$, upon transition from the mononucleate to a mature binucleate state, exit the cell cycle and lose their proliferative potential during a short postnatal period [14-16]. In the setting of common CVD such as acute myocardial infarction (MI), leading to the abrupt loss of up to $\sim 1$ billion $\mathrm{CM}$, this intrinsic regeneration potential is vastly inadequate, resulting in structural (i.e. scar) rather than functional (i.e. contractile) repair, and potentially to progressive deleterious ventricular remodeling and post-MI heart failure. However, the identification of adult $\mathrm{CM}$ repopulation raises the possibility that either normally resident cell populations such as cardiac progenitor cells (CPCs), or pre-existing CM may represent sources for myocardial repair post-injury $[13,17,18]$.

Accordingly, development of experimental protocols to robustly generate distinct cardiac cell types and define their specific clinical/preclinical applications is required. We will address the progress made recently with attempts at stem cell and somatic cell-based programming, detailing their therapeutic potential and current stage of development. A major contribution to these has been provided by applying insights gained from the study of cardiovascular developmental biology to which we turn our attention next. 


\section{Cardiogenesis during development and its regulation}

Cardiac development occurs during the early stages of the embryonic phase, and is crucial to ensure adequate nutrient and oxygen supply to, as well as removal of waste from, the growing organism. The mature mammalian heart is highly complex in structure, divided macroscopically into four chambers macroscopically and constituting specific muscle and non-muscle cell types, including left and right atrial $\mathrm{CM}$, left and right ventricular $\mathrm{CM}$, and cells forming the conduction system, sinoatrial pacemaker, vascular smooth muscle, endo- and epicardium [19-23]. The generation of such developmentally diverse cell fates are achieved via spatiotemporally stringent molecular regulation, with clear evidence that myocardial cells derive from Brachyury ${ }^{+}\left(\mathrm{Bry}^{+}\right)$mesodermal progenitor cells of the primitive streak during gastrulation through the impact of Wnt signaling [24-26].

Thereafter, two crucial transcription factors (TF) are regarded as cardiovascular fate-determining factors: the bHLH TF MesP1 (mesoderm posterior 1) [27-30] and the surface molecule Flk1 (also known as VEGFR2: vascular endothelial growth factor receptor 2) [31,32]. Further development is achieved from multipotent cardiac progenitor cells [33] and can be distinguished mainly in two origins: i) the first

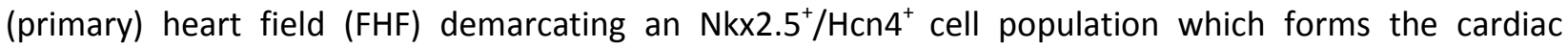
crescent [34-41], and ii) the second heart field (SHF) demarcating a $\mathrm{Nk} \times 2.5^{+} / \mathrm{Is} / 1^{+}$cell population derived from the pharyngeal mesoderm and lying medially and posterior to the FHF [41-46]. In avians, a decisive role for the tertiary heart field (THF) in pacemaker development of the sino-atrial (SA) node has also been reported $[47,48]$. Primary heart field progenitor cells will yield the myocardium of the left ventricle as well as a limited portion of the right ventricle, the right and left atria and large parts of the conduction system (CS), such as the atrioventricular (AV) node and the ventricular CS [20,42]. Multipotent progenitor cells of the SHF will yield myocardium of the right and left atria, the right ventricle and the outflow tract, as well as cardiac vascular smooth muscle and the endocardium $[31,46,49]$. In addition to these, epicardial progenitor cells give rise to cardiac fibroblasts, vascular smooth muscle, atrial and venous endothelial cells [20,50-52]. Moreover, pro-cardiogenic factors and signaling pathways play a decisive role during development and are distributed from the surrounding endoderm and mesoderm. These include bone morphogenetic proteins [53-57], notch [58], nodal and fibroblast growth factors [59-61], in addition to canonical and non-canonical Wnt/JNK [62-66].

A highly coordinated signaling network determines early cardiac progenitor as well as late specific cell fates, whose disruption can lead to abnormal embryonic development and congenital heart disease (CHD) characterized by malformation of specific cardiac structures [67]. CHD is the most common major congenital defect worldwide with a birth prevalence of between $0.58-0.9 \%[68,69]$. Thus, dysregulation of TFs (e.g. Nkx2.5 [70-78], Gata4 [77,79-82] or members of the forkhead family [83]) is associated with various abnormalities including atrioventricular block, septal defects or pulmonary stenosis [84-86]. Exemplifying this, smoking-associated cardiac defects have been linked to promotor DNA hypermethylation of Tbx5 and Gata4 caused by maternal nicotine exposure [87]. In contrast, mutations in genes encoding cardiac ion channels are largely associated with phenotypes associated with sudden cardiac death (SCD) resulting from lethal arrhythmias [88]. 


\section{Programming strategies for cardiovascular lineages}

Insights into cardiac development and the potential serious sequelae arising from its disruption are a critical prerequisite for furthering disease modelling, drug development and cell replacement strategies.

In this chapter, we address approaches to enhance cardiovascular cell differentiation from adult stem cells (ASCs) ("directed differentiation"; 4.1) and from ESCs and iPSCs ("forward programming"; 4.2), in addition to discussing attempts to convert terminally differentiated somatic cell types into cardiac cells ("direct reprogramming"; 4.3) (Figure 1).

The overriding aim of all programming strategies should be the generation of cells as physiologically close as possible to their natural counterparts. Moreover, to enable technology transfer from bench to bedside, procedures will have to be xeno-, serum-, feeder- and DNA-free. Accordingly, the approaches described below address potential options to overcome hurdles associated with the purity, yield and safety of physiologically functional $\mathrm{CM}$ subtypes (Figure 1). As an exemplar of this, we describe approaches aimed at the generation of biological pacemaker cells for both therapeutic replacement and in vitro drug testing (subsection 4.4), including our own recent progress in global transcriptome network analysis of "induced sino-atrial bodies (iSABs)" [89-91]. 


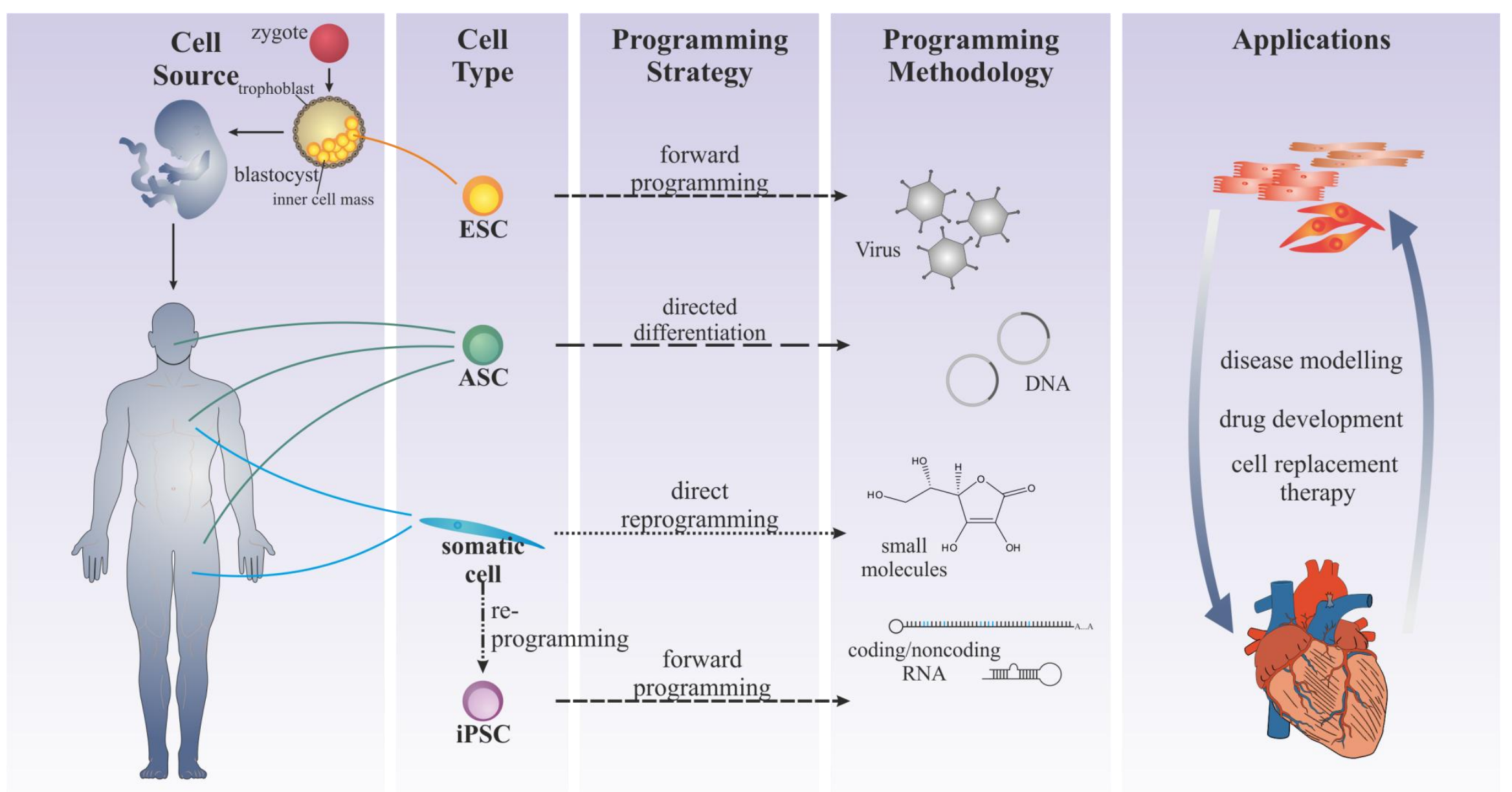

Figure 1: Common programming strategies for cardiovascular lineages. 


\subsection{Forward programming of multipotent stem cells}

\subsubsection{Cardiac programming of adult stem cells}

Early attempts at introducing adult (marrow) stem cells for transplantation therapy were performed in 1957 by E. Donnall Thomas between identical twins, with the recipient suffering from leukemia. This ushered in a phase of experimental work and clinical trials in haematopoietic transplantation which ultimately led to the award of Nobel Prize in Physiology or Medicine in 1990, for Thomas together with Joseph Murray "for their discoveries concerning organ and cell transplantation in the treatment of human disease" (http://www.nobelprize.org/nobel prizes/medicine/laureates/1990/).

While the use of stem cell transplantation for cardiovascular disorders is a promising concept approaching clinical translation [10,92,93], based on neovascularization and improved endothelial function [94], its clinical efficacy has been the subject of repeated debate in view of the modest outcomes [10]. A small study of intramyocardial delivery of purified CD133+ bone marrow SC demonstrated an encouraging but marginal improvement in left ventricular ejection fraction (LVEF) by $6 \%$ after coronary artery bypass graft (CABG) surgery: CABG-only - preoperative $37.9 \pm 10.3 \%$ to $41.3 \pm$ $9.1 \%$ after 6 months; CABG with CD133+ cell injection: preoperative $37.4 \%+/-8.4 \%$ to $47.1 \%+/-8.3 \%$ after 6 months [95]. Comparable results have been reported in studies of patients following acute myocardial infarction (AMI). Given the challenges in patient recruitment to cardiac regenerative trials [10], meta-analysis has been used to better discern the size of the potential therapeutic effect. A recent systematic review of 8 prospective randomized clinical trials containing 449 participants found no overall significant improvement in $\operatorname{LVEF}(1.47 \%, \mathrm{Cl}-4.5-7.45)$ in the setting of AMI following mesenchymal SC (MSC) transplantation [96]. However, exploratory subgroup analysis revealed a significant improvement in LVEF in those transplanted in the first week and also dependent upon cell dose administered (up to $3.3 \%)$.

(Re-)programming of ASCs may enable greater benefit from these multipotent cells. The sources of adult SC for potential cell fate alteration include MSC from bone marrow [97-104], adipose-tissue [105-110] or dental follicles [111], in addition to endothelial progenitor cells (EPCS) isolated from peripheral blood of patients with AMI or umbilical cord blood [112]. At least partial cardiogenic differentiation of these can be induced using a variety of exogenous manipulation strategies (Table1) including: i) treatment with methylation inhibitors, such as 5-azacytidine and histone deacetylase inhibitors, such as trichostatin A [97,99,100,103-106,109,112]; ii) co-culture with isolated neonatal cardiomyocytes [98,101,109]; iii) forced exogenous overexpression of either TFs, such as Shox2 [101] and Gata4, Nkx2.5 [98], or use of a TF-cocktail [106], or non-coding RNAs, including miRNAs [102] and IncRNAs [104]; or iv) stimulation via media supplemented with various growth factors $[100,107,108]$ or small molecules such as ascorbic acid [108] or suberoylanilide hydroxamic acid [111].

Recently published reports on cardiomyogenic differentiation suggest that cardiac marker expression of MSC- and $\mathrm{CD} 34^{+}$progenitor cell-derivatives are actually based on fusion with endogenous cardiomyocytes of the recipient rather than on trans-differentiation in vivo $[113,114]$. To clarify the relative roles of secreted factors versus direct cell-cell contact, indirect-co-culture using cell culture inserts has been tested, identifying that direct cell-cell contact improves results and can even lead to human adipose tissue-derived mesenchymal stem cell (ADSC)-originating spontaneously beating CM-like 
cells [109]. Future studies should define the cardiogenic differentiation potential of ASC by entirely excluding cell fusion as a mechanism, e.g. via specific labeling of the neonatal CM used, or employment of different species. However, if cell fusion is consistently demonstrated to exert a positive influence on myogenic and functional regeneration of the affected tissue, this approach should not be abandoned. The large number of studies using the epigenetic modifier 5-azacytidine highlights the potential for harnessing epigenetic modulation to modify cell fate decisions to drive regeneration. While the outcomes reported are highly variable, expression of specific cardiac markers such as desmin, cardiac actin and Troponin has been demonstrated, in association with Notch signaling. The benefits of MSC preconditioning modification such as improved cell survival and proliferation, stimulation of paracrine factor secretion and increased angiogenesis - thereby promoting cardiac repair - have been described in detail elsewhere [115].

\subsubsection{Forward programming of CM progenitor cells}

Another promising approach is the support of pre-existing precursor cells: cardiomyocyte progenitor cells (CMPC) can be efficiently isolated from fetal hearts, as either c-kit ${ }^{+}[116]$ or Sca- $1^{+}[117,118]$ cell populations. Overexpression of miR-1 and miR-499 in such cells has been shown to enhance their differentiation into cardiomyocytes via repression of histone deacetylase 4 and Sox6 [118], confirmed with overexpression of miR-499 in another CMPC population resulting in similar effects (repression of Sox6 and Rod1) by Hosoda and colleagues [116]. The cardiogenic potential of CMPC can also be efficiently enhanced using the methylation inhibitor 5-azacytidine in combination with TGF- $\beta$ [117]. 


\begin{tabular}{|c|c|c|c|c|c|c|c|}
\hline Cell origin & Host & $\begin{array}{l}\text { Delivery } \\
\text { system }\end{array}$ & $\begin{array}{l}\text { in vivo/ } \\
\text { in vitro }\end{array}$ & Factor / Substances & $\begin{array}{l}\text { Target } \\
\text { cell type }\end{array}$ & Special features & Literature \\
\hline CMPC & human & $\begin{array}{l}\text { synthetic } \\
\text { nucleoside } \\
\text { protein }\end{array}$ & in vitro & $\begin{array}{l}5 \mu \mathrm{mol} / \mathrm{L} 5-A Z A \\
\text { following } \\
1 \mathrm{ng} / \mathrm{mL} \text { TGF- } \beta 1\end{array}$ & CM-like & $\begin{array}{l}\text { spontaneously beating myocytes; gap- } \\
\text { junctional communication and action } \\
\text { potentials of maturing cardiomyocytes }\end{array}$ & $\begin{array}{l}\text { Goumans et al., } \\
2007 \text { [117] }\end{array}$ \\
\hline ADSC & rat & protein & in vitro & 10 ng/mL TGF- $\beta 1$ & CM-like & Actin, cMhc & $\begin{array}{l}\text { Gwak et al., } \\
2009 \text { [107] }\end{array}$ \\
\hline ADSC & human & $\begin{array}{l}\text { synthetic } \\
\text { nucleoside }\end{array}$ & in vitro & $\begin{array}{l}10 \mu \mathrm{mol} / \mathrm{L} 5-\mathrm{AZA} \\
\text { or } \\
100 \mathrm{ng} / \mathrm{mL} \text { TSA } \\
\text { or } \\
\text { Co-culture with RNCM } \\
\text { or } \\
\text { modified cardiomyogenic } \\
\text { medium }\end{array}$ & CM-like & $\begin{array}{l}\text { Highest expression in direct contact co- } \\
\text { culture with RNCM: } \\
\text { Actin, Gata4, Nkx2.5, cTnT } \\
\text { spontaneous contractions } \\
\text { synchronous } \mathrm{Ca}^{2+} \text { transient }\end{array}$ & $\begin{array}{l}\text { Choi et al., } 2010 \\
{[109]}\end{array}$ \\
\hline CMPC & human & miRNA & in vitro & miR-1 and miR-499 & CM-like & $\begin{array}{l}\text { Repression of HDAC4 and Sox6 } \\
\text { Enhanced cardiomyogenesis }\end{array}$ & $\begin{array}{l}\text { Sluijter et al., } \\
2010 \text { [118] }\end{array}$ \\
\hline CMPC & human & miRNA & $\begin{array}{l}\text { in vitro / } \\
\text { in vivo }\end{array}$ & miR-499 & CM-like & $\begin{array}{l}\text { Repression of Sox6 and Rod } 1 \\
\text { Enhanced cardiomyogenesis }\end{array}$ & $\begin{array}{l}\text { Hosoda et al., } \\
2011[116]\end{array}$ \\
\hline ADSC & rat & $\begin{array}{l}\text { synthetic } \\
\text { nucleoside }\end{array}$ & in vitro & $\begin{array}{l}\text { Planat-Bérnard } \\
\text { or } \\
5 \mu \mathrm{mol} / \mathrm{L} 5-\mathrm{AZA}\end{array}$ & CM-like & $\begin{array}{l}\text { no spontaneous contraction } \\
\text { Actn } 2, C x-43\end{array}$ & $\begin{array}{l}\text { Carvalho et al., } \\
2012 \text { [105] }\end{array}$ \\
\hline BMSC & mouse & $\begin{array}{l}\text { miRNA } \\
\text { (Lentiviral) }\end{array}$ & in vitro & miR-1 & CM-like & $\begin{array}{l}\text { downregulation of Hes-1 } \\
\text { expression of: Nkx2.5, GATA-4, cTnT, and } \\
\text { Cx43 }\end{array}$ & $\begin{array}{l}\text { Huang et al., } \\
2013 \text { [102] }\end{array}$ \\
\hline BMSC & human & $\begin{array}{l}\text { synthetic } \\
\text { nucleoside }\end{array}$ & in vitro & $\begin{array}{l}6 \mu \mathrm{mol} / \mathrm{L} 5-A Z A \\
\text { or } \\
10 \mathrm{ng} / \mathrm{mL} \text { TGF- } \beta 1\end{array}$ & CM-like & $\begin{array}{l}\text { Expression of: GATA-4, Nkx2.5, Mlc-2a, } \\
\text { actin } \\
\text { Higher expression in AZA-group to control: } \\
\text { Mlc-2a, Mlc-2v, cTnT }\end{array}$ & $\begin{array}{l}\text { Mohanty et al., } \\
2013[100]\end{array}$ \\
\hline EPC & human & $\begin{array}{l}\text { synthetic } \\
\text { nucleoside }\end{array}$ & in vitro & 5-AZA & CM-like & $\begin{array}{l}\text { expression of: Actn2, cTnT, cTnl and } \\
\text { desmin }\end{array}$ & $\begin{array}{l}\text { López-Ruiz et } \\
\text { al., 2014 [112] }\end{array}$ \\
\hline BMSC & pig & $\begin{array}{l}\text { synthetic } \\
\text { nucleoside }\end{array}$ & in vitro & $\begin{array}{l}10 \mu \mathrm{mol} / \mathrm{L} 5-A Z A \\
\text { IGF-1 }\end{array}$ & CM-like & $\begin{array}{l}\text { Expression of: GATA-4, Nkx2.5, } \beta-\mathrm{MHC} \text { and } \\
\text { MEF2c }\end{array}$ & $\begin{array}{l}\text { Li et al., } 2015 \\
\text { [99] }\end{array}$ \\
\hline
\end{tabular}




\begin{tabular}{|c|c|c|c|c|c|c|c|}
\hline & & lentiviral & & & & & \\
\hline BMSC & rabbit & DNA Plasmid & $\begin{array}{l}\text { in vitro / } \\
\text { in vivo }\end{array}$ & $\begin{array}{l}\text { GATA4, Nkx2.5 } \\
\text { extracellular environment } \\
\text { co-culture with RNCM }\end{array}$ & CM-like & $\begin{array}{l}\text { In combination with co-culture: } \\
\text { significantly effective and enhance the } \\
\text { ability to repair MI }\end{array}$ & $\begin{array}{l}\text { Li and Zhang, } \\
2015 \text { [98] }\end{array}$ \\
\hline BMSC & mouse & $\begin{array}{l}\text { specific } \\
\text { culture and } \\
\text { substrate } \\
\text { conditions }\end{array}$ & in vitro & $0.3 \mathrm{~mm}$-thick hcECM & CM-like & no evidence of $\mathrm{CM}$ differentiation & $\begin{array}{l}\text { Oberwallner et } \\
\text { al., } 2015 \text { [119] }\end{array}$ \\
\hline BAT & mouse & $\begin{array}{l}\text { specific } \\
\text { culture } \\
\text { conditions }\end{array}$ & $\begin{array}{l}\text { in vitro / } \\
\text { in vivo }\end{array}$ & $\begin{array}{l}1 \% \text { methylcellulose/ } \\
\text { Iscove's Modified } \\
\text { Dulbecco's Medium } \\
\text { containing hematopoietic } \\
\text { cytokines }\end{array}$ & CCS-like & $\begin{array}{l}\text { regular beating } \\
\text { expression of: } \\
\text { Nkx2.5, } \\
\text { GATA6, } \\
\text { Mef2c, } \\
\text { ANF, } \alpha-M H C \text {, } \\
\beta-M H C \text {, } \\
\text { MLC2a, } \\
\text { MLC2v, but not GATA4 }\end{array}$ & $\begin{array}{l}\text { Takahashi et al., } \\
2015 \text { [110] }\end{array}$ \\
\hline BMSC & rat & $\begin{array}{l}\text { synthetic } \\
\text { nucleoside }\end{array}$ & $\begin{array}{l}\text { in vitro / } \\
\text { in vivo }\end{array}$ & $10 \mu \mathrm{mol} / \mathrm{L} 5-A Z A$ & CM-like & Expression of: desmin, actin and cTnT & $\begin{array}{l}\text { Yang et al., } \\
2015 \text { [97] }\end{array}$ \\
\hline BMSC & canine & lentiviral & in vitro & $\begin{array}{l}\text { Shox2 } \\
\text { Co-culture with RNCMs }\end{array}$ & SAN-like & $\begin{array}{l}\text { High levels of: Tbx3, HCN4, Cx45 } \\
\text { Low levels of: Nkx2.5, Cx43 } \\
\text { Able to pace RNCMs with a faster rate }\end{array}$ & $\begin{array}{l}\text { Feng et al., } \\
2016[101]\end{array}$ \\
\hline $\begin{array}{l}\text { SC-ADSC } \\
\text { VL-ADSC } \\
\text { CA-ADSC } \\
\text { SS-ADSC }\end{array}$ & mouse & $\begin{array}{l}\text { specific } \\
\text { culture } \\
\text { conditions }\end{array}$ & $\begin{array}{l}\text { in vitro / } \\
\text { in vivo }\end{array}$ & $\begin{array}{l}\text { Medium suppl. with: } \\
\text { - for vascular smooth } \\
\text { muscle cell differentiation: } \\
\text { TGF- } \beta \\
\text { - for endothelial } \\
\text { differentiation: } \\
\text { hFGF, hVEGF, hIGF, AA, } \\
\text { hEGF } \\
\text { - for cardio- } \\
\text { myocyte differentiation: } \\
\text { PMA }\end{array}$ & $\begin{array}{l}\text { CM-like, } \\
\text { endotheli } \\
\text { al cells, } \\
\text { vascular } \\
\text { smooth } \\
\text { muscle } \\
\text { cells }\end{array}$ & Highest potential with: CA-ADSC & $\begin{array}{l}\text { Nagata et al., } \\
2016 \text { [108] }\end{array}$ \\
\hline DFC & human & small & in vitro / & $10 \mu \mathrm{M}$ SAHA in ADMEM & CM-like & in vitro: & Sung et al., \\
\hline
\end{tabular}




\begin{tabular}{|c|c|c|c|c|c|c|c|}
\hline & & molecule & in vivo & $\begin{array}{l}\text { media; } \\
\text { following continuous } \\
\text { culture in media containing } \\
1 \mu \mathrm{M} \text { of SAHA }\end{array}$ & & $\begin{array}{l}\text { expression of: } \alpha \text {-SMA, TnnT2, desmin, } \\
\text { Actc1 } \\
\text { in vivo homing: } \\
5.6 \pm 1.0 \% \text { heart } \\
3.6 \pm 1.1 \% \text { liver } \\
11.6 \pm 2.7 \% \text { kidney } \\
\text { With differences in IL-2 and IL-10 }\end{array}$ & 2016 [111] \\
\hline $\begin{array}{l}\text { E-ADSC } \\
\text { P-ADSC } \\
\text { O-ADSC }\end{array}$ & human & $\begin{array}{l}\text { synthetic } \\
\text { nucleoside } \\
\text { retroviral }\end{array}$ & in vitro & $\begin{array}{l}10 \mu \mathrm{mol} / \mathrm{L} 5-A Z A \\
\text { or } \\
\text { ESRRG, GATA4, MEF2C, } \\
\text { MESP1, MYOCD, TBX5, } \\
\text { ZFPM2 }\end{array}$ & CM-like & $\begin{array}{l}\text { 5-AZA: } \\
\text { no increased expression of Actn2 or cTnT } \\
\text { 7-factor-group: } \\
\text { E-ADSC: increased Actn2 and cTnT }\end{array}$ & $\begin{array}{l}\text { Wystrychowski } \\
\text { et al., } 2016 \\
{[106]}\end{array}$ \\
\hline BMSC & human & $\begin{array}{l}\text { synthetic } \\
\text { nucleoside }\end{array}$ & in vitro & $10 \mu \mathrm{mol} / \mathrm{L}$ 5-AZA & CM-like & $\begin{array}{l}\text { Upregulation of: Notch1, Gata4, Nkx2.5, } \alpha \text { - } \\
\text { actin, cTnT }\end{array}$ & $\begin{array}{l}\text { Yu et al., } 2016 \\
{[103]}\end{array}$ \\
\hline BMSC & mouse & IncRNA & in vitro & $\begin{array}{l}10 \mu \mathrm{mol} / \mathrm{L} 5-\mathrm{AZA} \\
\text { Braveheart } \\
\text { hypoxia/reoxygenation } \\
\text { treatment }\end{array}$ & CM-like & $\begin{array}{l}\text { Expressions of: } \alpha \text {-actin, cTnT, Nkx2.5, } \\
\text { Gata4, Gata6, Isl-1, EMT-associated genes } \\
\text { (Snail, Twist, N-cadherin) }\end{array}$ & $\begin{array}{l}\text { Hou et al., } 2017 \\
{[104]}\end{array}$ \\
\hline
\end{tabular}

AA: ascorbic acid; Actc1: cardiac muscle alpha actin; Actn2: sarcomeric alpha-actinin; ADSC: adipose tissue-derived mesenchymal stem cells (E: epicardium, P: pericardium, O: omentum, SC: subcutaneous white adipose tissue, VL: visceral white adipose tissue; CA: cardiac brown adipose tissue, SS: subscapular brown adipose tissue); $\alpha$-SMA: alpha-smooth muscle actin; BAT: brown adipose tissue derived stem cells from interscapular area; BMSC: bone marrow mesenchymal stem cells; CCS: cardiac conduction system; CM: cardiomyocyte; CMPC: cardiomyocyte progenitor cells; CPC: cardiac progenitor cells; cTnT: cardiac Troponin T; Cx43/45: Connexin43/45; DFC: dental follicle-derived mesenchymal stem cells; hcECM: human cardiac extracellular matrix; HDAC4: Histone deacetylase 4; hEGF: human epidermal growth factor; hFGF: human fibroblast growth factor; hIGF: human insulin-like growth factor; hVEGF: human vascular endothelial growth factor; IL-2/10: interleukin-2/10; IncRNA: long noncoding RNA; miR: microRNA; Mlc: myosin light chain; PMA: phorbol myristate acetate; RNCM: rat neonatale cardiomyocytes; SAHA: suberoylanilide hydroxamic acid; TGF- $\beta$ : transforming growth factor- $\beta$; TnnT2: cardiac muscle troponin T; TSA: trichostatin A; 5 -AZA: 5 azacytidine 


\subsection{Programming of pluripotent stem cells}

Pluripotent stem cells, encompassing embryonic and induced pluripotent stem cells, represent an attractive platform to study key cellular and molecular programs of early heart development. The Human Pluripotent Stem Cell registry (hPSCreg) listed a total of 1281 cell lines in August 2017 (hESC: 707, hiPSC: 574) (http://hpscreg.eu/). Worldwide, the majority of hESC lines are recorded in the U.S.A., while in Europe the highest numbers are in the U.K.. The number of hiPSC lines is constantly increasing, with a dramatic increase from 120 lines in January 2016.

Since their first successful differentiation towards cardiomyocytic phenotypes was demonstrated in 1991, ESCs have grown to become an invaluable in vitro model to study cardiac development [120]. Currently, the number of publications relying on murine and human ESCs is increasing daily - a selected portion of these published over the past five years is shown in Table 2. Importantly, gene expression analysis has revealed a unique profile for each individual hESC line [121,122], which obviously results in variable self-renewal behavior and differentiation preferences $[123,124]$. Moreover, even the in vitro "micro-environment" of each laboratory can exert a strong impact on the cell line's gene expression signature [125].

To overcome ethical concerns as well as the poor accessibility of ESCs, iPSCs have become a major focus of interest since their seminal description a decade ago [126,127]. Representative recent studies using murine and human iPSCs for cardiogenic differentiation are outlined in Table 3.

The starting cell types for iPSC generation are available on a large scale from various easily accessible sources. Furthermore, autologous material enables the production of patient-specific iPSCs which can be expected to become highly relevant for personalized therapy as well as in vitro drug testing. The retained epigenetic memory of such cells, demonstrated by the incomplete reprogramming of non-CG methylation as well as differences in CG methylation and histone modifications [128] are important considerations. They represent a drawback on the one hand, by leading to intra-line variability within clones from a single subject, but can also be construed as advantageous with respect to the cells' enhanced ability to differentiate preferentially into their cell type of origin $[129,130]$. Thus, iPSCs derived from murine neonatal ventricular myocytes display a higher propensity towards spontaneous differentiation into beating CM compared to iPSCs derived from other somatic cells (e.g. tail-tip fibroblasts) [131]. In addition, the re-programming strategy towards the iPS cell stage itself has both substantial influence on programming efficiency, and affects the genetic profile of iPSCs themselves, resulting in high line-to-line variability. To date, the application of synthetic modified mRNA has the highest programming efficiency ( $4.4 \%)$ using the TFs Oct4, Sox2, Klf4, c-Myc, Lin28 in combination with valproic acid [132]. Moreover, another study claimed "foot-print free" non-integrative mRNA-based reprogramming of somatic cells and subsequent effective differentiation towards a CM-like phenotype including sarcomeric marker expression and appropriate specific responses to pharmacological modulation [133]. In this regard, it has been shown that iPS-derived CMs can exhibit residual transgene expression of Oct4 and Nanog after lentiviral-mediated transduction [134], which has the potential to lead to tumor formation.

The multifaceted powerful potential of iPSC-derived cells has helped foster numerous preclinical studies, with the therapeutic effect of their derivatives largely ascribed to their paracrine effects in supporting ischemic tissue [135]. With regard to ESC, at present only a single phase I clinical trial using human ESC-derived $\mathrm{CD} 15^{+} \mathrm{Is} \mid 1^{+}$progenitors for transplantation in severe heart hailure is actively recruiting (ESCORT). 
Apart from the cellular origin, concepts regarding differentiation of various PSCs are highly dependent on insights gained from study of natural embryonic development, to enable the driving of cell fate alongside time-, space- and signaling-dependent patterns in order to overcome hurdles associated with species-specification and inter-personal variations. The direct application of PSCs as purely undifferentiated cells is unfeasible due to their high teratogenic potential in vivo $[136,137]$. Despite experimental progress with PSC-derived CMs, achieving functional maturation of these cells has so far proved elusive in vitro [138]. This is likely to reflect the current infeasibility of precisely mimicking the entire natural microenvironment, including topographical, electrical, adhesive, mechanical, biochemical, and cell-cell interaction cues [139].

In this chapter we will discuss the two main emerging strategies for efficient forward programming towards CM-like cells: i) molecular programming using forced exogenous overexpression of lineage-specific TFs and miRNAs (4.2.1); and ii) targeted differentiation via provision of optimized culture conditions (4.2.2). Furthermore, specific concepts will be considered regarding selection- (4.2.3) as well as maturation- (4.2.4) strategies to enhance the quality of the final cell product.

\subsubsection{Molecular programming}

Early molecular programming studies using ESCs have demonstrated MesP1 to be an essential cardiac fate determinant [140-143]. Recent in vivo studies have confirmed the positive effect of MesP1 CPCs in promoting cardiovascular repair of murine hearts [144]. Moreover, gain-and-loss-of function experiments have disclosed a major role for miR-322/-503 in a MesP1 progenitor population in regulating early cardiac fate decision by negatively effecting neuroectoderm differentiation [145]. Thus, $\mathrm{MesP}^{+}$mesodermal progenitors represent a heterogeneous population bearing a context-dependent potential to differentiate into cardiac, hematopoietic and skeletal myogenic progenitors [146-148], which is also the case for Flk1 ${ }^{+}$mesodermal cells [149]. Numerous factors affect MesP1 and subsequent cardiac TF expression, such as Bry ${ }^{+}$[141], Cited2 [150], CIBZ (BTB domain-containing zinc finger protein) [151] and Fndc5 (Fibronectin type III domain-containing 5 protein (also known as: peroxisomal protein (PEP)) [152]. Another group of RNAs, the so called long noncoding RNAs (IncRNAs) play a still incompletely understood role during cardiac development; for instance, the IncRNA Braveheart has been demonstrated to act as an epigenetic modulator upstream of MesP1 using multiple ESCS [153].

Forced overexpression of key fate-determining factors has also been applied to the generation of SAN-like cells from ESCs, using the TFs Tbx3 [89], Shox2 [154] and IsI1 [155], thereby directing cell fate towards a pacemakerlike phenotype. This topic is discussed in more detail below (4.4).

Data on molecular programming using forced exogenous overexpression of lineage-specific TFs are so far restricted to ESCs - to date; no attempts have been described in the literature for iPSCs.

\subsubsection{Targeted differentiation}

There are currently numerous direct programming protocols using PSCs which include a focus on continual optimization and refinement of the targeted differentiation process with respect to time- and dose-dependent application of cardiogenic modulators (Figure 2). This may allow precise manipulation of PSCs through 
activation or inhibition of diverse implicated molecular pathways. While the protocols schematically presented in Figure 2 have some similarities in common such as respective pathway activation or inhibition, they differ with respect to specific timeframes and overall duration of cell culture required.

Such approaches start, after preliminary ROCK inhibition [156-160], with initial activation of Wnt signaling using via Wnt activators such as CHIR99021 or direct application of Wnt3 in order to induce a mesodermal CPC population [144,156,157,160-162], together with the addition of Activin A and BMPs (bone morphogenetic proteins) $[144,158,159,161,163-166]$. Substances administered in the second step depend upon the desired lineage specification to either a working myocardial or a conduction system cellular phenotype. CM-like induction requires the inhibition of Wnt signaling via Wnt inhibitors [156,159-161], such as IWR1 and IWP2, as well as the addition of various growth factors (GFs), such as FGF (fibroblast GF) and VEGF (vascular endothelial GF) $[157,159,161,163,165]$. In addition, modulation of MAPK signaling, using SB203580 [133] and PD98059 [167] (both MAPK inhibitors), or Rho-kinase inhibitors (H1152) [158] are utilised. In contrast, differentiation towards SAN-like cells mandates inhibition of GF-, including Activin- and Nodal-signaling using inhibitors such as PD 173074 (FGF signaling inhibitor) and SB-431542 (Activin/Nodal/TGFß signaling inhibitor) [159].

The final cellular product varies among protocols with respect to marker gene expression, however, each approach results in expression profiles partly specific for CM-like or SAN-like cells, including a reported $>90 \%$ $\mathrm{cTnT}^{+}$cells [157], >90\% CD31 $/ \mathrm{VE}$-cadherin ${ }^{+}$ECs [164] or $35-40 \%$ double positive $\mathrm{cTnT}^{+} / \mathrm{MF}^{+} 0^{+}$cells [165]. In addition, targeted differentiation-derived pacemaker-like cells exhibit specific action potential profiles [159]. Enhanced proliferation (up to 14-fold) of ESC-derived CM-like cells has been obtained through the addition of specific GSK3 and CaMKII inhibitors, as well as ERK activators [168]. Furthermore, epigenetic modulators have been used such as ascorbic acid [169-171], which, when applied during a specific time-frame from day 0 to day 2 of differentiation, leads to a 2-4-fold increase in cardiogenesis [169].

Such in vitro differentiation protocols approximate the highly sensitive and finely-tuned interplay of signaling pathways required for healthy embryonic development. Their success is critically dependent upon careful, albeit protracted, step-by-step protocol optimization. 


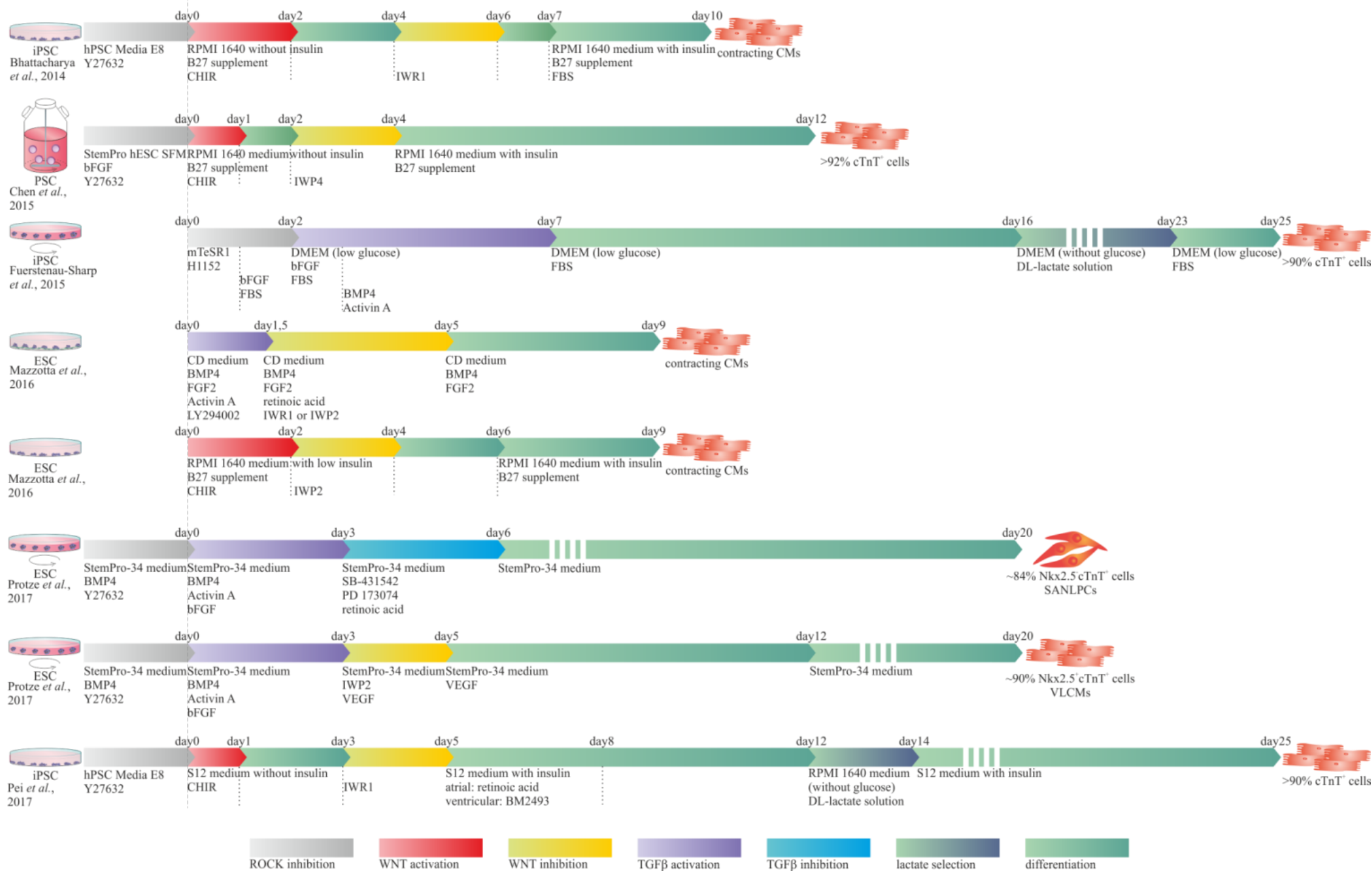

Figure 2: Schematic timescale for targeted differentiation of human PSCs. This cartoon summarizes various strategies and protocols of pluripotent stem cell (ESC, iPSC) differentiation towards cardiomyocytic cells, relying on time- and dose-dependent application of cardiogenic modulators without any nucleic acid introduction or factor overexpression. 


\subsubsection{Selection-strategies}

Notwithstanding the existence of in vitro approaches described above, purity of PSC-CMs is still a major issue, with the choice of suitable and highly reliable surface marker for use in standard flow cytometry or magnetic isolation procedures for differentiating CMs still under debate. Accordingly, purification strategies based on cardiac specific intra-cellular marker expression remain an important approach.

Stable PSC lines containing: i) aMHC (99\% $\mathrm{MHC}^{+}$cells) [171,172] or VE-cadherin $\left(47 \% \mathrm{cTnT}^{+}\right.$cells) [173] promotor-linked antibiotic resistance genes have been used to efficiently select $\alpha \mathrm{MHC}^{+}$cells or a cardiac and endothelial dual-progenitor population; ii) $\alpha \mathrm{MHC}$ promotor-linked green fluorescence protein (GFP) gene [168], enabling $\mathrm{GFP}^{+}$flow cytometric selection. Both methods have the disadvantage of requiring stable exogenous DNA introduction. iii) Another approach, applied by Bao's group, enables the purification of CMs through specific molecular beacons (MBs) which target mRNAs, such as MBs targeting myosin heavy chain 6/7 (97\% cTnT $^{+}$cells) [174] or NPPA (92\% $\alpha$-actinin ${ }^{+}$cells) [175] mRNA. Additional approaches used include the selection of CM-like cells via: iv) mitochondria-specific fluorescent dyes (99\% $\alpha$-actinin ${ }^{+}$cells) [176]; or v) antibodies against partially cardiomyocyte-specific markers, e.g. SIRPA (signal-reduced protein alpha) (98\% $\mathrm{cTnT}^{+}$cells) [177], EMILIN2 (elastin microfibril interface 2) (no qualitative statement about $\alpha$-actinin ${ }^{+} \mathrm{or}^{\mathrm{cTnT}^{+}}$ cell yield)[178], or VCAM1 (vascular cell adhesion molecule 1) (95\% cTnT ${ }^{+}$cells) [179]. A consequence of the increasing mitochondrial-to-cell volume ratio during $\mathrm{CM}$ development is the metabolic substrate shift from glucose and lactate in early developmental stages to the primary reliance on fatty acid oxidation characterizing adult mature CMs [180]. These changes have been applied in non-genetic metabolic purification strategies (98\% $\alpha$-actinin ${ }^{+}$cells) $[158,160,181,182]$. Initial approaches used glucose-deplete/lactate-enriched media, achieving quite homogenous populations and increased purity $[158,160]$. In this regard, Kuppusamy et al. demonstrated a positive impact on cardiac maturation exerted by the let-7 family of microRNAs which are associated with metabolic energetics in maturing CM [183]. Overall, at present, other than standard promotorlinked selection approaches, the remaining novel selection strategies still require further evidence of reproducibility in independent laboratories using different PS cell lines.

An important consideration is that current PSC-derived CMs represent a mixture of nodal-, atrial-, ventricularlike and early-intermediate immature phenotypes, as evident from electrophysiological and pharmacological studies [89,134]. Transplantation of such CM mixtures could induce significant arrhythmia [184], thus further purification will be an indispensable prerequisite for clinical translation.

\subsubsection{Maturation-strategies}

In general, all published reports have - to a greater or lesser extent - generated an immature and physiologically incomplete CM phenotype, reflecting the heterogeneity of PSCs used as well as the distinction between human and murine cell lines [138]. A variety of substrates and protocol modifications are under close scrutiny with the goal of obtaining improvements in cardiogenic differentiation during culture to enable safe bench-to-bedside implementation. 
Differential effects can arise from the cultivation procedure itself, including an important influence of cultured temperature and distinctions between use of 2D monolayer or 3D EB formation. Low oxygen preconditioning $\left(\begin{array}{ll}2 \% & \mathrm{O}_{2}\end{array}\right)$ can impact on lineage commitment [185], with murine ESCs displaying significantly increased expression of the early differentiation markers FGF5 and Eomes consistent with preferred differentiation towards mesodermal and endodermal lineages. In contrast, culturing human PSCs under low oxygen tension prior to spontaneous differentiation in EBs primes commitment to an ectodermal lineage, indicated by significant induction of $\beta 3$-tubulin and Nestin [185].

An important but contentious issue is the use of either diverse co-culture systems or an adjusted material surface. PSC-derived CMs cultured on fibronectin-coated micro-grooved polydimethylsiloxane (PDMS) scaffolds exhibit a more organized sarcomeric structure, together with a more homogenous alignment and improved sarcoplasmic reticulum-based $\mathrm{Ca}^{2+}$ cycling [186]. Angelo's group introduced a biomimetic aligned nanofibrous cardiac patch which resembles the extracellular matrix of decellularized myocardium from rats [187]. The material used, namely polylactide-co-glycolide (PLGA), is an FDA approved therapeutic device due to its biodegradability and biocompatibility and has great potential to form the basis of an implantable cardiac patch. Moreover, this anisotropic environment additionally results in symmetric alignment of iPSC-derived CMs. ESC differentiation on intermediate stiffness polyacrylate (PA) hydrogel substrate resulted in only a slight enhancement of differentiation in comparison to common (rigid) polystyrene tissue culture [188]. Promising approaches using matrix-free, GMP-compliant culture protocols have yielded $94 \% \mathrm{cTnT}^{+}$cells [157], which may facilitate advance towards clinical use.

hESCs co-cultured with AKT-activated endothelial cells led to an improvement in Nkx2.5 cell yield as well as faster beating frequencies compared to hESCs cultured on Matrigel alone [189]. These findings concur with observations of other groups exploiting the benefits of co-culture $[119,171,190]$. Co-culture with MEF or SNL feeder cells has yielded better results than Matrigel for the majority of cell lines investigated [190]. Other approaches rely on matrix-cell-composites, such as BCTs (bioartificial cardiac tissue: cells plus liquid collagen type I plus Matrigel) [171], or the application of cardiac extracellular matrix [119]. In order to mimic endogenous tissue with blood capillary networks, Akashi's group have developed a vascularized 3D-iPSC-CM tissue, which may provide more comprehensive data in the field of drug screening [191]. Another technique relies on the co-culture of human cardiac microvascular endothelial cells (hCMVECs) and hMSCs in combination with induced pluripotent stem cell-derived embryonic cardiac myocytes (hiPSC-ECMs) which also aims at generating in vitro vascularized cardiac tissue scaffolds [192]. The considerable potential importance of culturing hiPSC-CMs as human 3D heart tissues to overcome species-dependent discrepancies of CM behavior has also been highlighted, particularly with respect to preclinical drug screening [193].

To ensure valid comparisons between techniques, a standard characterization procedure is essential. However, to date the expression of a multitude of TF or surface markers have been interrogated at quite diverse time points. However, consistency with respect to both time and marker information is very important, substantiated by recently published data revealing time-dependent morphological and electrophysiological alterations of iPSC-derived CMs [194]. Reliance on 2D morphological analysis alone to determine CM growth and maturation has been suggested to be insufficient, with clear volume differences apparent with hypertrophic stimulation or long-term culture using 3D z-stack myofilament analysis [195]. In addition, the 
success of engraftment will be dependent on the state of the applied CMs, as has been demonstrated using an ischemic heart model in immuno-deficient mice [196].

To minimize risk of off-target effects attributable to incomplete knowledge of iPSC-derived CM behavior,their response to pharmacological manipulation is of central importance. Measurement on Multi-Electrode-Arrays (MEAs) are increasingly used for cell characterization and drug screening [197-199]. The use of voltagesensitive fluorescent dyes (VSDs), such as di-4-ANEPPS, will also likely facilitate the investigation of action potential characteristics as has been demonstrated for commercially available hiPSC-derived cardiomyocytes ("iCells" and "Cor.4U") post-substance administration [200]. Monitoring of iPSC-CMs under conditions simulating ischemia is a prerequisite to correctly evaluate the impact of hypoxia and nutrient deprivation on future cell replacement therapies. In this regard, Brodarac et al. demonstrated poorer tolerance of murine iPSC-CMs to hypoxia and nutrient deprivation compared to neonatal murine cardiomyocytes, with a significantly higher proportion of poly-caspase-active, 7-aminoactinomycin D-positive and TUNEL-positive cells [201].

In summary, much remains to be done before safe cardiac cell replacement therapy based on PSC strategies becomes a clinical reality, in particular the introduction of GMP-compliant standards underlying precise DNA-, viral- and xeno-free protocols for the generation of mature functional CMs. 


\begin{tabular}{|c|c|c|c|c|c|c|c|}
\hline Cell origin & Host & $\begin{array}{l}\text { Delivery } \\
\text { system }\end{array}$ & $\begin{array}{l}\text { in vivo/ } \\
\text { in vitro }\end{array}$ & Factor / Substances & $\begin{array}{l}\text { Target } \\
\text { cell type }\end{array}$ & Special features & Literature \\
\hline $\begin{array}{l}\text { ESC(HES-2, } \\
\text { H1, H9) }\end{array}$ & human & $\begin{array}{l}\text { specific } \\
\text { culture } \\
\text { conditions }\end{array}$ & in vitro & $\begin{array}{l}\text { day 0-1: } 0.5 \mathrm{ng} / \mathrm{mL} \text { of BMP- } \\
4 \\
\text { day 1-4: } 10 \mathrm{ng} / \mathrm{mL} \text { BMP-4, } \\
5 \mathrm{ng} / \mathrm{mL} \text { human bFGF, and } \\
6 \mathrm{ng} / \mathrm{mL} \text { Activin A } \\
\text { day 4-8: basal medium } \\
\text { containing } 10 \mathrm{ng} / \mathrm{mL} \text { VEGF, } \\
150 \mathrm{ng} / \mathrm{mL} \text { Dkk-1 } \\
\text { day } 8-\mathrm{end} \text { : basal medium } \\
\text { with } 10 \mathrm{ng} / \mathrm{mL} \text { VEGF, } \\
10 \mathrm{ng} / \mathrm{mL} \text { human bFGF } \\
\text { MEF-free and serum-free } \\
\text { hESC adherent culture } \\
\text { under cGMP and cGLP } \\
\text { conditions }\end{array}$ & CM-like & $\begin{array}{l}27 \% \mathrm{cTnT}^{+} \\
\text {expression of: sMHC, } \beta M H C \text {, Isl-1, Nkx2.5, } \\
\text { MYH6, Tnnt2, Myl2, and Myl7 }\end{array}$ & $\begin{array}{l}\text { Chen et al., } \\
2012 \text { [163] }\end{array}$ \\
\hline $\mathrm{ESC}(\mathrm{H} 7)$ & human & $\begin{array}{l}\text { specific } \\
\text { culture } \\
\text { conditions }\end{array}$ & in vitro & $\begin{array}{l}\text { 1) MEF and SNL feeder cell } \\
\text { layers + conventional SC } \\
\text { culture medium containing } \\
\text { ko-SR } \\
\text { 2) bFGF } \\
\text { 3) Matrigel matrix + } \\
\text { commercial } \\
\text { mTeSR1 medium }\end{array}$ & CM-like & $\begin{array}{l}\text { most efficient protocol: MEF and SNL } \\
\text { feeder cell layers + conventional SC culture } \\
\text { medium containing ko-SR } \\
\text { least efficient protocol: Matrigel matrix + } \\
\text { commercial mTeSR1 medium; neural } \\
\text { lineage induction }\end{array}$ & $\begin{array}{l}\text { Ojala et al., } \\
2012 \text { [190] }\end{array}$ \\
\hline $\begin{array}{l}\text { ESC (m: J1; } \\
h: H 1)\end{array}$ & $\begin{array}{l}\text { mouse } \\
\text { / } \\
\text { human }\end{array}$ & $\begin{array}{l}\text { specific } \\
\text { purification } \\
\text { method }\end{array}$ & $\begin{array}{l}\text { in vitro / } \\
\text { in vivo }\end{array}$ & CM-specific MBs & CM-like & $\begin{array}{l}\text { in vitro: myosin heavy chain-MB: } ~ 97 \% \\
\text { cTnT }{ }^{+} \text {cells } \\
\text { in vivo: improved cardiac function, without } \\
\text { tumor formation after } 4 \text { weeks }\end{array}$ & $\begin{array}{l}\text { Ban et al., } 2013 \\
\text { [174] }\end{array}$ \\
\hline ESC & mouse & $\begin{array}{l}\text { specific } \\
\text { culture } \\
\text { conditions }\end{array}$ & in vitro & $\begin{array}{l}\text { GSK3 inhibitor } \\
\text { P38 MAPK inhibitors } \\
\text { CaMKII inhibitors } \\
\text { ERK activators }\end{array}$ & CM-like & $\begin{array}{l}\text { ERK activators, CaMKII inhibitors: } \\
\text { proliferative effects only on CMs in early } \\
\text { developmental stage } \\
\text { GSK3 inhibitor (BIO, CHIR), ERK activator } \\
\text { (5 } \mu \text { M SU1498), CaMKII inhibitor ( } 5 \mu \mathrm{M}\end{array}$ & $\begin{array}{l}\text { Uosaki et al., } \\
2013 \text { [168] }\end{array}$ \\
\hline
\end{tabular}




\begin{tabular}{|c|c|c|c|c|c|c|c|}
\hline & & & & & & $\begin{array}{l}\mathrm{KN} 93) \text { : induced cell cycle progression in } \\
\mathrm{CM} \text {, resulting in } \mathrm{CM} \text { proliferation }\end{array}$ & \\
\hline ESC & mouse & $\begin{array}{l}\text { specific } \\
\text { culture } \\
\text { conditions }\end{array}$ & in vitro & $\begin{array}{l}44 \text { cytokines/signaling } \\
\text { molecules on day } 3 \text { of diff }\end{array}$ & $\begin{array}{l}\mathrm{CPC} \\
\left(\mathrm{Nk} \times 2.5^{+}\right)\end{array}$ & $\begin{array}{l}\text { IGF1, IGF2, insulin, Wnt3a: significantly } \\
\text { increase CPC formation } \\
\text { IGF, insulin: promote Bry }{ }^{+} \text {mesodermal cell } \\
\text { proliferation } \\
\text { Activin A, BMP2 or BMP4: decrease CPC } \\
\text { formation }\end{array}$ & $\begin{array}{l}\text { Engels et al., } \\
2014 \text { [162] }\end{array}$ \\
\hline ESC & mouse & $\begin{array}{l}\text { specific } \\
\text { culture } \\
\text { conditions }\end{array}$ & in vitro & $\begin{array}{l}2 \% \mathrm{O}_{2} \text { preconditioning ( } 3 \\
\text { passages) of } \mathrm{ESCs} \\
\text { diff as EBs in } 20 \% \mathrm{O}_{2}\end{array}$ & CM-like & $\begin{array}{l}\text { significant increased expression of early } \\
\text { differentiation markers FGF5, Eomes } \\
\text { increased gene expression of Eomes, } \\
\text { Goosecoid, Bry, AFP, Sox17, FoxA2, and } \\
\text { protein expression of Bry, Eomes, Sox17, } \\
\text { FoxA2 - diff into mesodermal and } \\
\text { endodermal lineages }\end{array}$ & $\begin{array}{l}\text { Fynes et al., } \\
2014 \text { [185] }\end{array}$ \\
\hline ESC & human & $\begin{array}{l}\text { specific } \\
\text { culture } \\
\text { conditions }\end{array}$ & in vitro & $\begin{array}{l}2 \% \mathrm{O}_{2} \text { preconditioning ( } 3 \\
\text { passages) of ESCs } \\
\text { diff as EBs in } 20 \% \mathrm{O}_{2}\end{array}$ & CM-like & $\begin{array}{l}\text { decreased expression of early } \\
\text { differentiation markers FGF5, Eomes } \\
\text { increased gene expression Nestin, } \beta 3 \text { - } \\
\text { tubulin - diff into ectodermal lineage }\end{array}$ & $\begin{array}{l}\text { Fynes et al., } \\
2014 \text { [185] }\end{array}$ \\
\hline ESC (H9) & human & $\begin{array}{l}\text { specific } \\
\text { substrate } \\
\text { mechanics } \\
\end{array}$ & in vitro & $\begin{array}{l}\text { 1) TCPS } \\
\text { 2) PA hydrogel substrate }\end{array}$ & CM-like & $\begin{array}{l}\text { intermediate stiffness of PA hydrogel } \\
\text { yielded slightly higher } \mathrm{CTnT}^{+} \text {cells without } \\
\text { significant difference to TCPS }\end{array}$ & $\begin{array}{l}\text { Hazeltine et al., } \\
2014 \text { [188] }\end{array}$ \\
\hline ESC (GSES) & mouse & $\begin{array}{l}\text { DNA-Plasmid } \\
\text { specific } \\
\text { purification } \\
\text { method }\end{array}$ & in vitro & $\begin{array}{l}\text { Tbx3 } \\
\text { Myh6-promoter-based } \\
\text { antibiotic selection }\end{array}$ & SAN-like & $\begin{array}{l}>80 \% \text { physiologically and } \\
\text { pharmacologically functional pacemaker } \\
\text { cells with highly increased beating rates } \\
(300-400 \mathrm{bpm})\end{array}$ & $\begin{array}{l}\text { Jung et al., } \\
2014 \text { [89] } \\
\text { Rimmbach et } \\
\text { al., } 2015 \text { [90] }\end{array}$ \\
\hline ESC & mouse & lentiviral & in vitro & Fndc5 & CM-like & $\begin{array}{l}\text { sign. expression of: Flk1, Isl1, Nkx2.5, } \\
\text { Gata4, Mef2C, } \alpha \text {-MHC, cTnT, } \alpha \text {-actinin, } \\
\text { SM22 } \alpha, \alpha-S M A\end{array}$ & $\begin{array}{l}\text { Rabiee et al., } \\
2014 \text { [152] }\end{array}$ \\
\hline $\begin{array}{l}\text { ESC (H7, ESI- } \\
\text { 017) }\end{array}$ & human & $\begin{array}{l}\text { specific } \\
\text { culture and } \\
\text { substrate } \\
\text { conditions }\end{array}$ & in vitro & $\begin{array}{l}\text { matrix-free, scalable, } \\
\text { and GMP-compliant process } \\
\text { culture: including first CHIR } \\
\text { and second IWP-4 induction }\end{array}$ & CM-like & $\begin{array}{l}>90 \% \text { pure CM; } 1.5 \text { to } 2 \times 10^{9} \mathrm{CM} / \mathrm{L} \text { (up to } \\
1 \mathrm{~L} \text { spinner flasks) } \\
\text { ESI-017: } 6 \mu \mathrm{M} \text { CHIR - } 91 \% \mathrm{cTnT}^{+} \\
\text {H7: } 12 \mu \mathrm{M} \text { CHIR - } 92 \% \mathrm{cTnT}^{+}\end{array}$ & $\begin{array}{l}\text { Chen et al., } \\
2015 \text { [157] }\end{array}$ \\
\hline
\end{tabular}




\begin{tabular}{|c|c|c|c|c|c|c|c|}
\hline ESC & mouse & lentiviral & $\begin{array}{l}\text { in vitro / } \\
\text { in vivo }\end{array}$ & $\begin{array}{l}\text { Nkx2.5 } \\
\text { Isl1 }\end{array}$ & $\begin{array}{l}\text { CM-like } \\
\text { SAN-like }\end{array}$ & $\begin{array}{l}\text { Overexpression of Nkx2.5: inhibition of Isl1 } \\
\text { expression } \\
\text { Overexpression of IsI1: enhanced } \\
\text { specification of cardiac progenitors, earlier } \\
\text { cardiac differentiation, and increased } \\
\text { cardiomyocyte number, upregulation of } \\
\text { nodal-specific genes (e.g. Hcn4), } \\
\text { downregulation of transcripts of working } \\
\text { myocardium }\end{array}$ & $\begin{array}{l}\text { Dorn et al., } \\
2015 \text { [155] }\end{array}$ \\
\hline ESC (R1) & mouse & adenoviral & in vitro & Shox2 & SAN-like & $\begin{array}{l}\text { increase in Cx45, decrease in Cx43, Nkx2.5 } \\
\text { SHOX2-EBs beat spontaneously }(83 \pm 7 \% \\
\text { versus } 15 \pm 6 \%) \\
\text { pacemaker-like AP profile ( } 62 \%)\end{array}$ & $\begin{array}{l}\text { lonta et al., } \\
2015 \text { [154] }\end{array}$ \\
\hline $\begin{array}{l}\text { ESC (CGR8, } \\
\alpha \text { PIG44) }\end{array}$ & mouse & $\begin{array}{l}\text { specific } \\
\text { culture } \\
\text { conditions }\end{array}$ & in vitro & $100 \mu \mathrm{M} \mathrm{AA}$ & CM-like & $\begin{array}{l}\text { AA application from day } 0-2 \text { increases } \\
\text { cardiogenesis } 2-4 \text {-fold } \\
\text { day 5: increased expression of genes } \\
\text { associated with angiogenesis, blood } \\
\text { vessel development, hematopoiesis/ } \\
\text { erythropoiesis, Bry, Mef2c, Myl7 }\end{array}$ & $\begin{array}{l}\text { Ivanyuk et al., } \\
2015 \text { [169] }\end{array}$ \\
\hline $\mathrm{ESC}(\mathrm{H} 7)$ & human & $\begin{array}{l}\text { specific } \\
\text { purification } \\
\text { method }\end{array}$ & in vitro & CM-specific MBs & CM-like & NPPA-MB: $\sim 92 \% \alpha$-actinin ${ }^{+}$cells & $\begin{array}{l}\text { Jha et al., } 2015 \\
\text { [175] }\end{array}$ \\
\hline ESC ( $\alpha-P I G)$ & mouse & $\begin{array}{l}\text { specific } \\
\text { culture and } \\
\text { substrate } \\
\text { conditions }\end{array}$ & in vitro & $0.3 \mathrm{~mm}$-thick hcECM & CM-like & $\begin{array}{l}\text { hcECM supported proliferation } \\
\text { significantly increased expression of: Myh6, } \\
\text { Tnnt2, Nkx2.5 } \\
\text { Matrigel or Geltrex use did not induce } \\
\text { cardiac-specific markers }\end{array}$ & $\begin{array}{l}\text { Oberwallner et } \\
\text { al., } 2015 \text { [119] }\end{array}$ \\
\hline $\begin{array}{l}\text { ESC (derived } \\
\text { from } \\
\text { C57BL/6 } \\
\text { mouse } \\
\text { strain) }\end{array}$ & mouse & $\begin{array}{l}\text { specific } \\
\text { culture } \\
\text { conditions }\end{array}$ & in vitro & $10 \mu \mathrm{M}$ resveratrol & CM-like & $\begin{array}{l}\text { promotes mESC differentiation towards } \\
\text { CM } \\
\text { enhanced beating properties of EBs } \\
\text { significantly higher expression of: Nkx2.5, } \\
\text { Mef2c, Tbx5, dHand2, aMHC, Cx43, cTnC1 }\end{array}$ & $\begin{array}{l}\text { Ding et al., } \\
2016[202]\end{array}$ \\
\hline ESC & mouse & DNA-Plasmid & in vitro & CIBZ & CM-like & $\begin{array}{l}\text { CIBZ depletion: induced expression of Bry, } \\
\text { MesP1, Gata6, Sox } 17 \\
\text { CIBZ overexpression: decreased expression }\end{array}$ & $\begin{array}{l}\text { Kotoku et al., } \\
2016[151]\end{array}$ \\
\hline
\end{tabular}




\begin{tabular}{|c|c|c|c|c|c|c|c|}
\hline & & & & & & $\begin{array}{l}\text { of Bry, MesP1, Flk1 Isl1, Gata4, Mhc, cTnl; } \\
\text { Significant suppression of beating EBs }\end{array}$ & \\
\hline $\begin{array}{l}\text { ESC (in- } \\
\text { house and } \\
\text { E14tg2a) }\end{array}$ & mouse & $\begin{array}{l}\text { specific } \\
\text { culture } \\
\text { conditions }\end{array}$ & in vitro & $\begin{array}{l}\text { monolayer culture without } \\
\text { feeder cells } \\
\text { day 0-1: IMDM/Ham's F12, } \\
\text { N2 supplement } \\
\text { B27 supplement, } \\
0.5 \mathrm{mM} \mathrm{AA,} 4.5 \times 10^{-4} \mathrm{M} \mathrm{MTG} \\
\text { day 1-3: } 8 \mathrm{ng} / \mathrm{mL} \text { Activin A, } \\
0.5 \mathrm{ng} / \mathrm{mL} \mathrm{BMP4,} 5 \mathrm{ng} / \mathrm{mL} \\
\text { hVEGF } \\
\text { day } 3-13: \text { StemPro-34 SF } \\
\text { medium, } 0.5 \mathrm{mM} \mathrm{AA} \text {, } \\
5 \mathrm{ng} / \mathrm{mL} \mathrm{hVEGF}, 10 \mathrm{ng} / \mathrm{mL} \\
\text { bFGF, } 50 \mathrm{ng} / \mathrm{mL} \text { hFGF10 }\end{array}$ & CM-like & 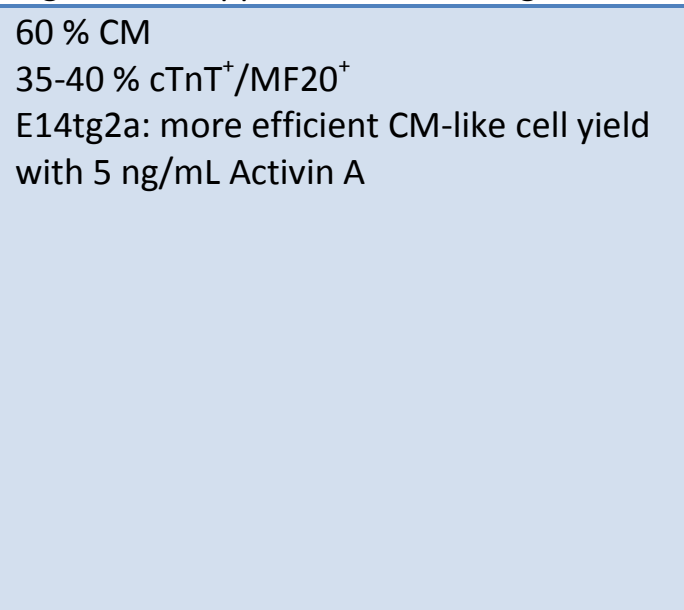 & $\begin{array}{l}\text { Kokkinopoulos } \\
\text { et al., } 2016 \\
{[165]}\end{array}$ \\
\hline ESC & mouse & $\begin{array}{l}\text { specific } \\
\text { culture } \\
\text { conditions }\end{array}$ & $\begin{array}{l}\text { in vitro / } \\
\text { in vivo }\end{array}$ & $\begin{array}{l}25 \mathrm{ng} / \mathrm{ml} \text { Activin, } 20 \mathrm{ng} / \mathrm{ml} \\
\mathrm{BMP} 2,20 \mathrm{ng} / \mathrm{ml} \mathrm{BMP4}, \\
100 \mathrm{ng} / \mathrm{ml} \mathrm{DLL1}, 10 \mathrm{ng} / \mathrm{ml} \\
\mathrm{bFGF}, 10 \mathrm{ng} / \mathrm{ml} \text { FGF8, } \\
20 \mathrm{ng} / \mathrm{ml} \mathrm{Tgfb}, 100 \mathrm{ng} / \mathrm{ml} \\
\text { Wnt3a, } 5 \mu \mathrm{M} \text { IWR1, } 5 \mu \mathrm{M} \\
\text { SB431542 }\end{array}$ & $\begin{array}{l}\text { MesP1- } \\
\text { CPC }\end{array}$ & 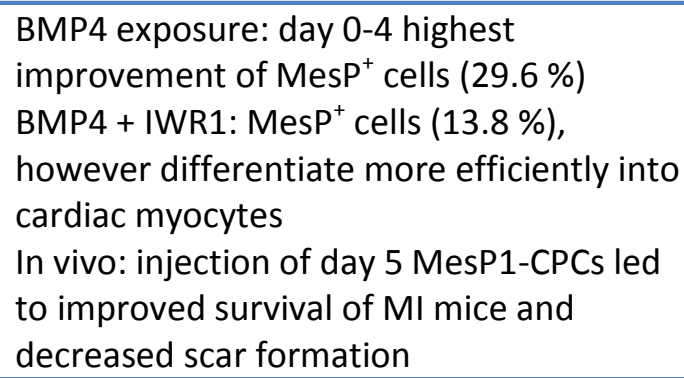 & $\begin{array}{l}\text { Liu et al., } 2016 \\
{[144]}\end{array}$ \\
\hline ESC (E14T) & mouse & $\begin{array}{l}\text { specific } \\
\text { purification } \\
\text { method }\end{array}$ & $\begin{array}{l}\text { in vitro/ } \\
\text { in vivo }\end{array}$ & $\begin{array}{l}\text { selection based on VE- } \\
\text { cadherin promoter }\end{array}$ & CEDP & $\begin{array}{l}\text { Differentiation into: } ~ 47 \% \mathrm{cTnT}^{+} \text {and } \\
\sim 28 \% \text { VE-cadherin }{ }^{+} \text {cells }\end{array}$ & $\begin{array}{l}\text { Maltabe et al., } \\
2016 \text { [173] }\end{array}$ \\
\hline $\begin{array}{l}\text { ESC (H7 and } \\
\text { H9) }\end{array}$ & human & $\begin{array}{l}\text { specific } \\
\text { culture } \\
\text { conditions }\end{array}$ & in vitro & $\begin{array}{l}\text { 1) day 0-1.5: BMP4, FGF2, } \\
\text { Activing A, LY294002 } \\
\text { day 1.5-5: BMP4, FGF2, RA, } \\
\text { IWR1/IWP2 } \\
\text { day 5-9: BMP4, FGF2 } \\
\text { 2) day 0-2: CHIR99021, day } \\
\text { 2-4: IWP2 }\end{array}$ & CM-like & $\begin{array}{l}\text { WNT3, WNT8: regulation of Bry expression } \\
\text { and mesoderm induction (via FZD7 + } \\
\text { canonical Wnt signaling) } \\
\text { WNT5A/5B: regulation of MesP1 } \\
\text { expression and cardiovascular } \\
\text { development (via ROR2 + noncanonical } \\
\text { Wnt signaling) } \\
\text { WNT2, WNT5A/5B, WNT11: regulation of } \\
\text { late functional CM diff (via FZD4, FZD6 + } \\
\text { noncanonical Wnt signaling) }\end{array}$ & $\begin{array}{l}\text { Mazzotta et al., } \\
2016[161]\end{array}$ \\
\hline
\end{tabular}




\begin{tabular}{|c|c|c|c|c|c|c|c|}
\hline ESC (5) & mouse & DNA-Plasmid & in vitro & CITED2 & CM-like & $\begin{array}{l}\text { Cited2 depletion: significantly decreased } \\
\text { expression of Brachyury, Mesp1, Isl1, } \\
\text { Gata4, Tbx5 } \\
\text { Cited2 overexpression: stimulation of } \\
\text { Brachyury, Mesp1, Isl1, Gata4, Tbx5, Myh6, } \\
\text { cTnT; protein interaction with Isl1 }\end{array}$ & $\begin{array}{l}\text { Pacheco-Leyva } \\
\text { et al., } 2016 \\
{[150]}\end{array}$ \\
\hline ESC & mouse & $\begin{array}{l}\text { miRNA } \\
\text { lentiviral }\end{array}$ & in vitro & miR-322/-503 & CM-like & $\begin{array}{l}\text { Highest enriched miRNA in Mesp1 lineage } \\
\text { (miR-322/-503) } \\
\text { Celf1 is a direct target of miR-322/-503 } \\
\text { miR-322/-503 selectively inhibits } \\
\text { neuroectoderm differentiation }\end{array}$ & $\begin{array}{l}\text { Shen et al., } \\
2016 \text { [145] }\end{array}$ \\
\hline ESC & human & $\begin{array}{l}\text { specific } \\
\text { culture } \\
\text { conditions }\end{array}$ & in vitro & $\begin{array}{l}\text { monolayer-directed } \\
\text { differentiation protocol } \\
\text { different concentrations of } \\
\text { activin A and BMP4 }\end{array}$ & $\begin{array}{l}\text { CM-like } \\
\text { EC-like }\end{array}$ & $\begin{array}{l}\text { generation of distinct CVP populations } \\
\text { following derivation of cardiogenic versus } \\
\text { hemogenic mesoderm } \\
>90 \% \mathrm{CD} 31^{+} / \text {VE-cadherin }{ }^{+} \text {ECs }\end{array}$ & $\begin{array}{l}\text { Palpant et al., } \\
2017 \text { [164] }\end{array}$ \\
\hline $\begin{array}{l}\text { ESC (HES3- } \\
\text { Nkx2.5 } \\
\text { HES2) }\end{array}$ & human & $\begin{array}{l}\text { specific } \\
\text { culture } \\
\text { conditions }\end{array}$ & $\begin{array}{l}\text { in vitro / } \\
\text { in vivo }\end{array}$ & 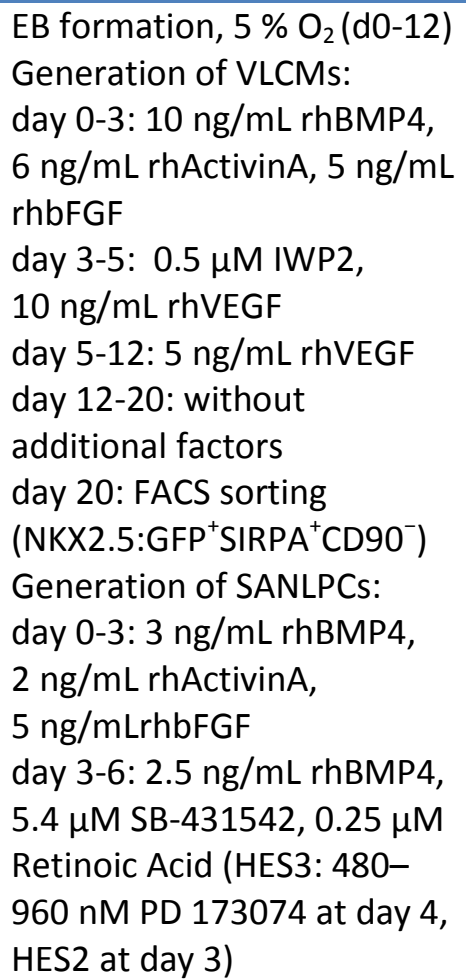 & $\begin{array}{l}\text { CM-like } \\
\text { SAN-like }\end{array}$ & $\begin{array}{l}\text { FGF pathway blocks the development of } \\
\text { NKX2- } 5^{+} \text {CM } \\
\text { Marker expression of the SAN lineage } \\
\text { (TBX18, SHOX2, TBX3), typical pacemaker } \\
\text { action potentials ( } 90 \% \text { ), ion current } \\
\text { profiles and chronotropic response }\end{array}$ & $\begin{array}{l}\text { Protze et al., } \\
2017 \text { [159] }\end{array}$ \\
\hline
\end{tabular}




\begin{tabular}{|l|l|l|l|l|l|}
\hline & & & $\begin{array}{l}\text { day 6-20: } 5 \mathrm{ng} / \mathrm{mL} \text { rhVEGF } \\
\text { day 20: FACS sorting } \\
\text { (NKX2.5:GFP'SIRPA }\end{array}$ & \\
\hline
\end{tabular}

AA: ascorbic acid; $\beta M H C$ : $\beta$ myosin heavy chain; bFGF: basic fibroblast growth factor; BMP: bone morphogenetic protein; bpm: beats per minute; Bry: Brachyury; CAMKII: $\mathrm{Ca}^{2+}$ /calmodulin-dependent protein kinase II; CEDP: cardiac and endothelial dual-progenitor population; CHIR: CHIR99021, Wnt activator; CIBZ: BTB domain-containing zinc finger protein; CM: cardiomyocytes; CPC: cardiac progenitor cell; cTnC1: cardiac troponin C1; CVP: cardiovascular progenitor cell; diff: differentiation; EB: embryoid bodies; EC: endothelial cell; ERK: extracellular signal-regulated kinase; ESC: embryonic stem cells; Fndc5: Fibronectin type III domain-containing 5 protein (also known as: peroxisomal protein (PEP)); GSK3: glycogen synthase kinase-3; hcECM: human cardiac extracellular matrix; IWP: WNT inhibitor; ko-SR: knockout serum replacement; LY294002: phosphoinositide 3kinase inhibitor; MAPK: p38 mitogen-activated protein kinase; MB: molecular beacon; MTG: monothioglycerol; PA: polyacrylamide; PD 173074: FGF signaling inhibitor; SAN: sinoatrial node; SB-431542: Activin/Nodal/TGF $\beta$ signaling inhibitor; sMHC: sarcomeric myosin heavy chain; TCPS: tissue culture polystyrene; Tnnt2: cardiac troponin T2; VEGF: vascular endothelial growth factor; (x): number of cell lines used. 


\begin{tabular}{|c|c|c|c|c|c|c|c|}
\hline Cell origin & Host & $\begin{array}{l}\text { Delivery } \\
\text { system }\end{array}$ & $\begin{array}{l}\text { in vivo/ } \\
\text { in vitro }\end{array}$ & Factor / Substances & $\begin{array}{l}\text { Target } \\
\text { cell type }\end{array}$ & Special features & Literature \\
\hline iPSC & $\begin{array}{l}\text { mouse } \\
\text { and } \\
\text { human }\end{array}$ & $\begin{array}{l}\text { specific } \\
\text { culture } \\
\text { conditions }\end{array}$ & in vitro & $\begin{array}{l}16 \text { cytokines and chemical } \\
\text { components }\end{array}$ & CM-like & $\begin{array}{l}\text { AA: CM enhancement in } 11 \text { lines } \\
\text { Application of } 50 \mu \mathrm{g} / \mathrm{mL} \text { AA during day 2-6: } \\
\text { 7.3-fold (miPSC) and } 30.2 \text {-fold (hiPSC) } \\
\text { enhanced yield through specific increase in } \\
\text { the proliferation of CPCs via the MEK- } \\
\text { ERK1/2 pathway }\end{array}$ & $\begin{array}{l}\text { Cao et al., } 2012 \\
\text { [203] }\end{array}$ \\
\hline $\begin{array}{l}\text { iPSC } \\
\text { (UTA.00112. } \\
\text { hFF, } \\
\text { UTA.04602. } \\
\text { WT, } \\
\text { UTA.00525.L } \\
\text { QT2, } \\
\text { UTA.00106.h } \\
\text { FF) }\end{array}$ & human & $\begin{array}{l}\text { specific } \\
\text { culture } \\
\text { conditions }\end{array}$ & in vitro & $\begin{array}{l}\text { 1) MEF and SNL feeder cell } \\
\text { layers + conventional SC } \\
\text { culture medium containing } \\
\text { ko-SR } \\
\text { 2) bFGF } \\
\text { 3) Matrigel matrix + } \\
\text { commercial } \\
\text { mTeSR1 medium }\end{array}$ & CM-like & $\begin{array}{l}\text { most efficient protocol: MEF and SNL } \\
\text { feeder cell layers + conventional SC culture } \\
\text { medium containing ko-SR } \\
\text { least efficient protocol: Matrigel matrix + } \\
\text { commercial mTeSR1 medium; neural } \\
\text { lineage induction } \\
\text { exception: UTA.04602.WT line - highest } \\
\text { amount of beating areas on Matrigel in } \\
\text { mTeSR1 }\end{array}$ & $\begin{array}{l}\text { Ojala et al., } \\
2012 \text { [190] }\end{array}$ \\
\hline $\begin{array}{l}\text { iPSC (BJ1- } \\
\text { iPS10) }\end{array}$ & human & $\begin{array}{l}\text { specific } \\
\text { selection } \\
\text { method }\end{array}$ & $\begin{array}{l}\text { in vitro / } \\
\text { in vivo }\end{array}$ & CM-specific MBs & CM-like & $\begin{array}{l}\text { in vitro: myosin heavy chain-MB: } ~ 97 \% \\
\text { cTnT }^{+} \text {cells } \\
\text { in vivo: improved cardiac function, without } \\
\text { tumor formation after } 4 \text { weeks }\end{array}$ & $\begin{array}{l}\text { Ban et al., } 2013 \\
\text { [174] }\end{array}$ \\
\hline iPSC & human & $\begin{array}{l}\text { long-term } \\
\text { culture }\end{array}$ & in vitro & $\begin{array}{l}\text { EB-formation } \\
360 \text { day culture }\end{array}$ & CM-like & $\begin{array}{l}\text { day 14: immature high-density Z-bands } \\
\text { day 180: mature Z-, A-, H-, and I-bands } \\
\text { day } 360: \text { M-, Z-, A-, H-, and I-bands }\end{array}$ & $\begin{array}{l}\text { Kamakura et al., } \\
2013 \text { [204] }\end{array}$ \\
\hline ¡PSC & $\begin{array}{l}\text { mouse } \\
\text { and } \\
\text { human }\end{array}$ & $\begin{array}{l}\text { specific } \\
\text { culture } \\
\text { conditions } \\
\text { antibiotic } \\
\text { selection }\end{array}$ & in vitro & $\begin{array}{l}\alpha M H C \text {-antibiotic resistance } \\
\text { gene } \\
\text { EB formation } \\
\text { BCT (cells + liquid collagen } \\
\text { type I and Matrigel) } \\
\text { AA } \\
\text { static stretch }\end{array}$ & CM-like & $\begin{array}{l}\text { structurally and functionally homogenous } \\
\text { syncytium } \\
\text { enhanced the contractility of murine and } \\
\text { human BCTs (active tension of } \\
4.4 \mathrm{mN} / \mathrm{mm}^{2} \text { ) }\end{array}$ & $\begin{array}{l}\text { Kensah et al., } \\
2013 \text { [171] }\end{array}$ \\
\hline $\begin{array}{l}\text { iPSC (from: } \\
\text { skeletal } \\
\text { muscle PC, }\end{array}$ & mouse & $\begin{array}{l}\text { retroviral } \\
\text { specific } \\
\text { culture }\end{array}$ & in vitro & $\begin{array}{l}16 \mathrm{~h} \text { after EB seeding onto } \\
\text { gelatin: exposure to hypoxia } \\
\left(3 \% \mathrm{O}_{2}\right) \text { for } 24 \mathrm{~h}\end{array}$ & CM-like & $\begin{array}{l}\text { EBs normoxic conditions: } \sim 59 \% \text { beating } \\
\text { EBs hypoxic conditions: abolished beating, } \\
\text { significant increased expression of Bry and }\end{array}$ & $\begin{array}{l}\text { Medley et al., } \\
2013 \text { [205] }\end{array}$ \\
\hline
\end{tabular}




\begin{tabular}{|c|c|c|c|c|c|c|c|}
\hline $\begin{array}{l}\text { skeletal } \\
\text { muscle } \\
\text { fibroblasts) }\end{array}$ & & conditions & & & & $\begin{array}{l}\text { IsI1, HIF- } 1 \alpha \text {; accumulation of HIF- } 1 \alpha \text { and } \beta \text { - } \\
\text { catenin in nuclear protein extracts, } \\
\text { suggesting involvement of } \\
\text { the Wnt/beta-catenin pathway }\end{array}$ & \\
\hline iPSC & human & $\begin{array}{l}\text { specific } \\
\text { culture } \\
\text { conditions }\end{array}$ & in vitro & $\begin{array}{l}\text { day 0-1: } 6 \mu \mathrm{M} \text { CHIR } \\
\text { day 2-3: diff medium } \\
\text { day 4-5: } 5 \mu \mathrm{M} \text { IWR-1 } \\
\text { day 6-7: diff medium } \\
\text { day 8-end: diff medium + } \\
\text { insulin }\end{array}$ & CM-like & $\begin{array}{l}\text { expression of: IRX4, MLC2v, MLC2a, TNNI3, } \\
\text { and TNNT2 }\end{array}$ & $\begin{array}{l}\text { Bhattacharya et } \\
\text { al., } 2014 \text { [156] }\end{array}$ \\
\hline $\begin{array}{l}\text { iPSC (from } \\
\text { BJ } \\
\text { fibroblasts) }\end{array}$ & human & $\begin{array}{l}\text { mRNA } \\
\text { reprogrammi } \\
\text { ng } \\
\text { specific } \\
\text { culture } \\
\text { conditions }\end{array}$ & in vitro & $\begin{array}{l}\text { day 0-8: EBs in low adhesion } \\
\text { culture dished, } 5 \mu \mathrm{M} \\
\text { SB203580 } \\
\text { day 9-week 8: EBs plated on } \\
0.1 \% \text { gelatin coated dishes, } \\
\text { without SB203580 }\end{array}$ & CM-like & $\begin{array}{l}\text { day 11-14 until day 50-60: rhythmically } \\
\text { contracting areas (55-75 \%) } \\
\text { day 6: expression of Isl1, Kdr, Mef2C, } \\
\text { NKx2.5, Gata4, Tbx3/5/20 } \\
\text { day 8, 14: expression of Tnni2, Mlc2a/v, } \\
\text { Myh7, Myl3/4, Cav1.3, Hcn4, Serca2a, Ryr2 } \\
\text { specific response to pharmacological } \\
\text { substance administration }\end{array}$ & $\begin{array}{l}\text { Mehta et al., } \\
2014 \text { [133] }\end{array}$ \\
\hline iPSC (IMR90) & human & $\begin{array}{l}\text { specific } \\
\text { culture } \\
\text { conditions }\end{array}$ & in vitro & day 20-27: $20 \mathrm{ng} / \mathrm{mL}$ T3 & CM-like & $\begin{array}{l}\text { increased cardiomyocyte size, anisotropy, } \\
\text { and sarcomere length } \\
\text { 2-fold higher force per-beat }\end{array}$ & $\begin{array}{l}\text { Yang et al., } \\
2014 \text { [206] }\end{array}$ \\
\hline $\begin{array}{l}\text { iPSC (from } \\
\text { Dr. Joseph } \\
\text { Wu, } \\
\text { Stanford) }\end{array}$ & human & $\begin{array}{l}\text { specific } \\
\text { culture and } \\
\text { substrate } \\
\text { conditions }\end{array}$ & in vitro & $\begin{array}{l}\text { matrix-free, scalable, } \\
\text { and GMP-compliant process } \\
\text { culture: including first CHIR } \\
\text { and second IWP-4 induction }\end{array}$ & CM-like & $\begin{array}{l}>90 \% \text { pure } \mathrm{CM} ; 1.5 \text { to } 2 \times 10^{9} \mathrm{CM} / \mathrm{L} \text { (up to } \\
1 \mathrm{~L} \text { spinner flasks) } \\
\text { relationship between } \\
\text { aggregate size and } \mathrm{CHIR} \text { concentration } \\
6 \mu \mathrm{M} \mathrm{CHIR} 94 \% \mathrm{CTnT}^{+}\end{array}$ & $\begin{array}{l}\text { Chen et al., } \\
2015 \text { [157] }\end{array}$ \\
\hline $\begin{array}{l}\text { iPSC (from } \\
\text { activated T } \\
\text { cells, } \\
\text { hPBMC) }\end{array}$ & human & $\begin{array}{l}\text { retroviral } \\
\text { specific } \\
\text { culture } \\
\text { conditions } \\
\text { metabolic } \\
\text { selection } \\
\text { (lactate) }\end{array}$ & in vitro & $\begin{array}{l}\text { day 1-13: } 5 \% \mathrm{O}_{2} \text { and } 7 \% \\
\mathrm{CO}_{2} \\
\text { day 1-2: } 50 \% \mathrm{mTeSR}, 45 \% \\
\text { DMEM (low } \\
\text { glucose), } 5 \% \mathrm{FBS}, 1 \mu \mathrm{M} \\
\mathrm{H} 1152,100 \mathrm{ng} / \mathrm{mL} \text { bFGF } \\
\text { day 2: } 2 / 3 \text { medium change } \\
\text { to: DMEM (low glucose), } \\
10 \% \mathrm{FBS}, 50 \mathrm{ng} / \mathrm{mL} \text { bFGF } \\
\text { day 3-7: DMEM (low }\end{array}$ & CM-like & $\begin{array}{l}\text { before selection: } 30-45 \% \mathrm{CM} \text {, expression } \\
\text { of cTnT and MLC2v } \\
\text { after lactate selection: } 90 \% \mathrm{CM} \text {, } \\
\text { electrophysiological characterization: } \\
\text { ventricular, atrial and nodal-like action } \\
\text { potentials }\end{array}$ & $\begin{array}{l}\text { Fuerstenau- } \\
\text { Sharp et al., } \\
2015 \text { [158] }\end{array}$ \\
\hline
\end{tabular}




\begin{tabular}{|c|c|c|c|c|c|c|c|}
\hline & & & & $\begin{array}{l}\text { glucose), } 10 \% \mathrm{FBS} \text {, } \\
50 \mathrm{ng} / \mathrm{mL} \mathrm{bFGF}, 6 \mathrm{ng} / \mathrm{mL} \\
\text { activing A, } 10 \mathrm{ng} / \mathrm{mL} \mathrm{BMP} 4 \\
\text { day } 8-13: \text { DMEM (low } \\
\text { glucose), } 10 \% \mathrm{FBS} \\
\text { day } 14-\mathrm{end}: 20 \% \mathrm{O}_{2} \text { and } \\
7 \% \mathrm{CO}_{2} \\
\text { day } 16-18: \text { DMEM (no } \\
\text { glucose), } 1 \% \text { sodium DL- } \\
\text { lactate solution }\end{array}$ & & & \\
\hline ¡PSC & mouse & $\begin{array}{l}\text { specific } \\
\text { culture } \\
\text { conditions }\end{array}$ & $\begin{array}{l}\text { in vitro / } \\
\text { in vivo }\end{array}$ & 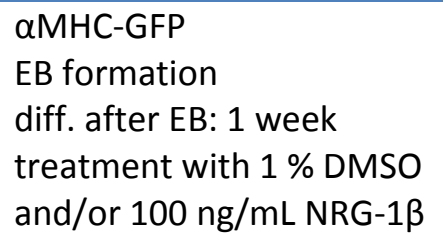 & CM-like & $\begin{array}{l}\text { significantly higher expression of: Gata4, } \\
\text { Gata6, aMhc, Myhl7, Myl3, cTnnc1, Ryr2, } \\
\text { Serca2a } \\
\text { ventricular-like AP } \\
\text { preserves cardiac function in mouse model }\end{array}$ & $\begin{array}{l}\text { Iglesias-García } \\
\text { et al., } 2015 \\
\text { [207] }\end{array}$ \\
\hline $\begin{array}{l}\text { iPSC (TiB7.4, } \\
\text { AT25) }\end{array}$ & mouse & $\begin{array}{l}\text { specific } \\
\text { culture } \\
\text { conditions }\end{array}$ & in vitro & $100 \mu \mathrm{M}$ AA & CM-like & $\begin{array}{l}\text { AA application from day } 0-2 \text { increases } \\
\text { cardiogenesis } 2-4 \text {-fold }\end{array}$ & $\begin{array}{l}\text { Ivanyuk et al., } \\
2015 \text { [169] }\end{array}$ \\
\hline $\begin{array}{l}\text { iPSC (DF19-9 } \\
-11 T . H)\end{array}$ & human & RNA & in vitro & $\begin{array}{l}\text { EB-formation } \\
\text { diff after EB: transfection } \\
\text { with CIR RNA }\end{array}$ & CM-like & $\begin{array}{l}\text { spindle-shaped cells with characteristic } \\
\text { expression of: cTnT, tropomyosin, } \alpha \text {-actinin }\end{array}$ & $\begin{array}{l}\text { Kochegarov et } \\
\text { al., } 2015 \text { [208] }\end{array}$ \\
\hline iPSC (AT25) & mouse & $\begin{array}{l}\text { specific } \\
\text { culture and } \\
\text { substrate } \\
\text { conditions }\end{array}$ & in vitro & $0.3 \mathrm{~mm}$-thick hcECM & CM-like & $\begin{array}{l}\text { hcECM supported the proliferation } \\
\text { significantly increased expression of: Myh6, } \\
\text { Tnnt2, Nkx2.5 } \\
\text { Matrigel, Geltrex: did not induce cardiac- } \\
\text { specific markers }\end{array}$ & $\begin{array}{l}\text { Oberwallner et } \\
\text { al., } 2015 \text { [119] }\end{array}$ \\
\hline ¡PSC & mouse & lentiviral & in vitro & $\begin{array}{l}\text { telomerase-competent cell } \\
\text { lines (TRF1 expression) } \\
\text { AA }\end{array}$ & CM-like & $\begin{array}{l}\text { iPSCs }^{\text {highTRF1 }}: \text { differentiate earlier and more } \\
\text { efficiently into CMs } \\
\text { iPSC }{ }^{\text {lowRF1 }} \text { : differentiate very efficiently to } \\
\text { the ectoderm lineage } \\
\text { AA: increase CM yield with iPSC }\end{array}$ & $\begin{array}{l}\text { Aguado et al., } \\
2016[170]\end{array}$ \\
\hline $\begin{array}{l}\text { ¡PSC } \\
\text { (Duanqing } \\
\text { Pei, Chinese } \\
\text { Academy of } \\
\text { Sciences) }\end{array}$ & mouse & $\begin{array}{l}\text { specific } \\
\text { selection } \\
\text { method }\end{array}$ & in vitro & $\begin{array}{l}0.001-0.2 \mu \mathrm{mol} / \mathrm{L} \text { EPI } \\
10 \mu \mathrm{mol} / \mathrm{L} \text { phentolamine } \\
5 \mu \mathrm{mol} / \mathrm{L} \text { propranolol } \\
10 \mu \mathrm{mol} / \mathrm{L} \text { phenylephrine } \\
10 \mu \mathrm{mol} / \mathrm{L} \text { clonidine }\end{array}$ & CM-like & $\begin{array}{l}\text { EPI and activation of } \alpha 1-A R \text { : enhancement } \\
\text { of CM differentiation via MEK-ERK1/2 } \\
\text { signaling }\end{array}$ & $\begin{array}{l}\text { Li et al., } 2016 \\
\text { [167] }\end{array}$ \\
\hline
\end{tabular}




\begin{tabular}{|c|c|c|c|c|c|c|c|}
\hline & & & & $\begin{array}{l}1 \mu \mathrm{mol} / \mathrm{L} \text { isoproterenol } \\
10 \mu \mathrm{mol} / \mathrm{L} \text { PD98059 }\end{array}$ & & & \\
\hline $\begin{array}{l}\text { iPSC (from: } \\
\text { MEFs) }\end{array}$ & mouse & $\begin{array}{l}\text { retroviral } \\
\text { specific } \\
\text { culture } \\
\text { conditions }\end{array}$ & in vitro & $\begin{array}{l}\text { EB formation } \\
\text { medium containing: DMEM, } \\
15 \% \text { fetal } \\
\text { bovine serum, } 0.2 \mathrm{mmol} / \mathrm{l} \mathrm{L}- \\
\text { glutamine, } 0.1 \mathrm{mmol} / \mathrm{I} \\
\text { nonessential amino } \\
\text { acids, and } 0.1 \mathrm{mmol} / \mathrm{l} \beta- \\
\text { mercaptoethanol }\end{array}$ & CM-like & $\begin{array}{l}\text { After EB formation: expression of Flk1, } \alpha \text { - } \\
\text { actinin, } \alpha \text {-MHC, cTnT, Cx43, Nkx2.5 } \\
\text { active beating: } 360 \mathrm{bpm} \\
\text { incompletely differentiated iPS cells: } \\
\text { teratoma formation after transplantation } \\
\text { into a SCID mouse model of } \mathrm{MI}\end{array}$ & $\begin{array}{l}\text { Wang et al., } \\
2016 \text { [209] }\end{array}$ \\
\hline $\begin{array}{l}\text { iPSC (from } \\
\text { foreskin } \\
\text { tissue) }\end{array}$ & human & $\begin{array}{l}\text { specific } \\
\text { culture } \\
\text { conditions } \\
\text { metabolic } \\
\text { selection } \\
\text { (lactate) }\end{array}$ & in vitro & $\begin{array}{l}\text { chemical-defined and } \\
\text { albumin-free medium } \\
\text { day 0-1: S12 without insulin } \\
\text { medium, } 4-8 \mu \mathrm{M} \text { CHIR } \\
\text { day 1-3: } S 12 \text { without insulin } \\
\text { medium } \\
\text { day 3-5: S12 without insulin } \\
\text { medium, } 5 \mu \mathrm{M} \text { IWR-1 } \\
\text { day 5-end: S12 with insulin } \\
\text { medium, atrial diff: } 1 \mu \mathrm{M} \\
\text { RA, ventricular diff: } 1 \mu \mathrm{M} \\
\text { BMS493 }\end{array}$ & $\begin{array}{l}\text { CM-like } \\
\text { Atrial-like }\end{array}$ & $\begin{array}{l}\text { highly homogenous atrial and ventricular } \\
\text { myocytes in a scalable fashion with normal } \\
\text { electrophysiological properties }\end{array}$ & $\begin{array}{l}\text { Pei et al., } 2017 \\
\text { [160] }\end{array}$ \\
\hline
\end{tabular}

AA: ascorbic acid; AP: action potential; AR: adrenergic receptor; BCT: bioartificial cardiac tissue; bpm: beats per minute; BMS493: RA inhibitor; Bry: Brachyury; CHIR: CHIR99021 (GSK-3 inhibitor, Wnt activator); CIR: specific fetal cardiac-inducing RNA (fragment of N-sulfoglucosaminesulfohydrolase and the caspase recruitment domain family member 14 precursor); Cx43: connexin 43; clonidine: selective $\alpha 2-A R$ agonist; cTnT: cardiac troponin T; DMSO: dimethyl sulfoxide; EPI: epinephrine; hcECM: human cardiac extracellular matrix; hPBMC: human peripheral blood mononuclear cells; H1152: Rho-kinase (ROCK) inhibitor; IRX4: iroquois-class homeodomain protein IRX-4; isoproterenol: $\beta$-AR agonist; IWP-4: WNT inhibitor; IWR-1: WNT inhibitor; MEF: mouse embryonic fibroblast; MLC2a: myosin regulatory light chain 2, atrial isoform; MLC2v: myosin regulatory light chain 2,

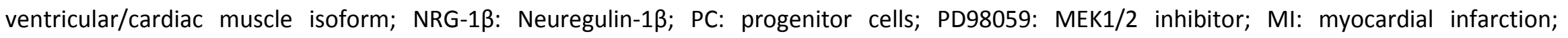
phenylephrine: selective $\alpha 1-A R$ agonist; phentolamine: $\alpha$-AR antagonist; propranolol: $\beta$-AR antagonist; RA: retinoic acid; SB203580: MAPK signaling inhibitor; SCID: severe combined immunodeficiency; TNNI3: cardiac troponin I; Tnnt2: cardiac troponin T2; TRF1: shelterin-complex protein; T3: Triiodo-L-thyronine. 


\subsection{Direct reprogramming of somatic cells}

Another ambitious approach to cell replacement therapy aims to avoid the relatively uncontainable pluripotent state, instead choosing to elicit a cell fate switch through the direct conversion of terminally differentiated somatic cells towards mature cell types of interest representing the same germ layer, or even across germ layers. Such an approach has a number of prerequisites for efficient and feasible reprogramming, including epigenetic modulation and lineage-specific intervention.

As early as 1987, murine fibroblasts were successfully converted into skeletal muscle cells using only a single key TF, namely MyoD [210]. Subsequently, numerous publications have reported direct conversion - with one or a number of TFs combined - into several somatic cell types, such as insulin ${ }^{+} \beta$-cells, hepatocytes, osteoblasts, hematopoietic lineage cells, neurons and cardiomyocytes (summarized in [211]). However, the quality of the cells obtained was highly variable. While, thus far, no single master regulator has been discovered to efficiently induce the switch of fully differentiated somatic cells towards a mature induced cardiomyocyte (iCM) lineage, promising results in the field of direct reprogramming have been made and will be discussed in this section.

The concept of patient-specific lineage-conversion holds enormous potential for future clinical applications including: i) elucidating individual disease pathogenesis; ii) lower risk of tumorigenesis and inflammation after cell transplantation compared with PSCs; iii) avoiding the need for transplantation through the possibility to directly convert resident cells; and iv) avoidance of ethical concerns regarding cellular source. Despite the many advantages, the actual consequences of massive fibroblast-to-myocyte programming in situ remain unknown and may potentially be detrimental to cardiac function [212].

Contemporary research efforts focus on readily available murine cell types, with murine neonatal cardiac fibroblasts (CFs) currently the most efficient somatic cell source for direct reprogramming based on their heterogeneity and plasticity, as well as their resistance to the hypoxic environment of the injured myocardium [213-215]. Another important source are murine embryonic fibroblasts [216-220]. However, neither of these two cell types are readily accessible from humans with few results so far reported using such human cell types [221,222]. In contrast to iPSC strategies, a cell fate switch is largely achieved through forced exogenous overexpression of lineage-specific TFs, with Gata4, Tbx5 and Mef2c the most frequently used TFs in combination [219,223-229], or at least a critical part of a more complex composition $[216,217,220,221,230,231]$ (Table 4). However, the reported marker gene expression patterns obtained vary widely between different laboratories and starting material; e.g. $30 \%$ [227] or $35 \%$ [223] cTnT+ cells, 10-15\% iCM [224], $3 \%$ [225] or $20 \%$ [229] aMHC+ cells. Moreover, the cells display only marginal similarity to mature $\mathrm{CM}$ based on their molecular and electrophysiological phenotype [223]. Such low efficiencies may reflect insufficient construct design with respect to expression stoichiometry, with a tailored ratio of protein expression - constituting higher protein levels of Mef2c in combination with lower levels of Gata4 and Tbx5 shown to enhance programming efficiency [228]. Several approaches now aim to improve reprogramming efficiency as well as maturation of iCMs by adding further TFs of the cardiac lineage such as Hand2 $[216,217,219,220,222]$, together with signaling modulators such as inhibitors of TGF- $\beta$ (A83-01, SB431542) [217,230], WNT (XAV939) [230] or ROCK (SR-3677, Thiazovivin, Y-27632) [217].

A number of pro-cardiogenic microRNAs have been identified [232-234] and applied in combination with TFs $[217,222]$ or as sole modulators [235-237] for direct re-programming. MicroRNAs, for example microRNA-1, can interact with myogenic TFs such as SRF (serum response factor), Mef2c, MyoD or Nkx2.5 in a regulatory 
loop as repressors and cooperators [238-240]. MicroRNA-1 negatively impacts the Notch signaling pathway via direct repression of DII1 [241] and its downstream factor Hes1 [102], resulting in expression of Gata4, Nkx2.5 and Myogenin. A combination of miR-1/-122/-208/499 and JAK inhibitor I has been demonstrated to induce a cell fate switch towards a cardiac-like phenotype with $28 \%$ aMHC+ cells in vitro and improved cardiac outcomes in vivo [235-237].

One approach focuses on the use of a chemical cocktail to convert murine embryonic fibroblasts to iCMs with spindle, rod and round shaped morphologies [218]. The cells generated manifest action potentials of atrial- and ventricular-like cells. Notwithstanding the heterogeneity of the cells obtained, this method offers a potential alternative to genome integrative methods which may prove safer. However, the effective time windows for each chemical modulator, which include signaling pathway activators/inhibitors or epigenetic regulators, has to be clearly defined to achieve optimal results [220].

While progress has been made, so far the iCMs obtained are still immature in phenotype and inhomogeneous as a population, lacking the terminal structural and electrophysiological characteristics of authentic adult CMs. 


\begin{tabular}{|c|c|c|c|c|c|c|c|}
\hline Cell origin & Host & $\begin{array}{l}\text { Delivery } \\
\text { system }\end{array}$ & $\begin{array}{l}\text { in vivo/ } \\
\text { in vitro }\end{array}$ & Factor / Substances & $\begin{array}{l}\text { Target } \\
\text { cell type }\end{array}$ & Special features & Literature \\
\hline $\begin{array}{l}\text { neonatal } \\
\text { cardiac } \\
\text { fibroblasts }\end{array}$ & mouse & $\begin{array}{l}\text { retroviral or } \\
\text { lentiviral }\end{array}$ & $\begin{array}{l}\text { in vitro / } \\
\text { in vivo }\end{array}$ & Gata4, Mef2c, Tbx5 & CM-like & $\begin{array}{l}30 \% \mathrm{CTnT}^{+} \text {cells (to a lesser extent in tail- } \\
\text { tip fibroblasts) } \\
\text { Upregulation of: Myh6, Actc1, Actn2, Nppa }\end{array}$ & $\begin{array}{l}\text { leda et al., } 2010 \\
\text { [227] }\end{array}$ \\
\hline $\begin{array}{l}\text { neonatal } \\
\text { cardiac } \\
\text { fibroblasts }\end{array}$ & mouse & $\begin{array}{l}\text { lentiviral } \\
\text { microRNA } \\
\text { specific } \\
\text { culture } \\
\text { conditions }\end{array}$ & $\begin{array}{l}\text { in vitro / } \\
\text { in vivo }\end{array}$ & $\begin{array}{l}\text { miR-1/-122/-208/499 } \\
\text { JAK inhibitor I }\end{array}$ & CM-like & $\begin{array}{l}\text { day 3: 2- to 3-fold upregulation of Mef2c, } \\
\text { Tbx5, Hand2, Nkx2.5, Gata4 } \\
\text { day 6: expression of cTnT, cTnl, sarcomeric } \\
\text { actinin } \\
\text { reprogramming efficiency: } 1.13-5.28 \% \text { in } \\
\text { non-JAK inhibitor I-treated cells } \\
\text { with JAK inhibitor I: } 28 \% \text { aMHC cells } \\
\text { enhanced cardiac function in mouse model }\end{array}$ & $\begin{array}{l}\text { Jayawardena et } \\
\text { al., } 2012 \text { and } \\
2014[235,236]\end{array}$ \\
\hline $\begin{array}{l}\text { fibroblasts } \\
\text { (from hESCs; } \\
\text { H9) }\end{array}$ & human & retroviral & in vitro & $\begin{array}{l}\text { EGFP, ESRRG, GATA4, } \\
\text { MEF2C, MESP1, TBX5, } \\
\text { MYOCD, ZFPM2 } \\
\text { SIS3 }\end{array}$ & CM-like & $\begin{array}{l}20 \% \text { functional } \mathrm{Ca}^{2+} \text { transients } \\
\text { cardiac marker expression of: } \mathrm{CTnT}, \alpha- \\
\text { Actinin, ACTC1, ACTN2, MYH6, MYL2, } \\
\text { MYL7, TNNT2, NPPA, } \\
\text { PLN, and RYR2 } \\
\text { SIS3 significantly decreases } \alpha \mathrm{MHC}^{+} \text {cells }\end{array}$ & $\begin{array}{l}\text { Fu et al., } 2013 \\
{[221]}\end{array}$ \\
\hline $\begin{array}{l}\text { tail tip and } \\
\text { embryonic } \\
\text { fibroblasts } \\
\text { (B6;129S4) }\end{array}$ & mouse & retroviral & in vitro & $\begin{array}{l}\text { M3 domain of mouse MyoD } \\
\text { fused on carboxy-terminus } \\
\text { of Mef2c, Gata4, Hand2, } \\
\text { Tbx5 } \\
\text { GSK126 (day 1-4), UNC0638 } \\
\text { (day 3-7) }\end{array}$ & CM-like & $\begin{array}{l}\text { Reprogramming efficiency: } \\
\mathrm{MM}_{3}-\mathrm{GHT}: 3.5 \% \text { (> 15-fold increase) } \\
\mathrm{MM}_{3}-\mathrm{GHT}+\mathrm{GSK} 126 \text { : further increase to } \\
\text { control 2.1-fold (most efficient } \\
\text { combination) } \\
\mathrm{MM}_{3}-\mathrm{GHT}+\text { UNC0638: further increase to } \\
\text { control 2-fold }\end{array}$ & $\begin{array}{l}\text { Hirai et al., } \\
2013 \text { [219] and } \\
2014[220]\end{array}$ \\
\hline NRVM & rat & adenoviral & $\begin{array}{l}\text { in vitro / } \\
\text { in vivo }\end{array}$ & Tbx18 & SAN-like & $\begin{array}{l}\text { downregulation of Cx43 } \\
\text { pacemaker-like AP profile (9.2\%) }\end{array}$ & $\begin{array}{l}\text { Kapoor et al., } \\
2013 \text { [242] }\end{array}$ \\
\hline $\begin{array}{l}\text { neonatal } \\
\text { foreskin and } \\
\text { adult } \\
\text { fibroblasts }\end{array}$ & human & retroviral & in vitro & $\begin{array}{l}\text { Gata4, Hand2, Tbx5, } \\
\text { myocardin, miR-1/-133 } \\
\text { Culture time: } 4-11 \text { weeks }\end{array}$ & CM-like & $\begin{array}{l}\sim 35 \% \text { tropomyosin }^{+} \text {cells } \\
\sim 20 \% \text { cTnT }^{+} \text {cells }\end{array}$ & $\begin{array}{l}\text { Nam et al., } \\
2013 \text { [222] }\end{array}$ \\
\hline $\mathrm{CM}$ & pig & adenoviral & in vitro / & Tbx18 & SAN-like & mean HR was higher in TBX18-transduced & Hu et al., 2014 \\
\hline
\end{tabular}




\begin{tabular}{|c|c|c|c|c|c|c|c|}
\hline & & & in vivo & & & $\begin{array}{l}\text { animals } \\
\text { sympathetic predominance in the } \\
\text { TBX18-transduced group } \\
\text { TBX18-transduced animals had persistent } \\
\text { and stable activity }\end{array}$ & [243] \\
\hline $\begin{array}{l}\text { embryonic } \\
\text { fibroblasts } \\
\text { (C57BL/6) }\end{array}$ & mouse & $\begin{array}{l}\text { chemical } \\
\text { cocktail }\end{array}$ & in vitro & 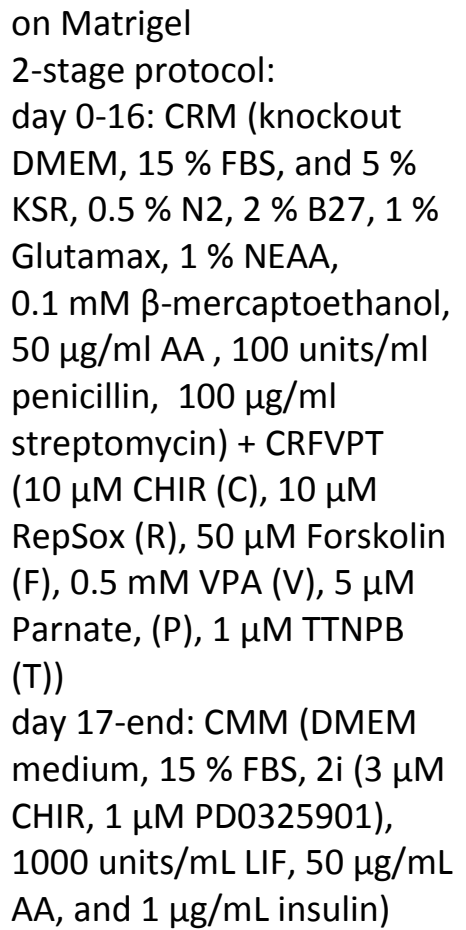 & CM-like & $\begin{array}{l}\text { morphology: spindle shape, rod shape or } \\
\text { round shape } \\
\text { spontaneously beating activity: increases } \\
\text { from day } 8 \\
\text { cardiac marker expression of: Mef2c, } \alpha \text { - } \\
\text { Actinin, Gata4, cTnT, Nkx2.5, } \alpha-M H C, N- \\
\text { cadherin, Cx43, cTnl } \\
\text { action potential of atrial- and ventricular- } \\
\text { like CMs }\end{array}$ & $\begin{array}{l}\text { Fu et al., } 2015 \\
\text { [218] }\end{array}$ \\
\hline $\begin{array}{l}\text { cardiac } \\
\text { fibroblasts }\end{array}$ & mouse & $\begin{array}{l}\text { retroviral } \\
\text { antibiotic } \\
\text { selection }\end{array}$ & in vitro & Gata4, Mef2c, Tbx5 & CM-like & $\begin{array}{l}\text { stoichiometry of } \mathrm{G}, \mathrm{M}, \mathrm{T} \text { protein expression } \\
\text { influences reprogramming efficiency } \\
\text { high Mef2c and low Gata4, Tbx5 most } \\
\text { efficient }\end{array}$ & $\begin{array}{l}\text { Wang et al., } \\
2015 \text { [228] }\end{array}$ \\
\hline $\begin{array}{l}\text { embryonic } \\
\text { fibroblasts }\end{array}$ & mouse & retroviral & in vitro & $\begin{array}{l}\text { Gata4, Hand2, Mef2c, Tbx5, } \\
\text { miR-1/-133, Y-27632, } \\
\text { Thiazovivin, SR-3677, A83- } \\
01\end{array}$ & CM-like & $\begin{array}{l}\text { spontaneously beating activity without } \\
\text { signaling inhibitors: GHMT > day } 21 \text {, } \\
\text { GHMT+miR-1/-133 > day } 8 \\
\text { ROCK inhibitors enhance reprogramming of } \\
\text { MEFs } \\
\text { TGF- } \beta \text { inhibitors enhance reprogramming } \\
\text { of MEFs most efficiently }\end{array}$ & $\begin{array}{l}\text { Zhao et al., } \\
2015 \text { [217] }\end{array}$ \\
\hline
\end{tabular}




\begin{tabular}{|c|c|c|c|c|c|c|c|}
\hline $\begin{array}{l}\text { embryonic, } \\
\text { adult } \\
\text { cardiac, tail } \\
\text { tip }\end{array}$ & mouse & retroviral & in vitro & $\begin{array}{l}\text { Gata4, Hand2, Mef2c, Tbx5, } \\
\text { Akt1 }\end{array}$ & CM-like & $\begin{array}{l}\text { spontaneously beating activity: MEFs }>\text { day } \\
7(50 \%>\text { day } 21), C F s>\text { day } 14, \text { TTFs }>\text { day } \\
21 \text {; } \\
\text { responsive to } \beta \text {-adrenoreceptor } \\
\text { pharmacologic modulation, polynucleated, } \\
\text { and hypertrophic }\end{array}$ & $\begin{array}{l}\text { Zhou et al., } \\
2015 \text { [216] }\end{array}$ \\
\hline $\begin{array}{l}\text { neonatal } \\
\text { cardiac } \\
\text { fibroblasts }\end{array}$ & mouse & $\begin{array}{l}\text { retroviral } \\
\text { (TFs) and } \\
\text { lentiviral } \\
\text { (shRNA) }\end{array}$ & in vitro & $\begin{array}{l}\text { Gata4, Mef2c, Tbx5 } \\
\text { shRNA of } 35 \text { selected } \\
\text { components of chromatin } \\
\text { modifying or remodeling } \\
\text { complexes }\end{array}$ & CM-like & $\begin{array}{l}\text { Bm1 downregulation significantly } \\
\text { enhanced } \mathrm{CM} \text { generation }\end{array}$ & $\begin{array}{l}\text { Zhou et al., } \\
2016[231]\end{array}$ \\
\hline $\begin{array}{l}\text { neonatal } \\
\text { cardiac } \\
\text { fibroblasts }\end{array}$ & mouse & $\begin{array}{l}\text { TFs } \\
\text { specific } \\
\text { culture } \\
\text { conditions }\end{array}$ & $\begin{array}{l}\text { in vitro / } \\
\text { in vivo }\end{array}$ & $\begin{array}{l}\text { Gata4, Mef2c, Tbx5 } \\
\text { SB431542 } \\
\text { XAV939 }\end{array}$ & CM-like & $\begin{array}{l}\text { 8-fold increased reprogramming efficiency } \\
\text { beating cells } 1 \text { week after reprogramming } \\
\text { enhanced cardiac function in mouse model }\end{array}$ & $\begin{array}{l}\text { Mohamed et } \\
\text { al., } 2017 \text { [230] }\end{array}$ \\
\hline
\end{tabular}

AA: ascorbic acid; Actc1: cardiac $\alpha$-actin; Actn2: actinin $\alpha 2$; AP: action potential; Akt1: Akt1/protein kinase B; A83-01: TGF- $\beta$ inhibitor; CHIR: CHIR99021 (GSK-3 inhibitor, Wnt activator); CM: cardiomyocytes; GSK126: Enhancer of Zeste Homolog 2 (Ezh2) inhibitor; KSR: knockout serum replacement; Myh6: $\alpha$-myosin heavy chain; NEAA: non-essential amino acid; Nppa: natriuretic peptide precursor type A; NRVM: neonatal rat ventricular myocytes; PD0325901: MEK1/2 inhibitor; RepSox: TGF- $\beta 1$ inhibitor; SAN: sino-atrial-nodal cells; SB431542: TGF- $\beta$ inhibitor; shRNA: small hairpin RNA; SIS3: SMAD3 inhibitor (activated downstream of TGF $\beta$ signaling); SR-3677: ROCK inhibitor; TF: transcription factor; Thiazovivin: ROCK inhibitor; TTNPB: analog of retinoic acid; UNC0638: G9a and GLP inhibitor; VPA: valproic acid (histone deacetylase inhibitor); XAV939: WNT inhibitor; Y-27632: ROCK inhibitor. 


\subsection{Programming of cardiac conduction system cells}

As outlined earlier, the availability of highly specific cardiomyocyte subtypes is critical for future tailored cell therapy of cardiovascular disease. The treatment of rhythm disorders by cardiac cell therapy will require a highly pure population of cells belonging to the cardiac conduction system [89,244-247]. As a corollary, while a mixture of cardiomyocyte subtypes is capable of coupling to working myocardium and setting the pace in vivo in a porcine model of complete atrioventricular block, the resulting rhythms are neither stable nor reliably exceed junctional escape rhythm rates [248].

\subsubsection{Composition of the cardiac conduction system}

Automaticity of the heart beat is crucial for life: the heart's regular contractile activity results from electrical impulses initiated and conducted by highly specialized cells within the heart which form the cardiac conduction system (CCS) [249-251].

The initial impulse is generated in a small number $(\sim 10,000)$ of highly specialized pacemaker myocytes which form the sinoatrial node (SAN) [242]. The SAN is located at the junction of the right atrium and the superior vena cava $[249,250]$. SAN cells differ from working myocardial cells in their content of ion channels and gap junction proteins $[252,253]$. In particular they are rich in hyperpolarization-activated cyclic nucleotide-gated cation channel 4 (HCN4) and t-type calcium channel (Cav3.1). SAN cells lack natriuretic factor (ANF) and the gap junction proteins connexin43 (Cx43, predominant in ventricular and atrial cells) and connexin40 (Cx40, expressed in atrial working myocardium) $[249,252,253]$. In contrast, the main gap junction protein in the SAN is connexin45 (Cx45). The membrane voltage clock (cyclic activation and deactivation of membrane ion channels, resulting in part from f-channel conductance of the "funny current") and the subsarcolemmal $\mathrm{Ca}^{2+} \mathrm{clock}^{2}$ (resulting from rhythmic spontaneous sarcoplasmic reticulum $\mathrm{Ca}^{2+}$ release) function synergistically to generate SAN automaticity [251]. An illustration of the major differences between these cells is that the upstroke of the action potential (AP) in SAN results from $\mathrm{Ca}^{2+}$-channels as opposed to voltage-gated $\mathrm{Na}^{+}$-channels typical of working myocardial cells [253].

The impulse that emerges then propagates rapidly and anisotropically through atrial myocardium until it reaches the atrioventricular node (AVN) where the signal is delayed. Atrial and ventricular myocardium are electrically isolated from each other, allowing the atria to contract first, a physiological requirement for optimal ventricular filling prior to ventricular systole $[249,250]$.

The electrical impulse then proceeds through the ventricular conduction system (VCS). The latter consists of a fast-conducting atrioventricular bundle (AVB) (or His bundle), left and right bundle branches (BBs) and the Purkinje fiber network. The AVB commences at the AVN and proceeds through the ventricular septum, where it sub-divides into the right and left BBs. The BBs themselves divide into Purkinje fibers, which are spread over the entirety of the left and right ventricles, enabling synchronous biventricular contraction $[249,250,254]$.

While AVN cells resemble those of the SAN, cells of the VCS differ significantly from both SAN and ventricular working myocardial cells. In particular, while depolarization involves voltage-gated $\mathrm{Na}^{+}$-channels, the "funny current" is still present in the VCS [253]. Similarly, the gap junction proteins are different, with Cx40 required in VCS cells to facilitate high conduction velocity from Purkinje fibers to ventricular cells [252]. 
Overall, a high degree of coordination is required between all these different cell types to ensure normal stability of cardiac rhythm and rate. One manifestation of a primary disturbance in cardiac pacemaker function is the so called "sick sinus syndrome" (SSS) [255].

\subsubsection{Manifestations of sick sinus syndrome}

SSS, or sinoatrial disease, refers to a chronic clinical syndrome reflecting SAN dysfunction which has a variety of causes [255]. It results in a variety of abnormalities, including sinus bradycardia, sinus pauses, sinus arrest and sinoatrial exit block and may result in chronotropic incompetence, i.e. insufficient augmentation of heart rate to meet physiological requirements during exercise or other stress [256]. In up to half of cases, SSS may be accompanied by paroxysmal atrial tachycardia and AVN conduction disturbance, as part of the tachycardiabradycardia syndrome [255-259]. The rhythm disturbances can result in a variety of symptoms, including palpitations, lightheadedness, shortness of breath, exercise intolerance, fatigue and frank syncope [255].

While SSS occurs predominantly in the elderly, it is prevalent at all ages [255,257-259]. In young adults and children, SSS commonly results from post-operative atrial trauma or inherited disease. In the elderly, SSS may reflect progressive age-related attrition in SAN cell number [258], or result from a distinct disease process such as atherosclerosis. The sinus node is supported by the right coronary artery whose compromise transiently with ischaemia or through actual infarction can result in permanent SAN dysfunction [255,259]. Familial SSS has been described to arise from genetic mutations, characteristically originating from alterations in one of three genes [255]: two of these, HCN4 and SCN5A (sodium channel, voltage-gated, type V, alpha subunit), are crucial for transmembrane ion exchange and thus highly relevant for action potential generation. The third gene implicated, MYH6 (myosin, heavy chain 6, cardiac muscle, alpha) plays an essential role in myosin formation to support cardiomyocyte contractility [255].

At present, symptomatic SSS is treated by implantation of an electrical pacemaker device, regardless of underlying aetiology, and constitutes one of the major indications for permanent pacemaker implantation globally (30-50 \% of all cases) [255,257-260].

While the advent of implantable permanent pacemakers has revolutionized the management of lifethreatening or highly symptomatic bradycardias, dramatically improving symptoms, quality of life and, in specific cases, prolonging survival [261] it bears some limitations. These can include the possibility of device infection (which can necessitate removal of the entire pacing system), limited battery lifespan (necessitating intermittent generator changes in those who are pacemaker dependent at specific intervals), lead damage or vessel thrombosis, dyssynchronous electromechanical activation and incomplete recapitulation of physiological heart rate increments and interference with external electromagnetic devices [262]. While many of these are theoretical or of small consequence at the individual patient level, their occurrence (particularly device infection) can be serious and can pose a relevant cumulative risk in certain groups, e.g. the paediatric pacingdependent population.

To circumvent the concerns inherent to implantable electronic devices, a number of quite promising approaches towards engineering a biological pacemaker have recently appeared. These employ two principle strategies [260]: virus-based gene transfer aimed at converting resident cardiac cells into cells with pacemaker properties $[242,243,263]$; or, a cell-based strategy, in which in-vitro pre-processed cells are transplanted into 
the heart as pacemakers $[89,159,264,265]$. Of note, when generated from patient-derived iPSCs, such cells may become of great importance for personalized in vitro drug testing.

\subsubsection{Modification and direct reprogramming of working myocardial cells}

Generation of CCS cells follows similar principles to those used for working cardiomyocyte (re-)programming. However, the programming factors need to be carefully selected for this highly specific purpose. TFs such as Tbox 3 (Tbx3), T-box 18 (Tbx18), short stature homeobox 2 (Shox2) or ISL LIM homeobox 1 (IsI1) play critical roles in the intrinsic development of PCs, but are absent or highly downregulated in the other cardiomyocyte subtypes [155,266-269]. The expression of ion channel components such as HCN4, calcium voltage-gated channel subunit alpha1 D (Cacna1d, $\mathrm{Ca}_{\mathrm{v}} 1.3$ ), or the calcium voltage-gated channel subunit alpha1 G (Cagna1g, $\mathrm{Ca}_{\mathrm{v}} 3.1$ ) also differs between PCs and the working myocardium, as do gap junction proteins such as Cx45 and Connexin30.2 (Cx30.2), both expressed instead of Cx43 [270-277].

The TF Tbx3 functions as transcriptional repressor during embryonic development, preventing expression of TFs typical for the working myocardium and thereby formation of working myocardial CMs. While Tbx3 is not solely responsible for SAN formation, it imposes a pacemaker gene program [269]. Accordingly, use of Tbx3 for direct reprogramming of resident myocardium cells appears attractive and has been evaluated in two different studies of Tbx3 overexpression in murine hearts. However, neither Tbx3 expression in atrial myocardium [267], nor tamoxifen-induced expression of Tbx3 in whole working myocardium [263] leads to fully functional PCs. While both reports demonstrate that Tbx3 can partially induce a number of pacemaker-related genes, the resulting cells still differ significantly from native pacemaker cells (PMCs) with regard to their overall expression patterns. In the first study, SAN specific markers were found to be upregulated such as Hcn4, Cx30.2 and Lbh. Similarly, atrial specific markers were downregulated, including natriuretic peptide A (Nppa), Cx40, Cx43 and sodium voltage-gated channel alpha subunit 5 (Scn5a, Nav1.5) [267]. The second study recapitulated the expression of some of these genes in isolated atrial cells (e.g. Lbh, Nppa, Cx43 and Cx40), but others reacted differently, such as Hon 4 which exhibited an unaltered expression pattern. Further, in the atrium another member of the cyclic nucleotide gated potassium channel family (Hon1) was upregulated, while Hcn4 was actually downregulated in ventricular cells. Remarkably, the expression level of the TF NK2 homeobox 5 (Nkx25), which plays a pivotal role in working myocardium, was not modified by Tbx3 expression in these cells [263]. Overall, these findings suggest that Tbx3 alone is insufficient to convert working myocardium into PCs.

A related SAN-specification factor, Tbx18, has been tested after initial experiments with rat neonatal ventricular myocytes [242]. In contrast to other TFs tested (Shox2, Tbx3, Tbx5 and Tbx20), only Tbx18 transduction has been shown to significantly increase the number of spontaneously beating cultures. The resulting cells exhibit a more pacemaker-like morphology, as well as enhanced HCN4 expression and pacemaker-like cellular automaticity. Although the beating frequency of the transduced cells was double that of control cells, it was still far lower than that observed in vivo in rat hearts (95 bpm vs. 350bpm) [242]. Importantly, the effect of Tbx18 has not only been demonstrated in vitro, but also reported in a large-animal model in vivo using adenoviral gene transfer. After pilot experiments in guinea pig hearts [242], a consecutive study evaluated the ability of Tbx18-expressing adenovirus injected into the interventricular septum of pigs to rescue induced complete heart block [243]. Examination of both animal models revealed evidence of partial transformation into pacemaker-like cells after transduction, as reflected by upregulation of Hcn4 and downregulation of working myocardial genes ( $\mathrm{C} \times 43$ and Nkx2-5). In addition, ventricular ectopic beats were 
induced in both guinea pig and pigs hearts [242,243], with automaticity of the pig heart largely independent of the backup implanted electronic pacemaker for the short duration of the study [243]. Single cell analysis of the transducted guinea pig heart indicated the effect of Tbx18-expression to be only very transient: after 6 weeks, less than one third of transduced cells retained their pacemaker-like-morphology. However, due to limitations with respect to the recovery of single cells from the pig heart, insights into in situ reprogramming that could be gained from single cell analysis were lacking. Consistent with the temporal time course of expression of adenoviral vectors, SAN functional testing using electronic burst ventricular pacing revealed a rapid recovery in Tbx18-transduced animals at day 8, which increased to levels comparable with the control group (percutaneous GFP injected) by 2 weeks [243]. While the study describes the first partially successful in situ reprogramming towards a biological pacemaker in a clinically relevant large animal model, the long term effects of Tbx18-based reprogramming of working myocardium remain to be determined [242,243]. In this regard, a recent study used two independent Cre/loxP-mediated conditional transgenic mouse models to express Tbx18 in the atrial and ventricular myocardium during fetal development to further investigate the ability of Tbx18 to convert working myocardium into pacemaker cells [278]. Ectopic expression of Tbx18 was discernible from E12.5 or E14.5 and caused right ventricular hypoplasia, atrial dilatation and ventricular septal defects. In contrast to the experiments of the Marban group, no upregulation in expression of SAN-related genes was found in working myocardium, despite downregulation in chamber specific genes such as $\mathrm{Cx} 40$ and Nav1.5. Notably, Tbx18 expression also induced ectopic expression of atrial and ventricular marker genes, including Nppa in the ventricles and myosin, light polypeptide 2, regulatory, cardiac, slow (Myl2, Mlc2v) and myosin, heavy polypeptide 7, cardiac muscle, beta (Myh7) in the atria [278]. It remains to be seen whether the contrasting outcomes of the two studies arise from application of Tbx18 in different species [243,278], or from differing expression time points in the heart (fetal [278] vs. adult [243]). Such considerations will need to be carefully addressed to obviate potential side effects before Tbx18 overexpression can be used to generate a biological pacemaker in patients.

Based on the experience with directly reprogramming fibroblasts into spontaneously beating cells, it seems likely that such an approach can be further developed to generate distinct cardiomyocyte subtypes, including pacemaker cells [279]. To identify possible TFs for such reprogramming, a study examined an initial group of 20 candidates by transducing them into embryonic fibroblasts of a mouse line expressing GFP under the control of Hcn4 regulatory promoter regions. An iterative process of successive omission of candidates expendable for EGFP expression led to the definition of the smallest group of factors promoting reporter expression, namely: Tbx5, Tbx3, Gata6 and either Retinoic acid receptor, gamma (Rarg) or Retinoid X receptor, alpha (Rxra). However, induction of significant Hon4 expression alone does not seem sufficient to generate functional pacemaker cells as no spontaneous beating activity was observed, nor were the cells excitable via depolarization stimuli [279]. Moreover, in further experiments fibroblast transduction experiments using the "classical" cardiomyocyte reprogramming factors Gata4, Hand2, Mef2C and Tbx5, some of the reprogrammed cells expressed Hcn4-GFP. More detailed analysis revealed that this approach yielded multiple potential cardiac cell types: atrial-like, pacemaker-like and ventricular-like. Together, these data suggest that reprogramming of fibroblasts into PMC may be feasible in principle, but is still currently far from being reliably established.

\subsubsection{Nodal cell programming of adult stem cells}

Several studies have described diverse modifications of adult stem cells for pacemaker cell generation. These have primarily employed mesenchymal stem cells [101,280-291] derived from canine [101,281-284], rat 
[285,292], rabbit [289-291] or human [280,286,287] tissue. Additional reports describe using adipose tissuederived stem cells [288,293]. Most groups using ASCs chose to overexpress an Hcn-family member [280,282287,289-291] to drive cell fate towards a nodal phenotype, while others used TFs such as Shox2 [101,281]. These have been combined with other treatments such as 5-Azacytidine [288] or electric-pulse current stimulation (EPCS) [281,282]. While utilizing divergent experimental setups, the scientific findings are quite comparable. Depending on the respective experiment, the resulting cells have displayed some nodal cell properties, for example measurable funny current (If) which could be enhanced with EPCS or with isoproterenol and blocked with cesium [281-283,287,290]. Moreover, expression of typical pacemaker genes like $\mathrm{Cx} 45, \mathrm{Hcn} 4, \mathrm{Tbx3}$ are observed to increase, while genes associated with working myocardium, such as $\mathrm{Cx} 43$ and Nkx2-5, are downregulated [101,281,282]. Furthermore, a change in cell morphology towards a more pacemaker-like phenotype has been reported [101,281,288]. Co-culture of the modified ASCs with myocytes from newborn mice, regardless of origin, has led to increased beating frequency of the neonatal myocytes when compared to co-cultures with unmodified ASCs $[101,287,290]$.

For in vivo testing, cells have been transplanted preferentially into canine hearts [283,287]. After induction of heart block, two publications describe the appearance of ventricular escape rhythms observed via ECG recordings [283,287]. However, this required vagal stimulation to induce sinus arrest to be apparent [283], and was associated with higher escape frequencies than control cell transplantation [287]. In all of these studies the lack of resulting cellular autonomous activity is strikingly consistent [101,280-292].

One report describes spontaneous activity of transformed ASCs derived from brown fat: interestingly, this phenomenon seems to reflect a reaction of the cells to the cultivation media as no genetic modification was applied [293]. While analysis of ultrastructural, proteomic, electrophysiological and pharmacological parameters of the resulting beating cells indicated the presence of some pacemaker-like features, further investigation is required, particularly over more prolonged culture periods [293].

In summary, significant further efforts are required to enable reprogramming of true nodal cells from ASCs.

\subsubsection{Forward programming of pluripotent stem cells into nodal cells}

PSCs represent a suitable source for any desired distinct cell type based on their unlimited differentiation potential. Concomitantly, this same unlimited differentiation potential represents a major obstacle to obtaining only a particular cell type. Thus a key challenge for the field is how to force PSCs exclusively towards a desired lineage.

The spontaneous differentiation rate of nodal cells from murine PSCs typically does not exceed $\sim 1 \%$. While great improvements have been made recently with regard to the differentiation of human PSCs into cardiac cell phenotypes using specific culture conditions [161,188,190,294,295], the typical proportion of rare nodal cell types elicited still needs to be accurately defined.

Since the first description of mouse embryonic stem cells being differentiated into cardiomyocytes for the first time in 1991 [120], studies have examined the composition of different beating cells and attempted to specifically direct fate during differentiation. Besides considering cellular morphology and canonical marker expression patterns, the importance of recapitulating electrophysiological properties has been increasingly recognized. If one uses classical random differentiation protocols, the cells obtained represent a variety of 
kinds of cardiomyocyte cell types: nodal, atrial, ventricular and immature cardiomyocytes [245]. Accordingly, a key focus of interest has been how to reliably influence cell fate during differentiation. At present, there are three main strategies to enhance the proportion of nodal cell types within culture: stimulation via intrinsic culture conditions, enrichment via selection and forced overexpression of specific TFs.

With respect to the first strategy, the small molecule compound EBIO (1-ethyl-2-benzimidazolinone), a small/intermediate-conductance $\mathrm{Ca}^{2+}$-activated potassium channel modulator, has been postulated to increase the formation of nodal cells from murine ES cells. While application of EBIO to ES cells has been reported to lead to induction of sino-atrial and reduction in chamber-specific myocardial programs, the resultant cells had low beating frequencies, with no confirmation of ability to pace myocardium, or electrophysiological discrimination between mature pacemaker cells and those of an early/intermediate cell type which also spontaneously contract [296]. Interestingly, a recent study addressed the influence of EBIO on human PSC differentiation, shedding light on a mechanism of action via lineage-specific effects. While addition of EBIO resulted in dosedependent enrichment of cardiomyocytes, with increased nodal- and atrial-like phenotypes, the effect was mainly attributable to a EBIO-induced severe reduction in cell survival, thereby favouring cardiac progenitor cell preservation [297].

Recently, a promising study described the generation of hPSC-derived pacemaker cells using a specific differentiation protocol combined with surface marker selection based on SIRPA (signal-regulatory protein alpha) [159]. SIRPA represents a cell-surface marker suitable to isolate populations of cardiomyocytes from hPSCs [177]. In combination with a transgene-independent differentiation protocol [159], the resulting hPSCderived SAN-like cardiomyocyte cells fulfill a number of typical pacemaker features; in particular they are capable of pacing host tissue post-transplantation into the apex of rat hearts. However, further points will need to be addressed to better understand the cell generated: early/intermediate cell types were not taken into account despite the fact that the funny channel densities reported resemble those of immature cells, with action potential curves revealing clear plateau phases; an investigation of the characteristic $\mathrm{Ca}^{2+}$ release from sarcoplasmic reticulum; an examination of the specific morphology of single cells, specifically for typical spindle- or spider-shaped cells. An additional concern is the observed atypical expression of Cx43 and Cx40 [159].

A separate study [298] based on surface marker purification to isolate SAN progenitors used the activated leukocyte cell adhesion molecule (Alcam, CD166 antigen) during murine ESC differentiation. While the cells obtained display some pacemaker characteristics, selection via Alcam appears to be extremely dependent on time point and species. Thus, cell sorting at different differentiation time points yielded different degrees of sarcomeric $\alpha$-actinin expression, a marker of cardiac-committed cells [298]. An earlier study using ALCAM as an expression marker in human embryonic stem cells revealed that the enriched cells manifested an embryonic cardiomyocyte phenotype [299]. Notably, only about 10\% of Alcam-selected cells retained Hcn4 expression after 3 weeks in culture, a finding which may reflect a maturation process of initially Hon4 positive early/intermediate CMs towards principally working myocardial cells over this timeframe [298].

In a further setting, the transcription factor Shox2 has been used with the goal of generating nodal cells from murine ESCs. Hashem and Claycomb transfected cells with a plasmid bearing a neomycin resistance gene controlled via the Shox 2 promoter. Subsequent neomycin application during differentiation led to an almost pure population of Shox 2 positive cells. Analysis of expression signatures revealed intrinsic nodal 
characteristics (Tbx3, HCN4, Cx45, Cav1.3, Cav3.1) as well as expression of other cardiac marker genes (Tbx5, Mlc2v, Cx43). however, while the cells were spontaneously active, no additional functional data were shown [300]. In a similar approach, lonta et al. used Shox2 overexpression in mouse embryonic stem cells to force cells into a nodal cell lineage [264]. However, while the resulting cells were spontaneously active, the beating frequencies were below $80 \mathrm{bpm}$ and therefore did not exceed those of WT-ES cell derived CM [264]. Consequently, it is unclear whether these cells represent functional pacemaker cells.

Our group has combined overexpression of the highly conserved key nodal cell inducer, Tbx3, with a neomycin resistance gene under controlled of the well-established $\alpha \mathrm{MHC}$-promoter. This approach leads to small aggregates consisting of 300 - 500 cells, which we term "induced sino-atrial bodies" (iSABs). iSABs exhibit high beating frequencies of between $400-500 \mathrm{bpm}$ in vitro, thereby for the first time truly corresponding to those of a murine heart and even exceeding in vitro cultivated nodal cells derived from mouse SAN. Evidence from extensive analysis of these cells, including confocal laser scanning microscopy, FACS, single-cell patch clamping (Figure $3 \mathrm{~A}$ ), funny channel density measurements and $\mathrm{Ca}^{2+}$ imaging reveals that iSABs consistently represent over $80 \%$ mature functional nodal cells, with the remainder constituting immature nodal cells. Additional single cell analysis identifies characteristic spindle (Figure $3 \mathrm{~B}$ ) and spider (Figure $3 \mathrm{C}$ ) cell morphology. To further address the pacing potential of iSABs, we employed the ex vivo model system of cultivated mouse ventricular slices. Remarkably, iSABs were capable of integrating into these slices, retaining their spontaneous activity and pacing the heart slices to result in robust contraction. We confirmed functional coupling to the slices using calcium-transient analysis, which revealed synchronization between iSABs and slices. Therefore, we have introduced, for the first time, highly pure PSC-derived nodal tissue which is functional on the physiological level in vitro, as well as in an ex vivo model [89]. Recently, we utilized iSABs as an in vitro model system to help decipher the role of the $\gamma 2$ subunit of AMP-activated protein kinase (AMPK) in the regulation of SAN biology and infer a role for AMPK in control of mammalian intrinsic heart rate [301]. An important next step will be to determine the ability of iSABs to pace cardiac tissue in vivo and to prove whether this approach can be extended to human PSCs. 
A

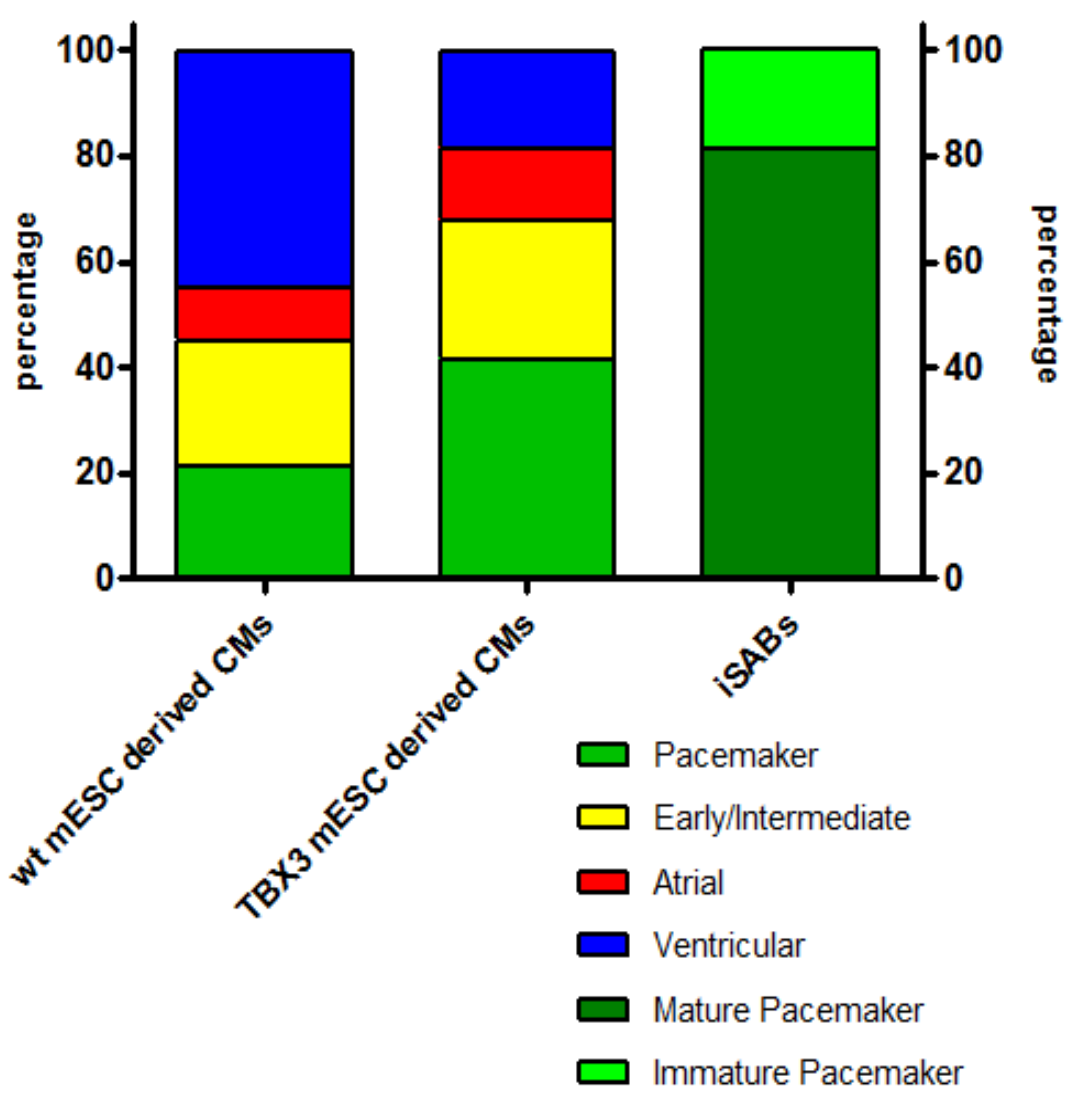

B
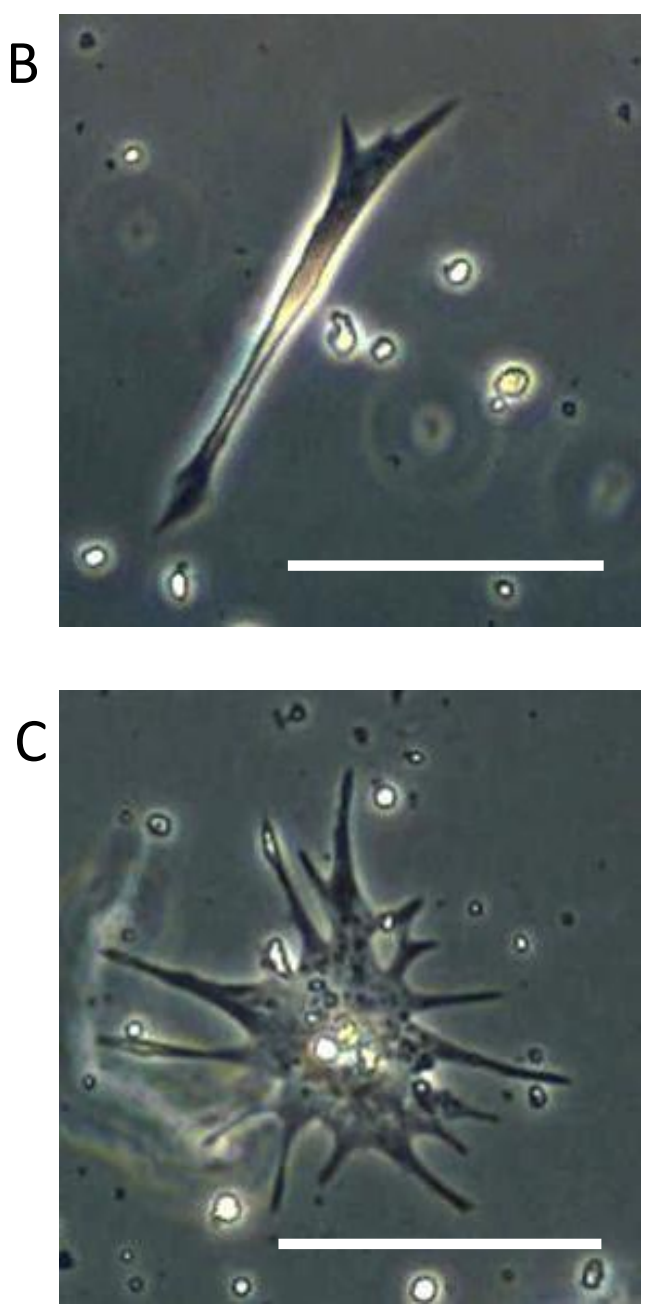

Figure 3: Properties of iSAB derived single cells. (A) Cardiac subtype distribution based on single cell patch clamp analysis and funny channel density measurements. Morphology of iSAB derived representative (B) spindle and (C) spider cells; scale bar $100 \mu \mathrm{m}$. 


\subsubsection{Systems-based network approaches to enhance nodal cell programming}

Further improvement of nodal cell programing will require an in depth understanding of underlying gene regulatory mechanisms. Given the complexity of the cardiovascular system and cardiovascular diseases, systems-based approaches play an increasingly important role in elucidating interactions between underlying traits and processes by using multiple 'omics' layers [302]. Such systems-based approaches are global analyses in which the different molecular levels are investigated and then integrated into qualitative and quantitative mathematical models (e.g. Boolean models, ordinary differential equations, network analysis concepts, etc.), providing an additional layer of understanding for cardiomyocyte dynamics [303]. Hence we used our recently developed iSABs, representing the first highly pure, stem cell programming-derived nodal cell tissue, to define the pacemaker transcriptome [91]. We highlight up-to-date systems-based approaches and compare our findings with the existing literature on a multi-level scale to verify the overall quality of the iSAB model system and address its potential transferability towards the human SAN (Figure 4).

The first step in such a systems-based data analysis procedure is to define the model system and available experimental input data (e.g. different SC-derived cardiomyocyte subtypes characterized by RNA-Seq data). Recent advances in high-throughput sequencing (HTS) have emphasized the important and versatile roles of coding and non-coding RNAs, including quantification of splice variants or identification of novel ncRNAs, during cardiac development. We used our RNA-Seq workflow, called TRAPLINE, to define the differences in transcriptomes between iSABs and randomly distributed mESC-derived cardiomyocyte subtypes [89,91]. Using the Galaxy framework, the numerous embedded data analysis workflows guarantees simple access, easy extension and flexible adaption of computational tools to individual needs, as well as sophisticated analyses that do not require in-depth command-line knowledge [304,305]. Data analysis with TRAPLINE results in a set of differentially expressed genes, their corresponding protein-protein interactions, splice variants, promoter activity and predicted miRNA-target interactions [91].

A central concept in systems biology is that networks, rather than classic linear pathways, underlie biological processes. The concept of biological networks arose when classic signaling pathways were represented as graphs in which the components (i.e. expressed gene transcripts) were termed nodes and their interactions (i.e. genes encoding transcription factors or protein-protein interactions) were called links or edges [306]. Demonstrating the general cellular differences between the two cell types through analysis of the transcriptome, we used the Biological Networks Gene Ontology tool (BiNGO) to determine the Gene Ontology (GO) terms significantly overrepresented in a set of significantly upregulated transcripts in iSABs (Figure 4A) [307]. These GO terms represent the accumulated biological processes of the significantly overexpressed transcripts. While the underlying statistical $p$-value, false discovery rate and family-wise error rate provide a good first impression of a specific functional category, it is important to also check the functional categories in the entire GO hierarchy. Thus it is highly likely that when a whole branch of the GO hierarchy is highlighted as being significantly overrepresented, the most intensely colored nodes furthest down the hierarchy can be expected to be the most biologically relevant ones.

The second step of the analysis characterizes the relevant components of the system (e.g. the actual set of significant differentially expressed gene transcripts driving the enhanced cardiac rhythm). A prominent method is that of gene set enrichment analysis (GWAS), performed by ClueGo [308]. The gene sets are analyzed on the basis of prior biological knowledge, such as use of GO or signaling pathways such as Wikipathways. Using 
statistical tests like the Fisher exact test, one can then ask whether the genes are enriched within a collection of pathways. Such analyses are highly dependent on using current versions of curated sets of GO annotations. Only annotated transcripts and ncRNAs can be integrated through GWAS analyses. Newly discovered transcripts or ncRNAs have to be characterized beforehand by other experiments or in silico prediction simulations [309,310]. One approach to overcome this limitation and independently link coding and non-coding transcripts without using annotations is the use of weighted correlation network analysis to identify clusters of highly correlated genes or an intramodular hub gene [311]. As described earlier, in using iSABs to define a function for AMPK in intrinsic heart rate regulation [301], we constructed a gene co-expression network from the iSAB transcriptome and identified Prkag2 in a module highly interconnected with known pacemakerrelevant genes. Hierarchical clustering and classical multi-dimensional scaling revealed, in common with the SAN transcriptome, that this Prkag2-containing module signified an important signaling hub with significant connectivity to genes vital for normal SAN function [301].

The third analysis step is to determine how the identified gene transcripts interact with each other or regulate other relevant interaction partners. This can be done by using data mining approaches [312] and databases such as BioGrid and String to incorporate resulting protein-protein interactions (PPTs) into the network, which is subsequently investigated for underlying dynamics and the molecular enrichment among genes within the network mathematically (i.e. how it responds to various perturbations and interconnects with other data layers). Based on the combined use of the BioGrid and String databases, we have obtained a network with 8,120 nodes and 55,720 edges, representing the interactome. After applying the tool KeyPathwayMiner [313], we were able to identify the most important subnetworks within the constructed interactome model to demonstrate known molecular interactions between significantly upregulated genes (Figure 4B). Once such a network is developed and available for the researcher, more sophisticated mathematical models can be applied to the network. Based on the input datatype available, one can employ ordinary differential equations (ODE), discrete modeling or hybrid modeling (composed of ODE and logic sub-modules) as a strategy to handle large scale, non-linear biochemical networks [314]. It has been shown that these kinds of network approaches are able to identify a specific regulatory core within a large gene network and, moreover, to predict receptor signatures associated with certain diseases [315]. Nevertheless, such in silico simulations and subsequent signature predictions still need experimental validation.

Ultimately, the information obtained at each analysis step is combined to draw conclusions about the complex behavior of the stem cell-derived cardiac pacemaker model and compared to current knowledge about the human SAN (Figure 4C). The results we have obtained for phenotypic associations such as contraction, electrophysiology, metabolism and differentiation factors, are in line with the current literature about the SAN. The knowledge gained from such systems-based analyses will be crucial for further optimization of cell programming and purification [91]. 
Data Analysis

Procedure

Experimental data (RNA-Seq)

iSABs vs aCABs

RNA-Seq analysis with TRAPLINE

Transcript analysis with BiNGO

GO enrichment with ClueGo

Characterization of stem cell derived pacemaker cells

B

Identification of subnetworks

String, BioGrid
Stabe knowledge

Molecular interaction

with KeyPathwayMiner

Literature text mining

Quality control

Verified phenotypica associations
Molecular Functionality, Interaction and Phenotypic Outcome

cell respiration

ATP-synthesis

oxidative phosphorylation

NTP metabolism

heart

development

ventricle morphogenesis
cardiac morphogenesis

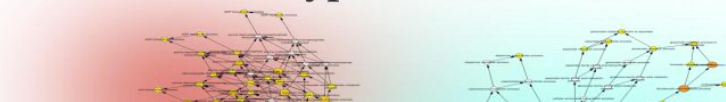

metabolism

citrate metabolic process

$y=3$. S

muscle fibrill organisatton

carbohydrate myosin filament assembly

metabolism glucan biosynthetic proces

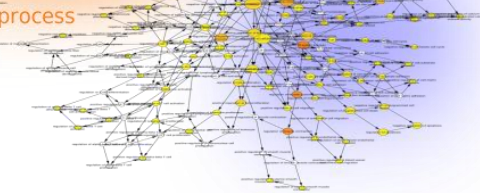

calcium ion transport regulation

I calcium ion transport

calcium-mediated signaling

cardiac muscle contraction
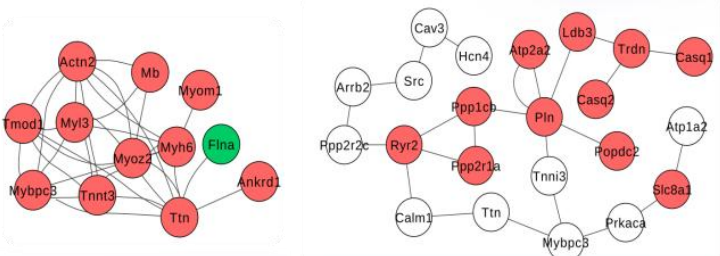

Electrophysiology

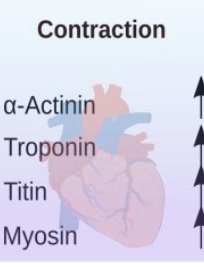

Funny Channel

SERCA

NCX

Ryanodin

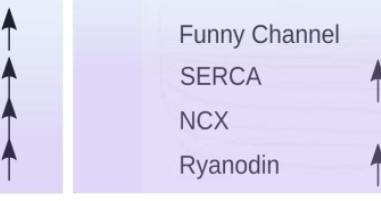

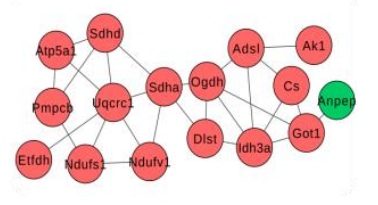

Metabolism

ATP-Synthase

Citrate Synthase

Dehydrogenases $\uparrow$

Peptidase beta

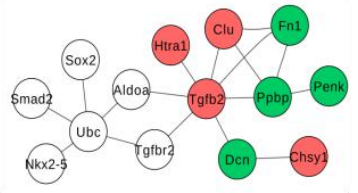

Differentiation-Factors

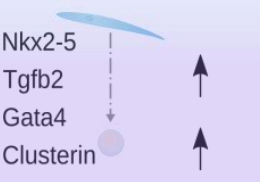

Figure 4: Systems-based data analysis procedure for the identification of molecular functionalities, interactions and phenotypic associations applied to stem cell-derived cardiac cell types by using RNA-Seq data. (A) Calculation of overrepresented GO terms using the Cytoscape applications BiNGO and ClueGo. (B) Identified subnetworks obtained after KeyPathwayMiner analysis of the former constructed interactome network. Red represents the upregulated transcripts within iSABs and green represents the downregulated transcripts. The edges (lines between encircled genes) are experimentally verified interactions obtained from String and BioGrid. (C) Summary of the upregulated factors identified in the data and the literature for processes within contraction, electrophysiology, metabolism and differentiation. 


\section{Acknowledgements}

This work was supported by the Federal Ministry of Education and Research Germany (FKZ 0312138A, FKZ 031L0106C, FKZ 02NUK043C and FKZ 316159), the State Mecklenburg-Western Pomerania with EU Structural Funds (ESF/IVWM-B34-0030/10 and ESF/IVBM-B35-0010/12), and the DFG (DA1296/2-1) and the German Heart Foundation (F/01/12). A.Y. is supported by the Wellcome Trust (204442/Z/16/Z); the Academy of Medical Sciences (Clinical Lecturer Starter Grant); and the National Institute of Health Research in the form of an Academic Clinical Lectureship. In addition, F.H. and R.D. are supported by the FORUN Program of Rostock University Medical Centre (889001) and the DAMP Foundation. R.D. is further funded by the BMBF (VIP+ 00240).

\section{References}

[1] A.P. Ambrosy, G.C. Fonarow, J. Butler, O. Chioncel, S.J. Greene, M. Vaduganathan, S. Nodari, C.S.P. Lam, N. Sato, A.N. Shah, M. Gheorghiade, The global health and economic burden of hospitalizations for heart failure: Lessons learned from hospitalized heart failure registries, Journal of the American College of Cardiology 63 (12) (2014) 1123-1133.

[2] A.L. Bui, T.B. Horwich, G.C. Fonarow, Epidemiology and risk profile of heart failure, Nature reviews. Cardiology 8 (1) (2011) 30-41.

[3] A. Seki, M.C. Fishbein, Predicting the development of cardiac allograft vasculopathy, Cardiovascular pathology the official journal of the Society for Cardiovascular Pathology 23 (5) (2014) 253-260.

[4] J.A. Kobashigawa, The Search for a Gold Standard to Detect Rejection in Heart Transplant Patients: Are We There Yet?, Circulation 135 (10) (2017) 936-938.

[5] Eurotransplant International Foundation, Annual Report 2015, Leiden, 2015.

[6] M. Tonsho, S. Michel, Z. Ahmed, A. Alessandrini, J.C. Madsen, Heart transplantation: Challenges facing the field, Cold Spring Harb Perspect Med 4 (5) (2014).

[7] A. Jain, R. Bansal, Applications of regenerative medicine in organ transplantation, Journal of pharmacy \& bioallied sciences 7 (3) (2015) 188-194.

[8] A. Heidary Rouchi, M. Mahdavi-Mazdeh, Regenerative Medicine in Organ and Tissue Transplantation: Shortly and Practically Achievable?, International journal of organ transplantation medicine 6 (3) (2015) 93-98.

[9] G. Orlando, S. Soker, R.J. Stratta, A. Atala, Will regenerative medicine replace transplantation?, Cold Spring Harbor perspectives in medicine 3 (8) (2013).

[10] N. Pavo, S. Charwat, N. Nyolczas, A. Jakab, Z. Murlasits, J. Bergler-Klein, M. Nikfardjam, I. Benedek, T. Benedek, I.J. Pavo, B.J. Gersh, K. Huber, G. Maurer, M. Gyöngyösi, Cell therapy for human ischemic heart diseases: critical review and summary of the clinical experiences, Journal of molecular and cellular cardiology 75 (2014) 12-24.

[11] S.A. Fisher, C. Doree, A. Mathur, D.P. Taggart, E. Martin-Rendon, Stem cell therapy for chronic ischaemic heart disease and congestive heart failure, The Cochrane database of systematic reviews 12 (2016) CD007888. 
[12] O. Bergmann, R.D. Bhardwaj, S. Bernard, S. Zdunek, F. Barnabe-Heider, S. Walsh, J. Zupicich, K. Alkass, B.A. Buchholz, H. Druid, S. Jovinge, J. Frisen, Evidence for Cardiomyocyte Renewal in Humans, Science 324 (5923) (2009) 98-102.

[13] M. Mollova, K. Bersell, S. Walsh, J. Savla, L.T. Das, S.-Y. Park, L.E. Silberstein, Dos Remedios, Cristobal G, D. Graham, S. Colan, B. Kühn, Cardiomyocyte proliferation contributes to heart growth in young humans, Proceedings of the National Academy of Sciences of the United States of America 110 (4) (2013) 14461451.

[14] A.N. Paradis, M.S. Gay, L. Zhang, Binucleation of cardiomyocytes: the transition from a proliferative to a terminally differentiated state, Drug discovery today 19 (5) (2014) 602-609.

[15] F. Li, X. Wang, J.M. Capasso, A.M. Gerdes, Rapid transition of cardiac myocytes from hyperplasia to hypertrophy during postnatal development, Journal of molecular and cellular cardiology 28 (8) (1996) 1737-1746.

[16] Z. Liu, S. Yue, X. Chen, T. Kubin, T. Braun, Regulation of cardiomyocyte polyploidy and multinucleation by CyclinG1, Circulation research 106 (9) (2010) 1498-1506.

[17] J.C. Garbern, R.T. Lee, Cardiac Stem Cell Therapy and the Promise of Heart Regeneration, Cell stem cell 12 (6) (2013) 689-698.

[18] S.E. Senyo, M.L. Steinhauser, C.L. Pizzimenti, V.K. Yang, L. Cai, M. Wang, T.-D. Wu, J.-L. Guerquin-Kern, C.P. Lechene, R.T. Lee, Mammalian heart renewal by pre-existing cardiomyocytes, Nature 493 (7432) (2013) 433-436.

[19] M. Sahara, F. Santoro, K.R. Chien, Programming and reprogramming a human heart cell, The EMBO journal 34 (6) (2015) 710-738.

[20] S.D. Vincent, M.E. Buckingham, How to make a heart: the origin and regulation of cardiac progenitor cells, in: Organogenesis in Development, Elsevier, 2010, pp. 1-41.

[21] M. Xin, E.N. Olson, R. Bassel-Duby, Mending broken hearts: cardiac development as a basis for adult heart regeneration and repair, Nature reviews. Molecular cell biology 14 (8) (2013) 529-541.

[22] S.L. Paige, K. Plonowska, A. Xu, S.M. Wu, Molecular regulation of cardiomyocyte differentiation, Circulation research 116 (2) (2015) 341-353.

[23] S.M. Meilhac, F. Lescroart, C. Blanpain, M.E. Buckingham, Cardiac cell lineages that form the heart, Cold Spring Harbor perspectives in medicine 4 (9) (2014) a013888.

[24] V. Garcia-Martinez, G.C. Schoenwolf, Primitive-streak origin of the cardiovascular system in avian embryos, Developmental biology 159 (2) (1993) 706-719.

[25] D.A. Turner, P. Rue, J.P. Mackenzie, E. Davies, A.A. Martinez, Brachyury cooperates with Wnt/beta-catenin signalling to elicit primitive-streak-like behaviour in differentiating mouse embryonic stem cells, BMC biology 12 (2014) 63.

[26] P.P. Tam, M. Parameswaran, S.J. Kinder, R.P. Weinberger, The allocation of epiblast cells to the embryonic heart and other mesodermal lineages: the role of ingression and tissue movement during gastrulation, Development (Cambridge, England) 124 (9) (1997) 1631-1642.

[27] G. Chiapparo, X. Lin, F. Lescroart, S. Chabab, C. Paulissen, L. Pitisci, A. Bondue, C. Blanpain, Mesp1 controls the speed, polarity, and directionality of cardiovascular progenitor migration, The Journal of cell biology 213 (4) (2016) 463-477.

[28] Y. Saga, Mesp1 Expression Is the Earliest Sign of Cardiovascular Development, Trends in Cardiovascular Medicine 10 (8) (2000) 345-352. 
[29] Y. Saga, S. Miyagawa-Tomita, A. Takagi, S. Kitajima, J.i. Miyazaki, T. Inoue, MesP1 is expressed in the heart precursor cells and required for the formation of a single heart tube, Development (Cambridge, England) 126 (15) (1999) 3437-3447.

[30] Q. Liang, C. Xu, X. Chen, X. Li, C. Lu, P. Zhou, L. Yin, R. Qian, S. Chen, Z. Ling, N. Sun, The roles of Mesp family proteins: functional diversity and redundancy in differentiation of pluripotent stem cells and mammalian mesodermal development, Protein \& cell 6 (8) (2015) 553-561.

[31] S.J. Kattman, T.L. Huber, G.M. Keller, Multipotent flk-1+ cardiovascular progenitor cells give rise to the cardiomyocyte, endothelial, and vascular smooth muscle lineages, Developmental cell 11 (5) (2006) 723732.

[32] Z. He, M. Grunewald, Y. Dor, E. Keshet, VEGF regulates relative allocation of IsI1+ cardiac progenitors to myocardial and endocardial lineages, Mechanisms of Development 142 (2016) 40-49.

[33] K. Musunuru, I.J. Domian, K.R. Chien, Stem cell models of cardiac development and disease, Annu. Rev. Cell Dev. Biol. 26 (2010) 667-687.

[34] X. Liang, G. Wang, L. Lin, J. Lowe, Q. Zhang, L. Bu, Y. Chen, J. Chen, Y. Sun, S.M. Evans, HCN4 dynamically marks the first heart field and conduction system precursors, Circulation research 113 (4) (2013) 399-407.

[35] S.M. Stevens, W.T. Pu, HCN4 charges up the first heart field, Circulation research 113 (4) (2013) 350-351.

[36] T. Brade, L.S. Pane, A. Moretti, K.R. Chien, K.-L. Laugwitz, Embryonic heart progenitors and cardiogenesis, Cold Spring Harbor perspectives in medicine 3 (10) (2013) a013847.

[37] D. Später, M.K. Abramczuk, K. Buac, L. Zangi, M.W. Stachel, J. Clarke, M. Sahara, A. Ludwig, K.R. Chien, A HCN4+ cardiomyogenic progenitor derived from the first heart field and human pluripotent stem cells, Nature cell biology 15 (9) (2013) 1098-1106.

[38] S.M. Wu, Y. Fujiwara, S.M. Cibulsky, D.E. Clapham, C.L. Lien, T.M. Schultheiss, S.H. Orkin, Developmental origin of a bipotential myocardial and smooth muscle cell precursor in the mammalian heart, Cell 127 (6) (2006) 1137-1150.

[39] A.F. Moorman, V.M. Christoffels, R.H. Anderson, M.J. van den Hoff, The heart-forming fields: one or multiple?, Philosophical transactions of the Royal Society of London. Series B, Biological sciences 362 (1484) (2007) 1257-1265.

[40] A. Sizarov, J. Ya, B.A. de Boer, W.H. Lamers, V.M. Christoffels, A.F. Moorman, Formation of the building plan of the human heart: morphogenesis, growth, and differentiation, Circulation 123 (10) (2011) 11251135.

[41] V. George, S. Colombo, K.L. Targoff, An early requirement for nkx2.5 ensures the first and second heart field ventricular identity and cardiac function into adulthood, Developmental biology 400 (1) (2015) 1022.

[42] M. Buckingham, S. Meilhac, S. Zaffran, Building the mammalian heart from two sources of myocardial cells, Nature reviews. Genetics 6 (11) (2005) 826-835.

[43] L.A. Dyer, M.L. Kirby, The role of secondary heart field in cardiac development, Dev. Biol. 336 (2) (2009) 137-144.

[44] F. Rochais, K. Mesbah, R.G. Kelly, Signaling pathways controlling second heart field development, Circulation research 104 (8) (2009) 933-942.

[45] P. Pandur, I.O. Sirbu, S.J. Kühl, M. Philipp, M. Kühl, Islet1-expressing cardiac progenitor cells: a comparison across species, Dev. Genes Evol. 223 (1-2) (2013) 117-129. 
[46] A. Moretti, L. Caron, A. Nakano, J.T. Lam, A. Bernshausen, Y. Chen, Y. Qyang, L. Bu, M. Sasaki, S. MartinPuig, Y. Sun, S.M. Evans, K.-L. Laugwitz, K.R. Chien, Multipotent embryonic isl1+ progenitor cells lead to cardiac, smooth muscle, and endothelial cell diversification, Cell 127 (6) (2006) 1151-1165.

[47] M. Bressan, G. Liu, T. Mikawa, Early mesodermal cues assign avian cardiac pacemaker fate potential in a tertiary heart field, Science (New York, N.Y.) 340 (6133) (2013) 744-748.

[48] M. Bressan, G. Liu, J.D. Louie, T. Mikawa, Cardiac Pacemaker Development from a Tertiary Heart Field 281-288.

[49] A.M. Misfeldt, S.C. Boyle, K.L. Tompkins, V.L. Bautch, P.A. Labosky, H.S. Baldwin, Endocardial cells are a distinct endothelial lineage derived from Flk1+ multipotent cardiovascular progenitors, Developmental biology 333 (1) (2009) 78-89.

[50] J. Schlueter, T. Brand, Epicardial progenitor cells in cardiac development and regeneration, Journal of cardiovascular translational research 5 (5) (2012) 641-653.

[51] T.C. Katz, M.K. Singh, K. Degenhardt, J. Rivera-Feliciano, R.L. Johnson, J.A. Epstein, C.J. Tabin, Distinct compartments of the proepicardial organ give rise to coronary vascular endothelial cells, Developmental cell 22 (3) (2012) 639-650.

[52] B. Zhou, Q. Ma, S. Rajagopal, S.M. Wu, I. Domian, J. Rivera-Feliciano, D. Jiang, A. von Gise, S. Ikeda, K.R. Chien, W.T. Pu, Epicardial progenitors contribute to the cardiomyocyte lineage in the developing heart, Nature 454 (7200) (2008) 109-113.

[53] J. Banach, W. Gilewski, A. Slomka, K. Buszko, J. Blazejewski, D. Karasek, D. Rogowicz, E. Zekanowska, W. Sinkiewicz, Bone morphogenetic protein 6-a possible new player in pathophysiology of heart failure, Clinical and experimental pharmacology \& physiology 43 (12) (2016) 1247-1250.

[54] F.-F. Li, X. Deng, J. Zhou, P. Yan, E.-Y. Zhao, S.-L. Liu, Characterization of human bone morphogenetic protein gene variants for possible roles in congenital heart disease, Molecular medicine reports 14 (2) (2016) 1459-1464.

[55] T.M. Schultheiss, J.B. Burch, A.B. Lassar, A role for bone morphogenetic proteins in the induction of cardiac myogenesis, Genes \& development 11 (4) (1997) 451-462.

[56] B. Andrée, D. Duprez, B. Vorbusch, H.-H. Arnold, T. Brand, BMP-2 induces ectopic expression of cardiac lineage markers and interferes with somite formation in chicken embryos, Mechanisms of Development 70 (1-2) (1998) 119-131.

[57] T. Schlange, B. Andrée, H.-H. Arnold, T. Brand, BMP2 is required for early heart development during a distinct time period, Mechanisms of Development 91 (1-2) (2000) 259-270.

[58] P. Han, J. Bloomekatz, J. Ren, R. Zhang, J.D. Grinstein, L. Zhao, C.G. Burns, C.E. Burns, R.M. Anderson, N.C. Chi, Coordinating cardiomyocyte interactions to direct ventricular chamber morphogenesis, Nature 534 (7609) (2016) 700-704.

[59] H.Y. Lin, D.C. Lee, H.D. Wang, Y.H. Chi, Im Chiu, Activation of FGF1B Promoter and FGF1 Are Involved in Cardiogenesis Through the Signaling of PKC, but Not MAPK, Stem cells and development 24 (24) (2015) 2853-2863.

[60] L.J. Samuel, B.V. Latinkic, Early activation of FGF and nodal pathways mediates cardiac specification independently of Wnt/beta-catenin signaling, PloS one 4 (10) (2009) e7650.

[61] Y. Watanabe, S. Zaffran, A. Kuroiwa, H. Higuchi, T. Ogura, R.P. Harvey, R.G. Kelly, M. Buckingham, Fibroblast growth factor 10 gene regulation in the second heart field by Tbx1, Nkx2-5, and Islet1 reveals a 
genetic switch for down-regulation in the myocardium, Proceedings of the National Academy of Sciences of the United States of America 109 (45) (2012) 18273-18280.

[62] P. Pandur, M. Lasche, L.M. Eisenberg, M. Kuhl, Wnt-11 activation of a non-canonical Wnt signalling pathway is required for cardiogenesis, Nature 418 (6898) (2002) 636-641.

[63] S.M. Ahmad, P. Bhattacharyya, N. Jeffries, S.S. Gisselbrecht, Am Michelson, Two Forkhead transcription factors regulate cardiac progenitor specification by controlling the expression of receptors of the fibroblast growth factor and Wnt signaling pathways, Development (Cambridge, England) 143 (2) (2016) 306-317.

[64] J. Martin, B.A. Afouda, S. Hoppler, Wnt/beta-catenin signalling regulates cardiomyogenesis via GATA transcription factors, Journal of anatomy 216 (1) (2010) 92-107.

[65] T. Nakamura, M. Sano, Z. Songyang, M.D. Schneider, A Wnt- and beta -catenin-dependent pathway for mammalian cardiac myogenesis, Proceedings of the National Academy of Sciences of the United States of America 100 (10) (2003) 5834-5839.

[66] C. Kwon, J. Arnold, E.C. Hsiao, M.M. Taketo, B.R. Conklin, D. Srivastava, Canonical Wnt signaling is a positive regulator of mammalian cardiac progenitors, Proceedings of the National Academy of Sciences of the United States of America 104 (26) (2007) 10894-10899.

[67] T. Nakanishi, R.R. Markwald, H.S. Baldwin, B.B. Keller, D. Srivastava, H. Yamagishi, Etiology and morphogenesis of congenital heart disease: From gene function and cellular interaction to morphology, Springer Open, Japan, 2016.

[68] A.J. Marelli, A.S. Mackie, R. Ionescu-Ittu, E. Rahme, L. Pilote, Congenital heart disease in the general population: changing prevalence and age distribution, Circulation 115 (2) (2007) 163-172.

[69] D. van der Linde, E.E. Konings, M.A. Slager, M. Witsenburg, W.A. Helbing, J.J. Takkenberg, J.W. RoosHesselink, Birth prevalence of congenital heart disease worldwide: a systematic review and meta-analysis, Journal of the American College of Cardiology 58 (21) (2011) 2241-2247.

[70] J.J. Schott, D.W. Benson, C.T. Basson, W. Pease, G.M. Silberbach, J.P. Moak, B.J. Maron, C.E. Seidman, J.G. Seidman, Congenital heart disease caused by mutations in the transcription factor NKX2-5, Science (New York, N.Y.) 281 (5373) (1998) 108-111.

[71] D.W. Benson, G.M. Silberbach, A. Kavanaugh-McHugh, C. Cottrill, Y. Zhang, S. Riggs, O. Smalls, M.C. Johnson, M.S. Watson, J.G. Seidman, C.E. Seidman, J. Plowden, J.D. Kugler, Mutations in the cardiac transcription factor NKX2.5 affect diverse cardiac developmental pathways, The Journal of clinical investigation 104 (11) (1999) 1567-1573.

[72] D.B. McElhinney, E. Geiger, J. Blinder, D. Woodrow Benson, E. Goldmuntz, NKX2.5 mutations in patients with congenital heart disease, Journal of the American College of Cardiology 42 (9) (2003) 1650-1655.

[73] H. Ashraf, L. Pradhan, E.I. Chang, R. Terada, N.J. Ryan, Le Briggs, R. Chowdhury, M.A. Zarate, Y. Sugi, H.J. Nam, D.W. Benson, R.H. Anderson, H. Kasahara, A mouse model of human congenital heart disease: high incidence of diverse cardiac anomalies and ventricular noncompaction produced by heterozygous Nkx2-5 homeodomain missense mutation, Circulation. Cardiovascular genetics 7 (4) (2014) 423-433.

[74] L. Gioli-Pereira, A.C. Pereira, S.M. Mesquita, J. Xavier-Neto, A.A. Lopes, J.E. Krieger, NKX2.5 mutations in patients with non-syndromic congenital heart disease, International journal of cardiology 138 (3) (2010) 261-265.

[75] M.M. Balci, R. Akdemir, NKX2.5 mutations and congenital heart disease: is it a marker of cardiac anomalies?, International journal of cardiology 147 (3) (2011) e44-5. 
[76] P. Ouyang, E. Saarel, Y. Bai, C. Luo, Q. Lv, Y. Xu, F. Wang, C. Fan, A. Younoszai, Q. Chen, X. Tu, Q.K. Wang, A de novo mutation in NKX2.5 associated with atrial septal defects, ventricular noncompaction, syncope and sudden death, Clinica chimica acta; international journal of clinical chemistry 412 (1-2) (2011) 170-175.

[77] M. Salazar, F. Consoli, V. Villegas, V. Caicedo, V. Maddaloni, P. Daniele, G. Caianiello, S. Pachon, F. Nunez, G. Limongelli, G. Pacileo, B. Marino, J.E. Bernal, A. de Luca, B. Dallapiccola, Search of somatic GATA4 and NKX2.5 gene mutations in sporadic septal heart defects, European journal of medical genetics 54 (3) (2011) 306-309.

[78] X. Xie, X. Shi, X. Xun, L. Rao, Associations of NKX2-5 Genetic Polymorphisms with the Risk of Congenital Heart Disease: A Meta-analysis, Pediatric cardiology (2016).

[79] V. Garg, I.S. Kathiriya, R. Barnes, M.K. Schluterman, I.N. King, C.A. Butler, C.R. Rothrock, R.S. Eapen, K. Hirayama-Yamada, K. Joo, R. Matsuoka, J.C. Cohen, D. Srivastava, GATA4 mutations cause human congenital heart defects and reveal an interaction with TBX5, Nature 424 (6947) (2003) 443-447.

[80] S.K. Rajagopal, Q. Ma, D. Obler, J. Shen, A. Manichaikul, A. Tomita-Mitchell, K. Boardman, C. Briggs, V. Garg, D. Srivastava, E. Goldmuntz, K.W. Broman, D.W. Benson, L.B. Smoot, W.T. Pu, Spectrum of heart disease associated with murine and human GATA4 mutation, Journal of molecular and cellular cardiology 43 (6) (2007) 677-685.

[81] W. Zhang, X. Li, A. Shen, W. Jiao, X. Guan, Z. Li, GATA4 mutations in 486 Chinese patients with congenital heart disease, European journal of medical genetics 51 (6) (2008) 527-535.

[82] Y. Chen, J. Mao, Y. Sun, Q. Zhang, H.B. Cheng, W.H. Yan, K.W. Choy, H. Li, A novel mutation of GATA4 in a familial atrial septal defect, Clinica chimica acta; international journal of clinical chemistry 411 (21-22) (2010) 1741-1745.

[83] H. Zhu, Forkhead box transcription factors in embryonic heart development and congenital heart disease, Life sciences 144 (2016) 194-201.

[84] M.A. Chaix, G. Andelfinger, P. Khairy, Genetic testing in congenital heart disease: A clinical approach, World journal of cardiology 8 (2) (2016) 180-191.

[85] M. Liu, L. Zhao, J. Yuan, Establishment of Relational Model of Congenital Heart Disease Markers and GO Functional Analysis of the Association between Its Serum Markers and Susceptibility Genes, Computational and mathematical methods in medicine 2016 (2016) 9506829.

[86] Cowan JR, S.M. Ware, Genetics and genetic testing in congenital heart disease, Clinics in perinatology 42 (2) (2015) 373-93, ix.

[87] X.-Y. Jiang, Y.-L. Feng, L.-T. Ye, X.-H. Li, J. Feng, M.-Z. Zhang, H.S. Shelat, M. Wassler, Y. Li, Y.-J. Geng, X.-Y. $\mathrm{Yu}$, Inhibition of Gata4 and Tbx 5 by Nicotine-Mediated DNA Methylation in Myocardial Differentiation, Stem cell reports (2017).

[88] D. Wei, L. Tao, M. Huang, Genetic variations involved in sudden cardiac death and their associations and interactions, Heart failure reviews 21 (4) (2016) 401-414.

[89] J.J. Jung, B. Husse, C. Rimmbach, S. Krebs, J. Stieber, G. Steinhoff, A. Dendorfer, W.-M. Franz, R. David, Programming and isolation of highly pure physiologically and pharmacologically functional sinus-nodal bodies from pluripotent stem cells, Stem cell reports 2 (5) (2014) 592-605.

[90] C. Rimmbach, J.J. Jung, R. David, Generation of murine cardiac pacemaker cell aggregates based on EScell-programming in combination with Myh6-promoter-selection, Journal of visualized experiments JoVE (96) (2015) e52465. 
[91] M. Wolfien, C. Rimmbach, U. Schmitz, J.J. Jung, S. Krebs, G. Steinhoff, R. David, O. Wolkenhauer, TRAPLINE: a standardized and automated pipeline for RNA sequencing data analysis, evaluation and annotation, BMC bioinformatics 17 (2016) 21.

[92] M.R. Rosen, R.J. Myerburg, D.P. Francis, G.D. Cole, E. Marbán, Translating stem cell research to cardiac disease therapies: pitfalls and prospects for improvement, Journal of the American College of Cardiology 64 (9) (2014) 922-937.

[93] A.A. Matar, J.J. Chong, Stem cell therapy for cardiac dysfunction, SpringerPlus 3 (2014) 440.

[94] K.E. Hatzistergos, J.M. Hare, Cell Therapy: Targeting Endogenous Repair Versus Remuscularization, Circulation research 117 (8) (2015) 659-661.

[95] C. Stamm, H.-D. Kleine, Y.-H. Choi, S. Dunkelmann, J.-A. Lauffs, B. Lorenzen, A. David, A. Liebold, C. Nienaber, D. Zurakowski, M. Freund, G. Steinhoff, Intramyocardial delivery of CD133+ bone marrow cells and coronary artery bypass grafting for chronic ischemic heart disease: safety and efficacy studies, The Journal of Thoracic and Cardiovascular Surgery 133 (3) (2007) 717-725.

[96] Z. Wang, L. Wang, X. Su, J. Pu, M. Jiang, B. He, Rational transplant timing and dose of mesenchymal stromal cells in patients with acute myocardial infarction: a meta-analysis of randomized controlled trials, Stem cell research \& therapy 8 (1) (2017) 21.

[97] W. Yang, H. Zheng, Y. Wang, F. Lian, Z. Hu, S. Xue, Nesprin-1 has key roles in the process of mesenchymal stem cell differentiation into cardiomyocyte-like cells in vivo and in vitro, Molecular medicine reports 11 (1) (2015) 133-142.

[98] P. Li, L. Zhang, Exogenous Nkx2.5- or GATA-4-transfected rabbit bone marrow mesenchymal stem cells and myocardial cell co-culture on the treatment of myocardial infarction in rabbits, Molecular medicine reports 12 (2) (2015) 2607-2621.

[99] J. Li, K. Zhu, Y. Wang, J. Zheng, C. Guo, H. Lai, C. Wang, Combination of IGF1 gene manipulation and 5AZA treatment promotes differentiation of mesenchymal stem cells into cardiomyocytelike cells, Molecular medicine reports 11 (2) (2015) 815-820.

[100] S. Mohanty, S. Bose, K.G. Jain, B. Bhargava, B. Airan, TGFß1 contributes to cardiomyogenic-like differentiation of human bone marrow mesenchymal stem cells, Int. J. Cardiol. 163 (1) (2013) 93-99.

[101] Y. Feng, P. Yang, S. Luo, Z. Zhang, H. Li, P. Zhu, Z. Song, Shox2 influences mesenchymal stem cell fate in a co-culture model in vitro, Molecular medicine reports 14 (1) (2016) 637-642.

[102] F. Huang, L. Tang, Z.-f. Fang, X.-q. Hu, J.-y. Pan, S.-h. Zhou, miR-1-mediated induction of cardiogenesis in mesenchymal stem cells via downregulation of Hes-1, BioMed research international 2013 (2013) 216286.

[103] Z. Yu, Y. Zou, J. Fan, C. Li, L. Ma, Notch1 is associated with the differentiation of human bone marrowderived mesenchymal stem cells to cardiomyocytes, Molecular medicine reports 14 (6) (2016) 5065-5071.

[104] J. Hou, H. Long, C. Zhou, S. Zheng, H. Wu, T. Guo, Q. Wu, T. Zhong, T. Wang, Long noncoding RNA Braveheart promotes cardiogenic differentiation of mesenchymal stem cells in vitro, Stem cell research \& therapy 8 (1) (2017) 4.

[105] P.H. Carvalho, A.P.F. Daibert, B.S. Monteiro, B.S. Okano, J.L. Carvalho, Cunha, Daise Nunes Queiroz da, L.S.C. Favarato, V.G. Pereira, L.E.F. Augusto, R.J.D. Carlo, Diferenciação de células-tronco mesenquimais derivadas do tecido adiposo em cardiomiócitos, Arq. Bras. Cardiol. 100 (1) (2013) 82-89. 
[106] W. Wystrychowski, B. Patlolla, Y. Zhuge, E. Neofytou, R.C. Robbins, R.E. Beygui, Multipotency and cardiomyogenic potential of human adipose-derived stem cells from epicardium, pericardium, and omentum, Stem cell research \& therapy 7 (1) (2016) 84.

[107] S.-J. Gwak, S.H. Bhang, H.S. Yang, S.-S. Kim, D.-H. Lee, S.-H. Lee, B.-S. Kim, In vitro cardiomyogenic differentiation of adipose-derived stromal cells using transforming growth factor-beta1, Cell biochemistry and function 27 (3) (2009) 148-154.

[108] H. Nagata, M. Ii, E. Kohbayashi, M. Hoshiga, T. Hanafusa, M. Asahi, Cardiac Adipose-Derived Stem Cells Exhibit High Differentiation Potential to Cardiovascular Cells in C57BL/6 Mice, Stem cells translational medicine 5 (2) (2016) 141-151.

[109] Y.S. Choi, G.J. Dusting, S. Stubbs, S. Arunothayaraj, X.L. Han, P. Collas, W.A. Morrison, R.J. Dilley, Differentiation of human adipose-derived stem cells into beating cardiomyocytes, Journal of cellular and molecular medicine 14 (4) (2010) 878-889.

[110] T. Takahashi, T. Nagai, M. Kanda, M.-L. Liu, N. Kondo, A.T. Naito, T. Ogura, H. Nakaya, J.-K. Lee, I. Komuro, Y. Kobayashi, Regeneration of the Cardiac Conduction System by Adipose Tissue-Derived Stem Cells, Circulation journal official journal of the Japanese Circulation Society 79 (12) (2015) 2703-2712.

[111] I.-Y. Sung, H.-N. Son, I. Ullah, D. Bharti, J.-M. Park, Y.-C. Cho, J.-H. Byun, Y.-H. Kang, S.-J. Sung, J.-W. Kim, G.-J. Rho, B.-W. Park, Cardiomyogenic Differentiation of Human Dental Follicle-derived Stem Cells by Suberoylanilide Hydroxamic Acid and Their In Vivo Homing Property, International journal of medical sciences 13 (11) (2016) 841-852.

[112] E. Lopez-Ruiz, M. Peran, M. Picon-Ruiz, M.A. Garcia, E. Carrillo, M. Jimenez-Navarro, M.C. Hernandez, I. Prat, E. de Teresa, J.A. Marchal, Cardiomyogenic differentiation potential of human endothelial progenitor cells isolated from patients with myocardial infarction, Cytotherapy 16 (9) (2014) 1229-1237.

[113] D. Avitabile, A. Crespi, C. Brioschi, V. Parente, G. Toietta, P. Devanna, M. Baruscotti, S. Truffa, A. Scavone, F. Rusconi, A. Biondi, Y. D'Alessandra, E. Vigna, D. Difrancesco, M. Pesce, M.C. Capogrossi, A. Barbuti, Human cord blood CD34+ progenitor cells acquire functional cardiac properties through a cell fusion process, American journal of physiology. Heart and circulatory physiology 300 (5) (2011) H1875-84.

[114] B.T. Freeman, N.A. Kouris, B.M. Ogle, Tracking fusion of human mesenchymal stem cells after transplantation to the heart, Stem cells translational medicine 4 (6) (2015) 685-694.

[115] A.A. Karpov, D.V. Udalova, M.G. Pliss, M.M. Galagudza, Can the outcomes of mesenchymal stem cellbased therapy for myocardial infarction be improved? Providing weapons and armour to cells, Cell proliferation (2016).

[116] T. Hosoda, H. Zheng, M. Cabral-da-Silva, F. Sanada, N. Ide-Iwata, B. Ogórek, J. Ferreira-Martins, C. Arranto, D. D'Amario, F. del Monte, K. Urbanek, D.A. D'Alessandro, R.E. Michler, P. Anversa, M. Rota, J. Kajstura, A. Leri, Human cardiac stem cell differentiation is regulated by a mircrine mechanism, Circulation 123 (12) (2011) 1287-1296.

[117] M.-J. Goumans, T.P. de Boer, A.M. Smits, L.W. van Laake, P. van Vliet, C.H.G. Metz, T.H. Korfage, K.P. Kats, R. Hochstenbach, G. Pasterkamp, M.C. Verhaar, M.A.G. van der Heyden, D. de Kleijn, C.L. Mummery, T.A.B. van Veen, J.P.G. Sluijter, P.A. Doevendans, TGF-beta1 induces efficient differentiation of human cardiomyocyte progenitor cells into functional cardiomyocytes in vitro, Stem cell research 1 (2) (2007) 138-149. 
[118] Sluijter, Joost P G, A. van Mil, P. van Vliet, Metz, Corina H G, J. Liu, P.A. Doevendans, M.-J. Goumans, MicroRNA-1 and -499 regulate differentiation and proliferation in human-derived cardiomyocyte progenitor cells, Arteriosclerosis, thrombosis, and vascular biology 30 (4) (2010) 859-868.

[119] B. Oberwallner, A. Brodarac, P. Anic, T. Saric, K. Wassilew, K. Neef, Y.-H. Choi, C. Stamm, Human cardiac extracellular matrix supports myocardial lineage commitment of pluripotent stem cells, European journal of cardio-thoracic surgery official journal of the European Association for Cardio-thoracic Surgery 47 (3) (2015) 416-25; discussion 425.

[120] A.M. Wobus, G. Wallukat, J. Hescheler, Pluripotent mouse embryonic stem cells are able to differentiate into cardiomyocytes expressing chronotropic responses to adrenergic and cholinergic agents and Ca2+ channel blockers, Differentiation 48 (3) (1991) 173-182.

[121] H. Skottman, M. Mikkola, K. Lundin, C. Olsson, A.-M. Stromberg, T. Tuuri, T. Otonkoski, O. Hovatta, R. Lahesmaa, Gene expression signatures of seven individual human embryonic stem cell lines, Stem cells (Dayton, Ohio) 23 (9) (2005) 1343-1356.

[122] M.J. Abeyta, A.T. Clark, R.T. Rodriguez, M.S. Bodnar, R.A.R. Pera, M.T. Firpo, Unique gene expression signatures of independently-derived human embryonic stem cell lines, Human molecular genetics 13 (6) (2004) 601-608.

[123] T. Tavakoli, X. Xu, E. Derby, Y. Serebryakova, Y. Reid, M.S. Rao, M.P. Mattson, W. Ma, Self-renewal and differentiation capabilities are variable between human embryonic stem cell lines 13,16 and BG01V, BMC cell biology 10 (2009) 44.

[124] L.C. Laurent, I. Ulitsky, I. Slavin, H. Tran, A. Schork, R. Morey, C. Lynch, J.V. Harness, S. Lee, M.J. Barrero, S. Ku, M. Martynova, R. Semechkin, V. Galat, J. Gottesfeld, Izpisua Belmonte, Juan Carlos, C. Murry, H.S. Keirstead, H.-S. Park, U. Schmidt, A.L. Laslett, F.-J. Muller, C.M. Nievergelt, R. Shamir, J.F. Loring, Dynamic changes in the copy number of pluripotency and cell proliferation genes in human ESCs and iPSCs during reprogramming and time in culture, Cell stem cell 8 (1) (2011) 106-118.

[125] A.M. Newman, J.B. Cooper, Lab-specific gene expression signatures in pluripotent stem cells, Cell stem cell 7 (2) (2010) 258-262.

[126] K. Takahashi, S. Yamanaka, Induction of pluripotent stem cells from mouse embryonic and adult fibroblast cultures by defined factors, Cell 126 (4) (2006) 663-676.

[127] K. Takahashi, K. Tanabe, M. Ohnuki, M. Narita, T. Ichisaka, K. Tomoda, S. Yamanaka, Induction of pluripotent stem cells from adult human fibroblasts by defined factors, Cell 131 (5) (2007) 861-872.

[128] R. Lister, M. Pelizzola, Y.S. Kida, R.D. Hawkins, J.R. Nery, G. Hon, J. Antosiewicz-Bourget, R. O'Malley, R. Castanon, S. Klugman, M. Downes, R. Yu, R. Stewart, B. Ren, J.A. Thomson, R.M. Evans, J.R. Ecker, Hotspots of aberrant epigenomic reprogramming in human induced pluripotent stem cells, Nature 471 (7336) (2011) 68-73.

[129] O. Bar-Nur, H.A. Russ, S. Efrat, N. Benvenisty, Epigenetic memory and preferential lineage-specific differentiation in induced pluripotent stem cells derived from human pancreatic islet beta cells, Cell stem cell 9 (1) (2011) 17-23.

[130] V. Sanchez-Freire, A.S. Lee, S. Hu, O.J. Abilez, P. Liang, F. Lan, B.C. Huber, S.-G. Ong, W.X. Hong, M. Huang, J.C. Wu, Effect of human donor cell source on differentiation and function of cardiac induced pluripotent stem cells, Journal of the American College of Cardiology 64 (5) (2014) 436-448.

[131] H. Xu, B.A. Yi, H. Wu, C. Bock, H. Gu, K.O. Lui, J.-H.C. Park, Y. Shao, A.K. Riley, I.J. Domian, E. Hu, R. Willette, J. Lepore, A. Meissner, Z. Wang, K.R. Chien, Highly efficient derivation of ventricular 
cardiomyocytes from induced pluripotent stem cells with a distinct epigenetic signature, Cell research 22 (1) (2012) 142-154.

[132] L. Warren, P.D. Manos, T. Ahfeldt, Y.-H. Loh, H. Li, F. Lau, W. Ebina, P.K. Mandal, Z.D. Smith, A. Meissner, G.Q. Daley, A.S. Brack, J.J. Collins, C. Cowan, T.M. Schlaeger, D.J. Rossi, Highly efficient reprogramming to pluripotency and directed differentiation of human cells with synthetic modified mRNA, Cell Stem Cell 7 (5) (2010) 618-630.

[133] A. Mehta, V. Verma, M. Nandihalli, C.J.A. Ramachandra, G.L. Sequiera, Y. Sudibyo, Y. Chung, W. Sun, W. Shim, A systemic evaluation of cardiac differentiation from mRNA reprogrammed human induced pluripotent stem cells, PloS one 9 (7) (2014) e103485.

[134] J. Zhang, G.F. Wilson, A.G. Soerens, C.H. Koonce, J. Yu, S.P. Palecek, J.A. Thomson, T.J. Kamp, Functional cardiomyocytes derived from human induced pluripotent stem cells, Circulation research 104 (4) (2009) e30-41.

[135] J.-H. Jung, X. Fu, P.C. Yang, Exosomes Generated From iPSC-Derivatives: New Direction for Stem Cell Therapy in Human Heart Diseases, Circulation research 120 (2) (2017) 407-417.

[136] V.F.M. Segers, R.T. Lee, Stem-cell therapy for cardiac disease, Nature 451 (7181) (2008) 937-942.

[137] H. Okano, M. Nakamura, K. Yoshida, Y. Okada, O. Tsuji, S. Nori, E. Ikeda, S. Yamanaka, K. Miura, Steps toward safe cell therapy using induced pluripotent stem cells, Circulation research 112 (3) (2013) 523533.

[138] C.C. Veerman, G. Kosmidis, C.L. Mummery, S. Casini, A.O. Verkerk, M. Bellin, Immaturity of human stem-cell-derived cardiomyocytes in culture: fatal flaw or soluble problem?, Stem cells and development 24 (9) (2015) 1035-1052.

[139] X. Yang, L. Pabon, C.E. Murry, Engineering adolescence: maturation of human pluripotent stem cellderived cardiomyocytes, Circulation research 114 (3) (2014) 511-523.

[140] R. David, C. Brenner, J. Stieber, F. Schwarz, S. Brunner, M. Vollmer, E. Mentele, J. Müller-Höcker, S. Kitajima, H. Lickert, R. Rupp, W.-M. Franz, MesP1 drives vertebrate cardiovascular differentiation through Dkk-1-mediated blockade of Wnt-signalling, Nat. Cell Biol. 10 (3) (2008) 338-345.

[141] R. David, V.B. Jarsch, F. Schwarz, P. Nathan, M. Gegg, H. Lickert, W.-M. Franz, Induction of MesP1 by Brachyury(T) generates the common multipotent cardiovascular stem cell, Cardiovasc. Res. 92 (1) (2011) 115-122.

[142] A. Bondue, G. Lapouge, C. Paulissen, C. Semeraro, M. lacovino, M. Kyba, C. Blanpain, Mesp1 acts as a master regulator of multipotent cardiovascular progenitor specification, Cell stem cell 3 (1) (2008) 69-84.

[143] A. Bondue, S. Tannler, G. Chiapparo, S. Chabab, M. Ramialison, C. Paulissen, B. Beck, R. Harvey, C. Blanpain, Defining the earliest step of cardiovascular progenitor specification during embryonic stem cell differentiation, The Journal of cell biology 192 (5) (2011) 751-765.

[144] Y. Liu, L. Chen, A.D. Diaz, A. Benham, X. Xu, C.S. Wijaya, F. Fa'ak, W. Luo, B. Soibam, A. Azares, W. Yu, Q. Lyu, M.D. Stewart, P. Gunaratne, A. Cooney, B.K. McConnell, R.J. Schwartz, Mesp1 Marked Cardiac Progenitor Cells Repair Infarcted Mouse Hearts, Scientific reports 6 (2016) 31457.

[145] X. Shen, B. Soibam, A. Benham, X. Xu, M. Chopra, X. Peng, W. Yu, W. Bao, R. Liang, A. Azares, P. Liu, P.H. Gunaratne, M. Mercola, A.J. Cooney, R.J. Schwartz, Y. Liu, miR-322/-503 cluster is expressed in the earliest cardiac progenitor cells and drives cardiomyocyte specification, Proceedings of the National Academy of Sciences of the United States of America 113 (34) (2016) 9551-9556. 
[146] S.C. den Hartogh, K. Wolstencroft, C.L. Mummery, R. Passier, A comprehensive gene expression analysis at sequential stages of in vitro cardiac differentiation from isolated MESP1-expressing-mesoderm progenitors, Scientific reports 6 (2016) 19386.

[147] S.S.-K. Chan, X. Shi, A. Toyama, R.W. Arpke, A. Dandapat, M. lacovino, J. Kang, G. Le, H.R. Hagen, D.J. Garry, M. Kyba, Mesp1 patterns mesoderm into cardiac, hematopoietic, or skeletal myogenic progenitors in a context-dependent manner, Cell Stem Cell 12 (5) (2013) 587-601.

[148] S.S.-K. Chan, H.H.W. Chan, M. Kyba, Heterogeneity of Mesp1+ mesoderm revealed by single-cell RNAseq, Biochemical and biophysical research communications 474 (3) (2016) 469-475.

[149] A. Okada, K. Tashiro, T. Yamaguchi, K. Kawabata, Selective Differentiation into Hematopoietic and Cardiac Cells from Pluripotent Stem Cells Based on the Expression of Cell Surface Markers, Methods in molecular biology (Clifton, N.J.) 1341 (2016) 181-195.

[150] I. Pacheco-Leyva, A.C. Matias, D.V. Oliveira, J.M.A. Santos, R. Nascimento, E. Guerreiro, A.C. Michell, A.M. van de Vrugt, G. Machado-Oliveira, G. Ferreira, I. Domian, J. Braganca, CITED2 Cooperates with ISL1 and Promotes Cardiac Differentiation of Mouse Embryonic Stem Cells, Stem cell reports 7 (6) (2016) 10371049.

[151] T. Kotoku, K. Kosaka, M. Nishio, Y. Ishida, M. Kawaichi, E. Matsuda, CIBZ Regulates Mesodermal and Cardiac Differentiation of by Suppressing T and Mesp1 Expression in Mouse Embryonic Stem Cells, Scientific reports 6 (2016) 34188.

[152] F. Rabiee, M. Forouzanfar, F. Ghazvini Zadegan, S. Tanhaei, K. Ghaedi, M. Motovali Bashi, H. Baharvand, M.H. Nasr-Esfahani, Induced expression of Fndc5 significantly increased cardiomyocyte differentiation rate of mouse embryonic stem cells, Gene 551 (2) (2014) 127-137.

[153] C.A. Klattenhoff, J.C. Scheuermann, L.E. Surface, R.K. Bradley, P.A. Fields, M.L. Steinhauser, H. Ding, V.L. Butty, L. Torrey, S. Haas, R. Abo, M. Tabebordbar, R.T. Lee, C.B. Burge, L.A. Boyer, Braveheart, a long noncoding RNA required for cardiovascular lineage commitment, Cell 152 (3) (2013) 570-583.

[154] V. Ionta, W. Liang, E.H. Kim, R. Rafie, A. Giacomello, E. Marban, H.C. Cho, SHOX2 overexpression favors differentiation of embryonic stem cells into cardiac pacemaker cells, improving biological pacing ability, Stem cell reports 4 (1) (2015) 129-142.

[155] T. Dorn, A. Goedel, J.T. Lam, J. Haas, Q. Tian, F. Herrmann, K. Bundschu, G. Dobreva, M. Schiemann, R. Dirschinger, Y. Guo, S.J. Kuhl, D. Sinnecker, P. Lipp, K.-L. Laugwitz, M. Kuhl, A. Moretti, Direct nkx2-5 transcriptional repression of isl1 controls cardiomyocyte subtype identity, Stem cells (Dayton, Ohio) 33 (4) (2015) 1113-1129.

[156] S. Bhattacharya, P.W. Burridge, E.M. Kropp, S.L. Chuppa, W.-M. Kwok, J.C. Wu, K.R. Boheler, R.L. Gundry, High efficiency differentiation of human pluripotent stem cells to cardiomyocytes and characterization by flow cytometry, Journal of visualized experiments JoVE (91) (2014) 52010.

[157] V.C. Chen, J. Ye, P. Shukla, G. Hua, D. Chen, Z. Lin, J.-c. Liu, J. Chai, J. Gold, J. Wu, D. Hsu, L.A. Couture, Development of a scalable suspension culture for cardiac differentiation from human pluripotent stem cells, Stem cell research 15 (2) (2015) 365-375.

[158] M. Fuerstenau-Sharp, M.E. Zimmermann, K. Stark, N. Jentsch, M. Klingenstein, M. Drzymalski, S. Wagner, L.S. Maier, U. Hehr, A. Baessler, M. Fischer, C. Hengstenberg, Generation of highly purified human cardiomyocytes from peripheral blood mononuclear cell-derived induced pluripotent stem cells, PloS one 10 (5) (2015) e0126596. 
[159] S.I. Protze, J. Liu, U. Nussinovitch, L. Ohana, P.H. Backx, L. Gepstein, G.M. Keller, Sinoatrial node cardiomyocytes derived from human pluripotent cells function as a biological pacemaker, Nature biotechnology 35 (1) (2017) 56-68.

[160] F. Pei, J. Jiang, S. Bai, H. Cao, L. Tian, Y. Zhao, C. Yang, H. Dong, Y. Ma, Chemical-defined and albuminfree generation of human atrial and ventricular myocytes from human pluripotent stem cells, Stem cell research 19 (2017) 94-103.

[161] S. Mazzotta, C. Neves, R.J. Bonner, A.S. Bernardo, K. Docherty, S. Hoppler, Distinctive Roles of Canonical and Noncanonical Wnt Signaling in Human Embryonic Cardiomyocyte Development, Stem cell reports 7 (4) (2016) 764-776.

[162] M.C. Engels, K. Rajarajan, R. Feistritzer, A. Sharma, U.B. Nielsen, M.J. Schalij, A.A.F. de Vries, D.A. Pijnappels, S.M. Wu, Insulin-like growth factor promotes cardiac lineage induction in vitro by selective expansion of early mesoderm, Stem cells (Dayton, Ohio) 32 (6) (2014) 1493-1502.

[163] V.C. Chen, S.M. Couture, J. Ye, Z. Lin, G. Hua, H.-I.P. Huang, J. Wu, D. Hsu, M.K. Carpenter, L.A. Couture, Scalable GMP compliant suspension culture system for human ES cells, Stem cell research 8 (3) (2012) 388-402.

[164] N.J. Palpant, L. Pabon, C.E. Friedman, M. Roberts, B. Hadland, R.J. Zaunbrecher, I. Bernstein, Y. Zheng, C.E. Murry, Generating high-purity cardiac and endothelial derivatives from patterned mesoderm using human pluripotent stem cells, Nature protocols 12 (1) (2017) 15-31.

[165] I. Kokkinopoulos, H. Ishida, R. Saba, S. Coppen, K. Suzuki, K. Yashiro, Cardiomyocyte differentiation from mouse embryonic stem cells using a simple and defined protocol, Developmental dynamics an official publication of the American Association of Anatomists 245 (2) (2016) 157-165.

[166] S.J. Kattman, A.D. Witty, M. Gagliardi, N.C. Dubois, M. Niapour, A. Hotta, J. Ellis, G. Keller, Stage-specific optimization of activin/nodal and BMP signaling promotes cardiac differentiation of mouse and human pluripotent stem cell lines, Cell stem cell 8 (2) (2011) 228-240.

[167] X.-L. Li, Di Zeng, Y. Chen, L. Ding, W.-J. Li, T. Wei, D.-B. Ou, S. Yan, B. Wang, Q.-S. Zheng, Role of alphaand beta-adrenergic receptors in cardiomyocyte differentiation from murine-induced pluripotent stem cells, Cell proliferation 50 (1) (2017).

[168] H. Uosaki, A. Magadum, K. Seo, H. Fukushima, A. Takeuchi, Y. Nakagawa, K.W. Moyes, G. Narazaki, K. Kuwahara, M. Laflamme, S. Matsuoka, N. Nakatsuji, K. Nakao, C. Kwon, D.A. Kass, F.B. Engel, J.K. Yamashita, Identification of chemicals inducing cardiomyocyte proliferation in developmental stagespecific manner with pluripotent stem cells, Circulation. Cardiovascular genetics 6 (6) (2013) 624-633.

[169] D. Ivanyuk, G. Budash, Y. Zheng, J.A. Gaspar, U. Chaudhari, A. Fatima, S. Bahmanpour, V.K. Grin, A.G. Popandopulo, A. Sachinidis, J. Hescheler, T. Saric, Ascorbic Acid-Induced Cardiac Differentiation of Murine Pluripotent Stem Cells: Transcriptional Profiling and Effect of a Small Molecule Synergist of Wnt/betaCatenin Signaling Pathway, Cellular physiology and biochemistry international journal of experimental cellular physiology, biochemistry, and pharmacology 36 (2) (2015) 810-830.

[170] T. Aguado, F.J. Gutierrez, E. Aix, R.P. Schneider, G. Giovinnazo, M.A. Blasco, I. Flores, Telomere Length Defines the Cardiomyocyte Differentiation Potency of Mouse Induced Pluripotent Stem Cells, Stem cells (Dayton, Ohio) (2016).

[171] G. Kensah, A. Roa Lara, J. Dahlmann, R. Zweigerdt, K. Schwanke, J. Hegermann, D. Skvorc, A. Gawol, A. Azizian, S. Wagner, L.S. Maier, A. Krause, G. Drager, M. Ochs, A. Haverich, I. Gruh, U. Martin, Murine and 
human pluripotent stem cell-derived cardiac bodies form contractile myocardial tissue in vitro, European heart journal 34 (15) (2013) 1134-1146.

[172] M.G. Klug, M.H. Soonpaa, G.Y. Koh, L.J. Field, Genetically selected cardiomyocytes from differentiating embronic stem cells form stable intracardiac grafts, The Journal of clinical investigation 98 (1) (1996) 216224.

[173] V.A. Maltabe, E. Barka, M. Kontonika, D. Florou, M. Kouvara-Pritsouli, M. Roumpi, S. Agathopoulos, T.M. Kolettis, P. Kouklis, Isolation of an ES-Derived Cardiovascular Multipotent Cell Population Based on VE-Cadherin Promoter Activity, Stem cells international 2016 (2016) 8305624.

[174] K. Ban, B. Wile, S. Kim, H.-J. Park, J. Byun, K.-W. Cho, T. Saafir, M.-K. Song, S.P. Yu, M. Wagner, G. Bao, Y.-S. Yoon, Purification of cardiomyocytes from differentiating pluripotent stem cells using molecular beacons that target cardiomyocyte-specific mRNA, Circulation 128 (17) (2013) 1897-1909.

[175] R. Jha, B. Wile, Q. Wu, A.H. Morris, K.O. Maher, M.B. Wagner, G. Bao, C. Xu, Molecular beacon-based detection and isolation of working-type cardiomyocytes derived from human pluripotent stem cells, Biomaterials 50 (2015) 176-185.

[176] F. Hattori, H. Chen, H. Yamashita, S. Tohyama, Y.-S. Satoh, S. Yuasa, W. Li, H. Yamakawa, T. Tanaka, T. Onitsuka, K. Shimoji, Y. Ohno, T. Egashira, R. Kaneda, M. Murata, K. Hidaka, T. Morisaki, E. Sasaki, T. Suzuki, M. Sano, S. Makino, S. Oikawa, K. Fukuda, Nongenetic method for purifying stem cell-derived cardiomyocytes, Nature methods 7 (1) (2010) 61-66.

[177] N.C. Dubois, A.M. Craft, P. Sharma, D.A. Elliott, E.G. Stanley, A.G. Elefanty, A. Gramolini, G. Keller, SIRPA is a specific cell-surface marker for isolating cardiomyocytes derived from human pluripotent stem cells, Nature biotechnology 29 (11) (2011) 1011-1018.

[178] D. van Hoof, W. Dormeyer, S.R. Braam, R. Passier, J. Monshouwer-Kloots, D. Ward-van Oostwaard, Heck, Albert J R, J. Krijgsveld, C.L. Mummery, Identification of cell surface proteins for antibody-based selection of human embryonic stem cell-derived cardiomyocytes, Journal of proteome research 9 (3) (2010) 1610-1618.

[179] H. Uosaki, H. Fukushima, A. Takeuchi, S. Matsuoka, N. Nakatsuji, S. Yamanaka, J.K. Yamashita, Efficient and scalable purification of cardiomyocytes from human embryonic and induced pluripotent stem cells by VCAM1 surface expression, PloS one 6 (8) (2011) e23657.

[180] G.D. Lopaschuk, J.S. Jaswal, Energy metabolic phenotype of the cardiomyocyte during development, differentiation, and postnatal maturation, Journal of cardiovascular pharmacology 56 (2) (2010) 130-140.

[181] S. Tohyama, F. Hattori, M. Sano, T. Hishiki, Y. Nagahata, T. Matsuura, H. Hashimoto, T. Suzuki, H. Yamashita, Y. Satoh, T. Egashira, T. Seki, N. Muraoka, H. Yamakawa, Y. Ohgino, T. Tanaka, M. Yoichi, S. Yuasa, M. Murata, M. Suematsu, K. Fukuda, Distinct metabolic flow enables large-scale purification of mouse and human pluripotent stem cell-derived cardiomyocytes, Cell stem cell 12 (1) (2013) 127-137.

[182] N. Hemmi, S. Tohyama, K. Nakajima, H. Kanazawa, T. Suzuki, F. Hattori, T. Seki, Y. Kishino, A. Hirano, M. Okada, R. Tabei, R. Ohno, C. Fujita, T. Haruna, S. Yuasa, M. Sano, J. Fujita, K. Fukuda, A massive suspension culture system with metabolic purification for human pluripotent stem cell-derived cardiomyocytes, Stem cells translational medicine 3 (12) (2014) 1473-1483.

[183] K.T. Kuppusamy, D.C. Jones, H. Sperber, A. Madan, K.A. Fischer, M.L. Rodriguez, L. Pabon, W.-Z. Zhu, N.L. Tulloch, X. Yang, N.J. Sniadecki, M.A. Laflamme, W.L. Ruzzo, C.E. Murry, H. Ruohola-Baker, Let-7 family of microRNA is required for maturation and adult-like metabolism in stem cell-derived 
cardiomyocytes, Proceedings of the National Academy of Sciences of the United States of America 112 (21) (2015) E2785-94.

[184] Chong, James J H, X. Yang, C.W. Don, E. Minami, Y.-W. Liu, J.J. Weyers, W.M. Mahoney, B. van Biber, S.M. Cook, N.J. Palpant, J.A. Gantz, J.A. Fugate, V. Muskheli, G.M. Gough, K.W. Vogel, C.A. Astley, C.E. Hotchkiss, A. Baldessari, L. Pabon, H. Reinecke, E.A. Gill, V. Nelson, H.-P. Kiem, M.A. Laflamme, C.E. Murry, Human embryonic-stem-cell-derived cardiomyocytes regenerate non-human primate hearts, Nature 510 (7504) (2014) 273-277.

[185] K. Fynes, R. Tostoes, L. Ruban, B. Weil, C. Mason, F.S. Veraitch, The differential effects of $2 \%$ oxygen preconditioning on the subsequent differentiation of mouse and human pluripotent stem cells, Stem cells and development 23 (16) (2014) 1910-1922.

[186] C. Rao, T. Prodromakis, L. Kolker, U.A.R. Chaudhry, T. Trantidou, A. Sridhar, C. Weekes, P. Camelliti, S.E. Harding, A. Darzi, M.H. Yacoub, T. Athanasiou, C.M. Terracciano, The effect of microgrooved culture substrates on calcium cycling of cardiac myocytes derived from human induced pluripotent stem cells, Biomaterials 34 (10) (2013) 2399-2411.

[187] M. Khan, Y. Xu, S. Hua, J. Johnson, A. Belevych, P.M.L. Janssen, S. Gyorke, J. Guan, M.G. Angelos, Evaluation of Changes in Morphology and Function of Human Induced Pluripotent Stem Cell Derived Cardiomyocytes (HiPSC-CMs) Cultured on an Aligned-Nanofiber Cardiac Patch, PloS one 10 (5) (2015) e0126338.

[188] L.B. Hazeltine, M.G. Badur, X. Lian, A. Das, W. Han, S.P. Palecek, Temporal impact of substrate mechanics on differentiation of human embryonic stem cells to cardiomyocytes, Acta biomaterialia 10 (2) (2014) 604-612.

[189] J. Pasquier, R. Gupta, D. Rioult, J. Hoarau-Vechot, R. Courjaret, K. Machaca, J. Al Suwaidi, E.G. Stanley, S. Rafii, D.A. Elliott, C. Abi Khalil, A. Rafii, Coculturing with endothelial cells promotes in vitro maturation and electrical coupling of human embryonic stem cell-derived cardiomyocytes, The Journal of heart and lung transplantation the official publication of the International Society for Heart Transplantation (2017).

[190] M. Ojala, K. Rajala, M. Pekkanen-Mattila, M. Miettinen, H. Huhtala, K. Aalto-Setala, Culture conditions affect cardiac differentiation potential of human pluripotent stem cells, PloS one 7 (10) (2012) e48659.

[191] Y. Amano, A. Nishiguchi, M. Matsusaki, H. Iseoka, S. Miyagawa, Y. Sawa, M. Seo, T. Yamaguchi, M. Akashi, Development of vascularized iPSC derived 3D-cardiomyocyte tissues by filtration Layer-by-Layer technique and their application for pharmaceutical assays, Acta biomaterialia 33 (2016) 110-121.

[192] M.T. Valarmathi, J.W. Fuseler, J.M. Davis, R.L. Price, A Novel Human Tissue-Engineered 3-D Functional Vascularized Cardiac Muscle Construct, Frontiers in cell and developmental biology 5 (2017) 2.

[193] A. Eder, I. Vollert, A. Hansen, T. Eschenhagen, Human engineered heart tissue as a model system for drug testing, Advanced drug delivery reviews 96 (2016) 214-224.

[194] C.Y. Ivashchenko, G.C. Pipes, I.M. Lozinskaya, Z. Lin, X. Xiaoping, S. Needle, E.T. Grygielko, E. Hu, J.R. Toomey, J.J. Lepore, R.N. Willette, Human-induced pluripotent stem cell-derived cardiomyocytes exhibit temporal changes in phenotype, American journal of physiology. Heart and circulatory physiology 305 (6) (2013) H913-22.

[195] C.E. Rupert, H.H. Chang, K.L.K. Coulombe, Hypertrophy changes 3D shape of hiPSC-cardiomyocytes: Implications for cellular maturation in regenerative medicine, Cellular and molecular bioengineering 10 (1) (2017) 54-62. 
[196] S. Funakoshi, K. Miki, T. Takaki, C. Okubo, T. Hatani, K. Chonabayashi, M. Nishikawa, I. Takei, A. Oishi, M. Narita, M. Hoshijima, T. Kimura, S. Yamanaka, Y. Yoshida, Enhanced engraftment, proliferation, and therapeutic potential in heart using optimized human iPSC-derived cardiomyocytes, Scientific reports 6 (2016) 19111.

[197] T. Kitaguchi, Y. Moriyama, T. Taniguchi, A. Ojima, H. Ando, T. Uda, K. Otabe, M. Oguchi, S. Shimizu, H. Saito, M. Morita, A. Toratani, M. Asayama, W. Yamamoto, E. Matsumoto, D. Saji, H. Ohnaka, K. Tanaka, I. Washio, N. Miyamoto, CSAHi study: Evaluation of multi-electrode array in combination with human iPS cell-derived cardiomyocytes to predict drug-induced QT prolongation and arrhythmia--effects of 7 reference compounds at 10 facilities, Journal of pharmacological and toxicological methods 78 (2016) 93102.

[198] T. Kitaguchi, Y. Moriyama, T. Taniguchi, S. Maeda, H. Ando, T. Uda, K. Otabe, M. Oguchi, S. Shimizu, H. Saito, A. Toratani, M. Asayama, W. Yamamoto, E. Matsumoto, D. Saji, H. Ohnaka, N. Miyamoto, CSAHi study: Detection of drug-induced ion channel/receptor responses, QT prolongation, and arrhythmia using multi-electrode arrays in combination with human induced pluripotent stem cell-derived cardiomyocytes, Journal of pharmacological and toxicological methods (2017).

[199] L.G.J. Tertoolen, S.R. Braam, B.J. van Meer, R. Passier, C.L. Mummery, Interpretation of field potentials measured on a multi electrode array in pharmacological toxicity screening on primary and human pluripotent stem cell-derived cardiomyocytes, Biochemical and biophysical research communications (2017).

[200] M.P. Hortigon-Vinagre, V. Zamora, F.L. Burton, J. Green, G.A. Gintant, G.L. Smith, The Use of Ratiometric Fluorescence Measurements of the Voltage Sensitive Dye Di-4-ANEPPS to Examine Action Potential Characteristics and Drug Effects on Human Induced Pluripotent Stem Cell-Derived Cardiomyocytes, Toxicological sciences an official journal of the Society of Toxicology 154 (2) (2016) 320331.

[201] A. Brodarac, T. Saric, B. Oberwallner, S. Mahmoodzadeh, K. Neef, J. Albrecht, K. Burkert, M. Oliverio, F. Nguemo, Y.-H. Choi, W.F. Neiss, I. Morano, J. Hescheler, C. Stamm, Susceptibility of murine induced pluripotent stem cell-derived cardiomyocytes to hypoxia and nutrient deprivation, Stem cell research \& therapy 6 (2015) 83.

[202] H. Ding, X. Xu, X. Qin, C. Yang, Q. Feng, Resveratrol promotes differentiation of mouse embryonic stem cells to cardiomyocytes, Cardiovascular therapeutics (2016).

[203] N. Cao, Z. Liu, Z. Chen, J. Wang, T. Chen, X. Zhao, Y. Ma, L. Qin, J. Kang, B. Wei, L. Wang, Y. Jin, H.-T. Yang, Ascorbic acid enhances the cardiac differentiation of induced pluripotent stem cells through promoting the proliferation of cardiac progenitor cells, Cell research 22 (1) (2012) 219-236.

[204] T. Kamakura, T. Makiyama, K. Sasaki, Y. Yoshida, Y. Wuriyanghai, J. Chen, T. Hattori, S. Ohno, T. Kita, M. Horie, S. Yamanaka, T. Kimura, Ultrastructural maturation of human-induced pluripotent stem cell-derived cardiomyocytes in a long-term culture, Circulation journal official journal of the Japanese Circulation Society 77 (5) (2013) 1307-1314.

[205] T.L. Medley, M. Furtado, N.T. Lam, R. Idrizi, D. Williams, P.J. Verma, M. Costa, D.M. Kaye, Effect of oxygen on cardiac differentiation in mouse iPS cells: role of hypoxia inducible factor-1 and Wnt/betacatenin signaling, PloS one 8 (11) (2013) e80280. 
[206] X. Yang, M. Rodriguez, L. Pabon, K.A. Fischer, H. Reinecke, M. Regnier, N.J. Sniadecki, H. Ruohola-Baker, C.E. Murry, Tri-iodo-I-thyronine promotes the maturation of human cardiomyocytes-derived from induced pluripotent stem cells, Journal of molecular and cellular cardiology 72 (2014) 296-304.

[207] O. Iglesias-Garcia, S. Baumgartner, L. Macri-Pellizzeri, J.R. Rodriguez-Madoz, G. Abizanda, E. Guruceaga, E. Albiasu, D. Corbacho, C. Benavides-Vallve, M. Soriano-Navarro, S. Gonzalez-Granero, J.J. Gavira, B. Krausgrill, M. Rodriguez-Manero, J.M. Garcia-Verdugo, C. Ortiz-de-Solorzano, M. Halbach, J. Hescheler, B. Pelacho, F. Prosper, Neuregulin-1beta induces mature ventricular cardiac differentiation from induced pluripotent stem cells contributing to cardiac tissue repair, Stem cells and development 24 (4) (2015) 484496.

[208] A. Kochegarov, A. Moses-Arms, L.F. Lemanski, A fetal human heart cardiac-inducing RNA (CIR) promotes the differentiation of stem cells into cardiomyocytes, In vitro cellular \& developmental biology. Animal 51 (7) (2015) 739-748.

[209] H. Wang, Y. Xi, Y. Zheng, X. Wang, A.J. Cooney, Generation of electrophysiologically functional cardiomyocytes from mouse induced pluripotent stem cells, Stem cell research 16 (2) (2016) 522-530.

[210] R.L. Davis, H. Weintraub, A.B. Lassar, Expression of a Single Transfected cDNA Converts Fibroblasts to Myoblasts, Cell Press 51 (51 // 6) (1987) 987-1000.

[211] F. Hausburg, R. David, Cell Programming for Future Regenerative Medicine, in: G. Steinhoff (Ed.), Regenerative Medicine - from Protocol to Patient: 2. Stem Cell Science and Technology, 3rd ed., Springer International Publishing, Cham, s.I., 2016, pp. 389-424.

[212] R.S. Nagalingam, H.A. Safi, M.P. Czubryt, Gaining myocytes or losing fibroblasts: Challenges in cardiac fibroblast reprogramming for infarct repair, Journal of molecular and cellular cardiology 93 (2016) 108114.

[213] J.K. Lighthouse, E.M. Small, Transcriptional control of cardiac fibroblast plasticity, Journal of molecular and cellular cardiology 91 (2016) 52-60.

[214] Y. Gao, M. Chu, J. Hong, J. Shang, Di Xu, Hypoxia induces cardiac fibroblast proliferation and phenotypic switch: a role for caveolae and caveolin-1/PTEN mediated pathway, Journal of thoracic disease 6 (10) (2014) 1458-1468.

[215] T. Moore-Morris, P. Cattaneo, M. Puceat, S.M. Evans, Origins of cardiac fibroblasts, Journal of molecular and cellular cardiology 91 (2016) 1-5.

[216] H. Zhou, M.E. Dickson, M.S. Kim, R. Bassel-Duby, E.N. Olson, Akt1/protein kinase B enhances transcriptional reprogramming of fibroblasts to functional cardiomyocytes, Proceedings of the National Academy of Sciences of the United States of America 112 (38) (2015) 11864-11869.

[217] Y. Zhao, P. Londono, Y. Cao, E.J. Sharpe, C. Proenza, R. O'Rourke, K.L. Jones, M.Y. Jeong, L.A. Walker, P.M. Buttrick, T.A. McKinsey, K. Song, High-efficiency reprogramming of fibroblasts into cardiomyocytes requires suppression of pro-fibrotic signalling, Nature communications 6 (2015) 8243.

[218] Y. Fu, C. Huang, X. Xu, H. Gu, Y. Ye, C. Jiang, Z. Qiu, X. Xie, Direct reprogramming of mouse fibroblasts into cardiomyocytes with chemical cocktails, Cell research 25 (9) (2015) 1013-1024.

[219] H. Hirai, N. Katoku-Kikyo, S.A. Keirstead, N. Kikyo, Accelerated direct reprogramming of fibroblasts into cardiomyocyte-like cells with the MyoD transactivation domain, Cardiovasc. Res. 100 (1) (2013) 105-113.

[220] H. Hirai, N. Kikyo, Inhibitors of suppressive histone modification promote direct reprogramming of fibroblasts to cardiomyocyte-like cells, Cardiovasc. Res. 102 (1) (2014) 188-190. 
[221] J.-D. Fu, N.R. Stone, L. Liu, C.I. Spencer, L. Qian, Y. Hayashi, P. Delgado-Olguin, S. Ding, B.G. Bruneau, D. Srivastava, Direct Reprogramming of Human Fibroblasts toward a Cardiomyocyte-like State, Stem Cell Reports 1 (3) (2013) 235-247.

[222] Y.-J. Nam, K. Song, X. Luo, E. Daniel, K. Lambeth, K. West, J.A. Hill, J.M. DiMaio, L.A. Baker, R. BasselDuby, E.N. Olson, Reprogramming of human fibroblasts toward a cardiac fate, Proc. Natl. Acad. Sci. U.S.A. 110 (14) (2013) 5588-5593.

[223] J.X. Chen, M. Krane, M.-A. Deutsch, L. Wang, M. Rav-Acha, S. Gregoire, M.C. Engels, K. Rajarajan, R. Karra, E.D. Abel, J.C. Wu, D. Milan, S.M. Wu, Inefficient reprogramming of fibroblasts into cardiomyocytes using Gata4, Mef2c, and Tbx5, Circ. Res. 111 (1) (2012) 50-55.

[224] L. Qian, Y. Huang, C.I. Spencer, A. Foley, V. Vedantham, L. Liu, S.J. Conway, J.-D. Fu, D. Srivastava, In vivo reprogramming of murine cardiac fibroblasts into induced cardiomyocytes, Nature 485 (7400) (2012) 593-598.

[225] K. Inagawa, K. Miyamoto, H. Yamakawa, N. Muraoka, T. Sadahiro, T. Umei, R. Wada, Y. Katsumata, R. Kaneda, K. Nakade, C. Kurihara, Y. Obata, K. Miyake, K. Fukuda, M. leda, Induction of cardiomyocyte-like cells in infarct hearts by gene transfer of Gata4, Mef2c, and Tbx5, Circ. Res. 111 (9) (2012) 1147-1156.

[226] D. Srivastava, Making or breaking the heart: from lineage determination to morphogenesis, Cell 126 (6) (2006) 1037-1048.

[227] M. leda, J.-D. Fu, P. Delgado-Olguin, V. Vedantham, Y. Hayashi, B.G. Bruneau, D. Srivastava, Direct reprogramming of fibroblasts into functional cardiomyocytes by defined factors, Cell 142 (3) (2010) 375386.

[228] L. Wang, Z. Liu, C. Yin, H. Asfour, O. Chen, Y. Li, N. Bursac, J. Liu, L. Qian, Stoichiometry of Gata4, Mef2c, and Tbx5 influences the efficiency and quality of induced cardiac myocyte reprogramming, Circulation research 116 (2) (2015) 237-244.

[229] L. Qian, E.C. Berry, J.-D. Fu, M. leda, D. Srivastava, Reprogramming of mouse fibroblasts into cardiomyocyte-like cells in vitro, Nature protocols 8 (6) (2013) 1204-1215.

[230] T.M.A. Mohamed, N.R. Stone, E.C. Berry, E. Radzinsky, Y. Huang, K. Pratt, Y.-S. Ang, P. Yu, H. Wang, S. Tang, S. Magnitsky, S. Ding, K.N. Ivey, D. Srivastava, Chemical Enhancement of In Vitro and In Vivo Direct Cardiac Reprogramming, Circulation 135 (10) (2017) 978-995.

[231] Y. Zhou, L. Wang, H.R. Vaseghi, Z. Liu, R. Lu, S. Alimohamadi, C. Yin, J.-D. Fu, G.G. Wang, J. Liu, L. Qian, Bmi1 Is a Key Epigenetic Barrier to Direct Cardiac Reprogramming, Cell stem cell 18 (3) (2016) 382-395.

[232] J.A. Kamps, G. Krenning, Micromanaging cardiac regeneration: Targeted delivery of microRNAs for cardiac repair and regeneration, World journal of cardiology 8 (2) (2016) 163-179.

[233] J.-D. Fu, S.N. Rushing, D.K. Lieu, C.W. Chan, C.-W. Kong, L. Geng, K.D. Wilson, N. Chiamvimonvat, K.R. Boheler, J.C. Wu, G. Keller, R.J. Hajjar, R.A. Li, Distinct roles of microRNA-1 and -499 in ventricular specification and functional maturation of human embryonic stem cell-derived cardiomyocytes, PloS one 6 (11) (2011) e27417.

[234] K.D. Wilson, S. Hu, S. Venkatasubrahmanyam, J.-D. Fu, N. Sun, O.J. Abilez, Baugh, Joshua J A, F. Jia, Z. Ghosh, R.A. Li, A.J. Butte, J.C. Wu, Dynamic microRNA expression programs during cardiac differentiation of human embryonic stem cells: role for miR-499, Circulation. Cardiovascular genetics 3 (5) (2010) 426435. 
[235] T.M. Jayawardena, B. Egemnazarov, E.A. Finch, L. Zhang, J.A. Payne, K. Pandya, Z. Zhang, P. Rosenberg, M. Mirotsou, V.J. Dzau, MicroRNA-mediated in vitro and in vivo direct reprogramming of cardiac fibroblasts to cardiomyocytes, Circ. Res. 110 (11) (2012) 1465-1473.

[236] T. Jayawardena, M. Mirotsou, V.J. Dzau, Direct reprogramming of cardiac fibroblasts to cardiomyocytes using microRNAs, Methods Mol. Biol. 1150 (2014) 263-272.

[237] T.M. Jayawardena, E.A. Finch, L. Zhang, H. Zhang, C.P. Hodgkinson, R.E. Pratt, P.B. Rosenberg, M. Mirotsou, V.J. Dzau, MicroRNA induced cardiac reprogramming in vivo: evidence for mature cardiac myocytes and improved cardiac function, Circulation research 116 (3) (2015) 418-424.

[238] Y. Zhao, E. Samal, D. Srivastava, Serum response factor regulates a muscle-specific microRNA that targets Hand2 during cardiogenesis, Nature 436 (7048) (2005) 214-220.

[239] N. Liu, A.H. Williams, Y. Kim, J. McAnally, S. Bezprozvannaya, L.B. Sutherland, J.A. Richardson, R. BasselDuby, E.N. Olson, An intragenic MEF2-dependent enhancer directs muscle-specific expression of microRNAs 1 and 133, Proceedings of the National Academy of Sciences of the United States of America 104 (52) (2007) 20844-20849.

[240] L. Qian, J.D. Wythe, J. Liu, J. Cartry, G. Vogler, B. Mohapatra, R.T. Otway, Y. Huang, I.N. King, M. Maillet, Y. Zheng, T. Crawley, O. Taghli-Lamallem, C. Semsarian, S. Dunwoodie, D. Winlaw, R.P. Harvey, D. Fatkin, J.A. Towbin, J.D. Molkentin, D. Srivastava, K. Ocorr, B.G. Bruneau, R. Bodmer, Tinman/Nkx2-5 acts via miR1 and upstream of Cdc42 to regulate heart function across species, The Journal of cell biology 193 (7) (2011) 1181-1196.

[241] K.N. Ivey, A. Muth, J. Arnold, F.W. King, R.-F. Yeh, J.E. Fish, E.C. Hsiao, R.J. Schwartz, B.R. Conklin, H.S. Bernstein, D. Srivastava, MicroRNA regulation of cell lineages in mouse and human embryonic stem cells, Cell stem cell 2 (3) (2008) 219-229.

[242] N. Kapoor, W. Liang, E. Marban, H.C. Cho, Direct conversion of quiescent cardiomyocytes to pacemaker cells by expression of Tbx18, Nature biotechnology 31 (1) (2013) 54-62.

[243] Y.-F. Hu, J.F. Dawkins, H.C. Cho, E. Marban, E. Cingolani, Biological pacemaker created by minimally invasive somatic reprogramming in pigs with complete heart block, Science translational medicine 6 (245) (2014) 245 ra94.

[244] E. Bardot, D. Calderon, F. Santoriello, S. Han, K. Cheung, B. Jadhav, I. Burtscher, S. Artap, R. Jain, J. Epstein, H. Lickert, V. Gouon-Evans, A.J. Sharp, N.C. Dubois, Foxa2 identifies a cardiac progenitor population with ventricular differentiation potential, Nature communications 8 (2017) 14428.

[245] R. David, J. Stieber, E. Fischer, S. Brunner, C. Brenner, S. Pfeiler, F. Schwarz, W.-M. Franz, Forward programming of pluripotent stem cells towards distinct cardiovascular cell types, Cardiovasc. Res. 84 (2) (2009) 263-272.

[246] K. Maass, A. Shekhar, J. Lu, G. Kang, F. See, E.E. Kim, C. Delgado, S. Shen, L. Cohen, G.I. Fishman, Isolation and characterization of embryonic stem cell-derived cardiac Purkinje cells, Stem cells (Dayton, Ohio) 33 (4) (2015) 1102-1112.

[247] Q. Zhang, J. Jiang, P. Han, Q. Yuan, J. Zhang, X. Zhang, Y. Xu, H. Cao, Q. Meng, L. Chen, T. Tian, X. Wang, P. Li, J. Hescheler, G. Ji, Y. Ma, Direct differentiation of atrial and ventricular myocytes from human embryonic stem cells by alternating retinoid signals, Cell research 21 (4) (2011) 579-587.

[248] I. Kehat, L. Khimovich, O. Caspi, A. Gepstein, R. Shofti, G. Arbel, I. Huber, J. Satin, J. Itskovitz-Eldor, L. Gepstein, Electromechanical integration of cardiomyocytes derived from human embryonic stem cells, Nature biotechnology 22 (10) (2004) 1282-1289. 
[249] J.H. van Weerd, V.M. Christoffels, The formation and function of the cardiac conduction system, Development (Cambridge, England) 143 (2) (2016) 197-210.

[250] A. Kennedy, D.D. Finlay, D. Guldenring, R. Bond, K. Moran, J. McLaughlin, The Cardiac Conduction System: Generation and Conduction of the Cardiac Impulse, Critical care nursing clinics of North America 28 (3) (2016) 269-279.

[251] B. Joung, M. Ogawa, S.-F. Lin, P.-S. Chen, The calcium and voltage clocks in sinoatrial node automaticity, Korean circulation journal 39 (6) (2009) 217-222.

[252] I.P. Temple, S. Inada, H. Dobrzynski, M.R. Boyett, Connexins and the atrioventricular node, Heart rhythm 10 (2) (2013) 297-304.

[253] D.C. Bartos, E. Grandi, C.M. Ripplinger, lon Channels in the Heart, Comprehensive Physiology 5 (3) (2015) 1423-1464.

[254] J.P. Moore, J.A. Aboulhosn, Introduction to the Congenital Heart Defects: Anatomy of the Conduction System, Cardiac electrophysiology clinics 9 (2) (2017) 167-175.

[255] C. Walsh-Irwin, G.B. Hannibal, Sick Sinus Syndrome, AACN advanced critical care 26 (4) (2015) 376-380.

[256] R.M. John, S. Kumar, Sinus Node and Atrial Arrhythmias, Circulation 133 (19) (2016) 1892-1900.

[257] H. Dobrzynski, M.R. Boyett, R.H. Anderson, New insights into pacemaker activity: promoting understanding of sick sinus syndrome, Circulation 115 (14) (2007) 1921-1932.

[258] G.A. Ewy, Sick sinus syndrome: synopsis, Journal of the American College of Cardiology 64 (6) (2014) 539-540.

[259] M. Semelka, J. Gera, S. Usman, Sick sinus syndrome: a review, American family physician 87 (10) (2013) 691-696.

[260] G. Tse, T. Liu, K.H. Li, V. Laxton, A.O. Wong, Y.W. Chan, W. Keung, C.W. Chan, R.A. Li, Tachycardiabradycardia syndrome: Electrophysiological mechanisms and future therapeutic approaches (Review), International journal of molecular medicine 39 (3) (2017) 519-526.

[261] Indications and recommendations for pacemaker therapy, American family physician 71 (8) (2005) 1563-1570.

[262] M.R. Rosen, R.B. Robinson, P.R. Brink, I.S. Cohen, The road to biological pacing, Nature reviews. Cardiology 8 (11) (2011) 656-666.

[263] M.L. Bakker, G.J. Boink, B.J. Boukens, A.O. Verkerk, M. van den Boogaard, A.D. den Haan, W.M. Hoogaars, H.P. Buermans, J.M. de Bakker, J. Seppen, H.L. Tan, A.F. Moorman, P.A. t Hoen, V.M.

Christoffels, T-box transcription factor TBX3 reprogrammes mature cardiac myocytes into pacemaker-like cells, Cardiovascular research 94 (3) (2012) 439-449.

[264] V. Ionta, W. Liang, E.H. Kim, R. Rafie, A. Giacomello, E. Marban, H.C. Cho, SHOX2 overexpression favors differentiation of embryonic stem cells into cardiac pacemaker cells, improving biological pacing ability, Stem Cell Reports 4 (1) (2015) 129-142.

[265] B. Lown, Electrical reversion of cardiac arrhythmias, British heart journal 29 (4) (1967) 469-489.

[266] D.U. Frank, K.L. Carter, K.R. Thomas, R.M. Burr, M.L. Bakker, W.A. Coetzee, M. Tristani-Firouzi, M.J. Bamshad, V.M. Christoffels, A.M. Moon, Lethal arrhythmias in Tbx3-deficient mice reveal extreme dosage sensitivity of cardiac conduction system function and homeostasis, Proceedings of the National Academy of Sciences of the United States of America 109 (3) (2012) E154-63.

[267] W.M.H. Hoogaars, A. Engel, J.F. Brons, A.O. Verkerk, F.J. de Lange, L.Y.E. Wong, M.L. Bakker, D.E. Clout, V. Wakker, P. Barnett, J.H. Ravesloot, A.F.M. Moorman, E.E. Verheijck, V.M. Christoffels, Tbx3 controls the 
sinoatrial node gene program and imposes pacemaker function on the atria, Genes \& development 21 (9) (2007) 1098-1112.

[268] V. Vedantham, G. Galang, M. Evangelista, R.C. Deo, D. Srivastava, RNA sequencing of mouse sinoatrial node reveals an upstream regulatory role for Islet-1 in cardiac pacemaker cells, Circulation research 116 (5) (2015) 797-803.

[269] C. Wiese, T. Grieskamp, R. Airik, M.T.M. Mommersteeg, A. Gardiwal, C. de Gier-de Vries, K. SchusterGossler, A.F.M. Moorman, A. Kispert, V.M. Christoffels, Formation of the sinus node head and differentiation of sinus node myocardium are independently regulated by Tbx18 and Tbx3, Circulation research 104 (3) (2009) 388-397.

[270] M.R. Boyett, S. Inada, S. Yoo, J. Li, J. Liu, J. Tellez, I.D. Greener, H. Honjo, R. Billeter, M. Lei, H. Zhang, I.R. Efimov, H. Dobrzynski, Connexins in the sinoatrial and atrioventricular nodes, Advances in cardiology 42 (2006) 175-197.

[271] D. Eckardt, M. Theis, J. Degen, T. Ott, H.V.M. van Rijen, S. Kirchhoff, J.-S. Kim, J.M.T. de Bakker, K. Willecke, Functional role of connexin43 gap junction channels in adult mouse heart assessed by inducible gene deletion, Journal of molecular and cellular cardiology 36 (1) (2004) 101-110.

[272] M.M. Kreuzberg, J.W. Schrickel, A. Ghanem, J.-S. Kim, J. Degen, U. Janssen-Bienhold, T. Lewalter, K. Tiemann, K. Willecke, Connexin30.2 containing gap junction channels decelerate impulse propagation through the atrioventricular node, Proceedings of the National Academy of Sciences of the United States of America 103 (15) (2006) 5959-5964.

[273] M.M. Kreuzberg, G. Sohl, J.-S. Kim, V.K. Verselis, K. Willecke, F.F. Bukauskas, Functional properties of mouse connexin30.2 expressed in the conduction system of the heart, Circulation research 96 (11) (2005) 1169-1177.

[274] L. Marger, P. Mesirca, J. Alig, A. Torrente, S. Dubel, B. Engeland, S. Kanani, P. Fontanaud, J. Striessnig, H.-S. Shin, D. Isbrandt, H. Ehmke, J. Nargeot, M.E. Mangoni, Functional roles of Ca(v)1.3, Ca(v)3.1 and HCN channels in automaticity of mouse atrioventricular cells: insights into the atrioventricular pacemaker mechanism, Channels (Austin, Tex.) 5 (3) (2011) 251-261.

[275] J. Stieber, S. Herrmann, S. Feil, J. Loster, R. Feil, M. Biel, F. Hofmann, A. Ludwig, The hyperpolarizationactivated channel HCN4 is required for the generation of pacemaker action potentials in the embryonic heart, Proceedings of the National Academy of Sciences of the United States of America 100 (25) (2003) 15235-15240.

[276] A.G. Torrente, P. Mesirca, P. Neco, R. Rizzetto, S. Dubel, C. Barrere, M. Sinegger-Brauns, J. Striessnig, S. Richard, J. Nargeot, A.M. Gomez, M.E. Mangoni, L-type Cav1.3 channels regulate ryanodine receptordependent Ca2+ release during sino-atrial node pacemaker activity, Cardiovascular Research 109 (3) (2016) 451-461.

[277] M. Yamamoto, H. Dobrzynski, J. Tellez, R. Niwa, R. Billeter, H. Honjo, I. Kodama, M.R. Boyett, Extended atrial conduction system characterised by the expression of the HCN4 channel and connexin45, Cardiovascular Research 72 (2) (2006) 271-281.

[278] F. Greulich, M.-O. Trowe, A. Leffler, C. Stoetzer, H.F. Farin, A. Kispert, Misexpression of Tbx18 in cardiac chambers of fetal mice interferes with chamber-specific developmental programs but does not induce a pacemaker-like gene signature, Journal of molecular and cellular cardiology 97 (2016) 140-149. 
[279] Y.-J. Nam, C. Lubczyk, M. Bhakta, T. Zang, A. Fernandez-Perez, J. McAnally, R. Bassel-Duby, E.N. Olson, N.V. Munshi, Induction of diverse cardiac cell types by reprogramming fibroblasts with cardiac transcription factors, Development (Cambridge, England) 141 (22) (2014) 4267-4278.

[280] I. Bruzauskaite, D. Bironaite, E. Bagdonas, V.A. Skeberdis, J. Denkovskij, T. Tamulevicius, V. Uvarovas, E. Bernotiene, Relevance of HCN2-expressing human mesenchymal stem cells for the generation of biological pacemakers, Stem cell research \& therapy 7 (1) (2016) 67.

[281] Y. Feng, S. Luo, S. Tong, L. Zhong, C. Zhang, P. Yang, Z. Song, Electric-Pulse Current Stimulation Increases If Current in mShox 2 Genetically Modified Canine Mesenchymal Stem Cells, Cardiology 132 (1) (2015) 49-57.

[282] Y. Feng, S. Luo, P. Yang, Z. Song, Electric pulse current stimulation increases electrophysiological properties of If current reconstructed in mHCN4-transfected canine mesenchymal stem cells, Experimental and therapeutic medicine 11 (4) (2016) 1323-1329.

[283] C. Jun, Z. Zhihui, W. Lu, N. Yaoming, W. Lei, Q. Yao, S. Zhiyuan, Canine bone marrow mesenchymal stromal cells with lentiviral mHCN4 gene transfer create cardiac pacemakers, Cytotherapy 14 (5) (2012) 529-539.

[284] W. Lu, N. Yaoming, R. Boli, C. Jun, Z. Changhai, Z. Yang, S. Zhiyuan, mHCN4 genetically modified canine mesenchymal stem cells provide biological pacemaking function in complete dogs with atrioventricular block, Pacing and clinical electrophysiology PACE 36 (9) (2013) 1138-1149.

[285] J. Ma, C. Zhang, S. Huang, G. Wang, X. Quan, Use of rats mesenchymal stem cells modified with mHCN2 gene to create biologic pacemakers, Journal of Huazhong University of Science and Technology. Medical sciences $=$ Hua zhong ke ji da xue xue bao. Yi xue Ying De wen ban = Huazhong keji daxue xuebao. Yixue Yingdewen ban 30 (4) (2010) 447-452.

[286] A.N. Plotnikov, I. Shlapakova, M.J. Szabolcs, P. Danilo, B.H. Lorell, I.A. Potapova, Z. Lu, A.B. Rosen, R.T. Mathias, P.R. Brink, R.B. Robinson, I.S. Cohen, M.R. Rosen, Xenografted adult human mesenchymal stem cells provide a platform for sustained biological pacemaker function in canine heart, Circulation 116 (7) (2007) 706-713.

[287] I. Potapova, A. Plotnikov, Z. Lu, P. Danilo, V. Valiunas, J. Qu, S. Doronin, J. Zuckerman, I.N. Shlapakova, J. Gao, Z. Pan, A.J. Herron, R.B. Robinson, P.R. Brink, M.R. Rosen, I.S. Cohen, Human mesenchymal stem cells as a gene delivery system to create cardiac pacemakers, Circulation research 94 (7) (2004) 952-959.

[288] J. Yang, T. Song, P. Wu, Y. Chen, X. Fan, H. Chen, J. Zhang, C. Huang, Differentiation potential of human mesenchymal stem cells derived from adipose tissue and bone marrow to sinus node-like cells, Molecular medicine reports 5 (1) (2012) 108-113.

[289] X.-J. Yang, Y.-F. Zhou, H.-X. Li, L.-H. Han, W.-P. Jiang, Mesenchymal stem cells as a gene delivery system to create biological pacemaker cells in vitro, The Journal of international medical research 36 (5) (2008) 1049-1055.

[290] Y.-F. Zhou, X.-J. Yang, H.-X. Li, L.-H. Han, W.-P. Jiang, Genetically-engineered mesenchymal stem cells transfected with human HCN1 gene to create cardiac pacemaker cells, The Journal of international medical research 41 (5) (2013) 1570-1576.

[291] Y.-F. Zhou, X.-J. Yang, H.-X. Li, L.-H. Han, W.-P. Jiang, Mesenchymal stem cells transfected with HCN2 genes by LentiV can be modified to be cardiac pacemaker cells, Medical hypotheses 69 (5) (2007) 10931097. 
[292] M. Tong, X.-J. Yang, B.-y. Geng, L.-H. Han, Y.-F. Zhou, X. Zhao, H.-X. Li, Overexpression of connexin 45 in rat mesenchymal stem cells improves the function as cardiac biological pacemakers, Chinese medical journal 123 (12) (2010) 1571-1576.

[293] L. Chen, Z.-J. Deng, J.-S. Zhou, R.-J. Ji, X. Zhang, C.-S. Zhang, Y.-Q. Li, X.-Q. Yang, Tbx18-dependent differentiation of brown adipose tissue-derived stem cells toward cardiac pacemaker cells, Molecular and cellular biochemistry (2017).

[294] P.W. Burridge, E. Matsa, P. Shukla, Z.C. Lin, J.M. Churko, A.D. Ebert, F. Lan, S. Diecke, B. Huber, N.M. Mordwinkin, J.R. Plews, O.J. Abilez, B. Cui, J.D. Gold, J.C. Wu, Chemically defined generation of human cardiomyocytes, Nature methods 11 (8) (2014) 855-860.

[295] X. Lian, C. Hsiao, G. Wilson, K. Zhu, L.B. Hazeltine, S.M. Azarin, K.K. Raval, J. Zhang, T.J. Kamp, S.P. Palecek, Robust cardiomyocyte differentiation from human pluripotent stem cells via temporal modulation of canonical Wnt signaling, Proceedings of the National Academy of Sciences of the United States of America 109 (27) (2012) E1848-57.

[296] A. Kleger, T. Seufferlein, D. Malan, M. Tischendorf, A. Storch, A. Wolheim, S. Latz, S. Protze, M. Porzner, C. Proepper, C. Brunner, S.-F. Katz, G. Varma Pusapati, L. Bullinger, W.-M. Franz, R. Koehntop, K. Giehl, A. Spyrantis, O. Wittekindt, Q. Lin, M. Zenke, B.K. Fleischmann, M. Wartenberg, A.M. Wobus, T.M. Boeckers, S. Liebau, Modulation of calcium-activated potassium channels induces cardiogenesis of pluripotent stem cells and enrichment of pacemaker-like cells, Circulation 122 (18) (2010) 1823-1836.

[297] M. Jara-Avaca, H. Kempf, M. Ruckert, D. Robles-Diaz, A. Franke, J. de La Roche, M. Fischer, D. Malan, P. Sasse, W. Solodenko, G. Drager, A. Kirschning, U. Martin, R. Zweigerdt, EBIO Does Not Induce Cardiomyogenesis in Human Pluripotent Stem Cells but Modulates Cardiac Subtype Enrichment by Lineage-Selective Survival, Stem cell reports 8 (2) (2017) 305-317.

[298] A. Scavone, D. Capilupo, N. Mazzocchi, A. Crespi, S. Zoia, G. Campostrini, A. Bucchi, R. Milanesi, M. Baruscotti, S. Benedetti, S. Antonini, G. Messina, D. DiFrancesco, A. Barbuti, Embryonic stem cell-derived CD166+ precursors develop into fully functional sinoatrial-like cells, Circulation research 113 (4) (2013) 389-398.

[299] W. Rust, T. Balakrishnan, R. Zweigerdt, Cardiomyocyte enrichment from human embryonic stem cell cultures by selection of ALCAM surface expression, Regenerative medicine 4 (2) (2009) 225-237.

[300] S.I. Hashem, W.C. Claycomb, Genetic isolation of stem cell-derived pacemaker-nodal cardiac myocytes, Molecular and cellular biochemistry 383 (1-2) (2013) 161-171.

[301] Arash Yavari, Mohamed Bellahcene, Annalisa Bucchi, Syevda Sirenko, Katalin Pinter, Neil Herring, Julia J. Jung, Kirill Tarasov, Gabor Czibik, Violetta Steeples, Sahar Ghaffari, Chinh Nguyen, Alexander Stockenhuber, Emily J. Sharpe, Joshua R. St. Clair, Christian Rimmbach, Markus Wolfien, Yosuke Okamoto, Mingyi Wang, Bruce D. Ziman, Jack M. Moen, Dongmei Yang, Daniel Riordon, Christopher Ramirez, Manuel Paina, Joonho Lee, Jing Zhang, Ismayil Ahmet, Michael G. Matt, Yelena S. Tarasova, Dilair Baban, Natasha Sahgal, Helen Lockstone, Rathi Puliyadi, Joseph de Bono, John Gomes, Hannah Muskett, Mahon L. Maguire, Matthew Kelly, Pedro P.N. dos Santos, Nicola J. Bright, Angela Woods, Katja Gehmlich, Henrik Isackson, Gillian Douglas, David J.P. Ferguson, Jürgen E. Schneider, Andrew Tinker, Olaf Wolkenhauer, Keith M. Channon, Eduardo B. Sternick, David J. Paterson, Charles S. Redwood, David Carling, Catherine Proenza, Robert David, Mirko Baruscotti, Dario DiFrancesco, Edward G. Lakatta, Hugh Watkins \& Houman Ashrafian, The $\gamma 2$ subunit of AMP-activated protein kinase regulates mammalian heart rate, Nature communications accepted for publication. 
[302] R.-S. Wang, B.A. Maron, J. Loscalzo, Systems medicine: evolution of systems biology from bench to bedside, Wiley interdisciplinary reviews. Systems biology and medicine 7 (4) (2015) 141-161.

[303] W.R. MacLellan, Y. Wang, A.J. Lusis, Systems-based approaches to cardiovascular disease, Nature reviews. Cardiology 9 (3) (2012) 172-184.

[304] S.C. Lott, M. Wolfien, K. Riege, A. Bagnacani, O. Wolkenhauer, S. Hoffmann, W.R. Hess, Customized workflow development and data modularization concepts for RNA-Sequencing and metatranscriptome experiments, Journal of biotechnology (2017).

[305] B.A. Grüning, J. Fallmann, D. Yusuf, S. Will, A. Erxleben, F. Eggenhofer, T. Houwaart, B. Batut, P. Videm, A. Bagnacani, M. Wolfien, S.C. Lott, Y. Hoogstrate, W.R. Hess, O. Wolkenhauer, S. Hoffmann, A. Akalin, U. Ohler, P.F. Stadler, R. Backofen, The RNA workbench: best practices for RNA and high-throughput sequencing bioinformatics in Galaxy, Nucleic acids research (2017).

[306] P. Shannon, A. Markiel, O. Ozier, N.S. Baliga, J.T. Wang, D. Ramage, N. Amin, B. Schwikowski, T. Ideker, Cytoscape: a software environment for integrated models of biomolecular interaction networks, Genome research 13 (11) (2003) 2498-2504.

[307] S. Maere, K. Heymans, M. Kuiper, BiNGO: a Cytoscape plugin to assess overrepresentation of gene ontology categories in biological networks, Bioinformatics (Oxford, England) 21 (16) (2005) 3448-3449.

[308] G. Bindea, B. Mlecnik, H. Hackl, P. Charoentong, M. Tosolini, A. Kirilovsky, W.-H. Fridman, F. Pages, Z. Trajanoski, J. Galon, ClueGO: a Cytoscape plug-in to decipher functionally grouped gene ontology and pathway annotation networks, Bioinformatics (Oxford, England) 25 (8) (2009) 1091-1093.

[309] A.R. Paschoal, V. Maracaja-Coutinho, J.C. Setubal, Z.L.P. Simões, S. Verjovski-Almeida, A.M. Durham, Non-coding transcription characterization and annotation: a guide and web resource for non-coding RNA databases, RNA biology 9 (3) (2012) 274-282.

[310] L. Wang, X. Ma, X. Xu, Y. Zhang, Systematic identification and characterization of cardiac long intergenic noncoding RNAs in zebrafish, Scientific reports 7 (1) (2017) 1250.

[311] P. Langfelder, S. Horvath, WGCNA: an R package for weighted correlation network analysis, BMC bioinformatics 9 (2008) 559.

[312] M. Shouman, T. Turner, R. Stocker, Using data mining techniques in heart disease diagnosis and treatment 173-177.

[313] N. Alcaraz, J. Pauling, R. Batra, E. Barbosa, A. Junge, A.G.L. Christensen, V. Azevedo, H.J. Ditzel, J. Baumbach, KeyPathwayMiner 4.0: condition-specific pathway analysis by combining multiple omics studies and networks with Cytoscape, BMC systems biology 8 (2014) 99.

[314] F.M. Khan, U. Schmitz, S. Nikolov, D. Engelmann, B.M. Pützer, O. Wolkenhauer, J. Vera, Hybrid modeling of the crosstalk between signaling and transcriptional networks using ordinary differential equations and multi-valued logic, Biochimica et biophysica acta 1844 (1 Pt B) (2014) 289-298.

[315] F.M. Khan, S. Marquardt, S.K. Gupta, S. Knoll, U. Schmitz, A. Spitschak, D. Engelmann, J. Vera, O. Wolkenhauer, B.M. Pützer, Unraveling a tumor type-specific regulatory core underlying E2F1-mediated epithelial-mesenchymal transition to predict receptor protein signatures, Nature communications 8 (1) (2017) 198. 


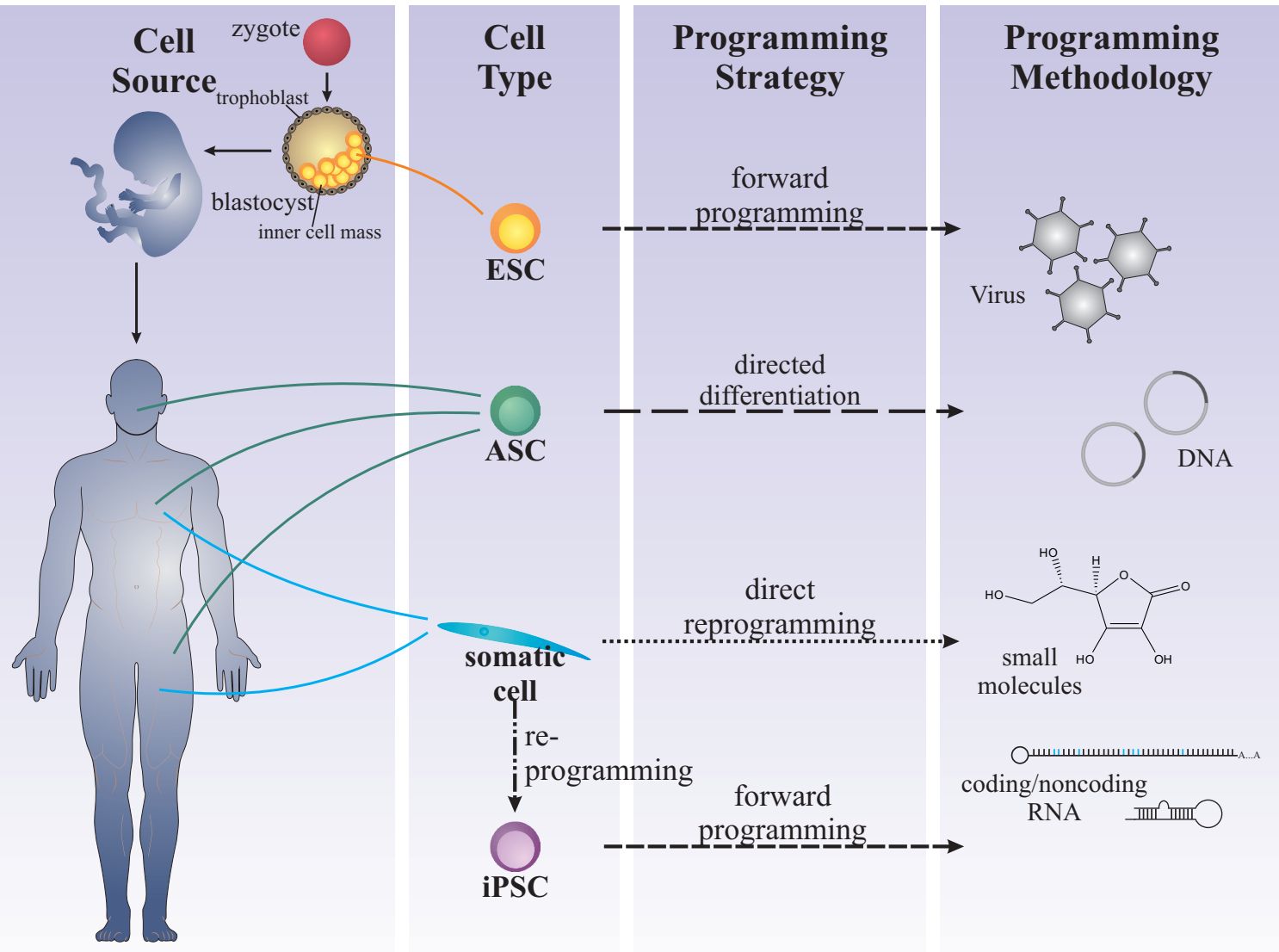

\section{Applications}

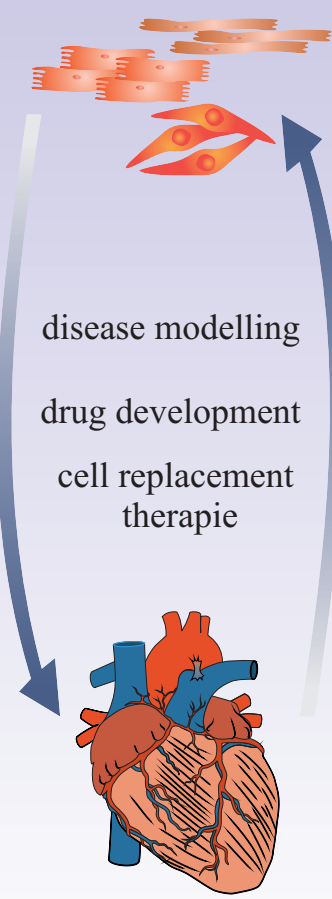


Figure 2

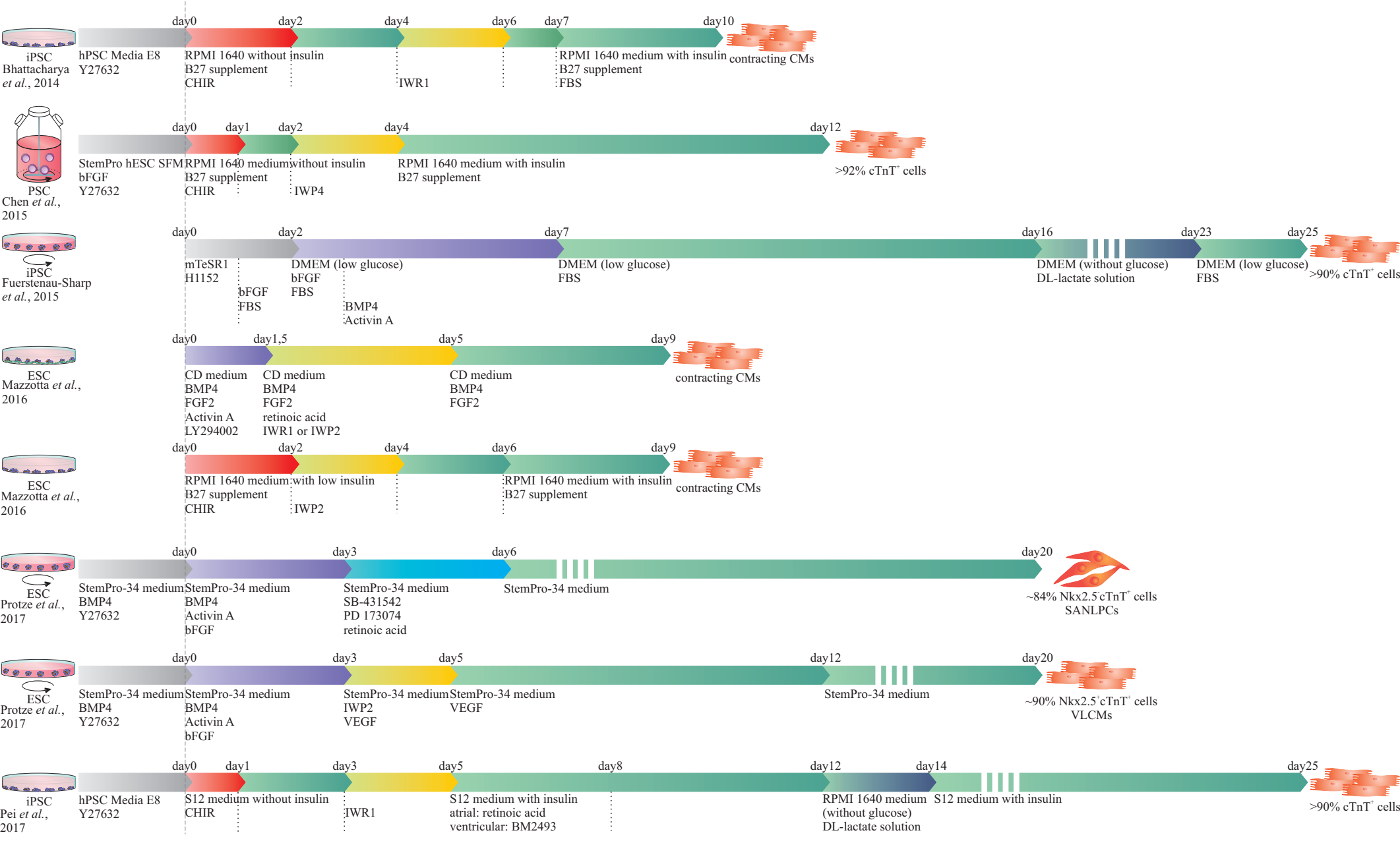

ROCK intibition

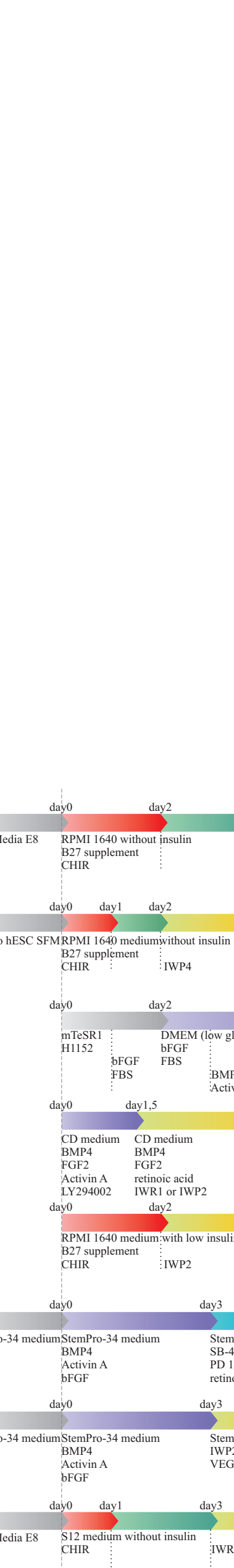


A

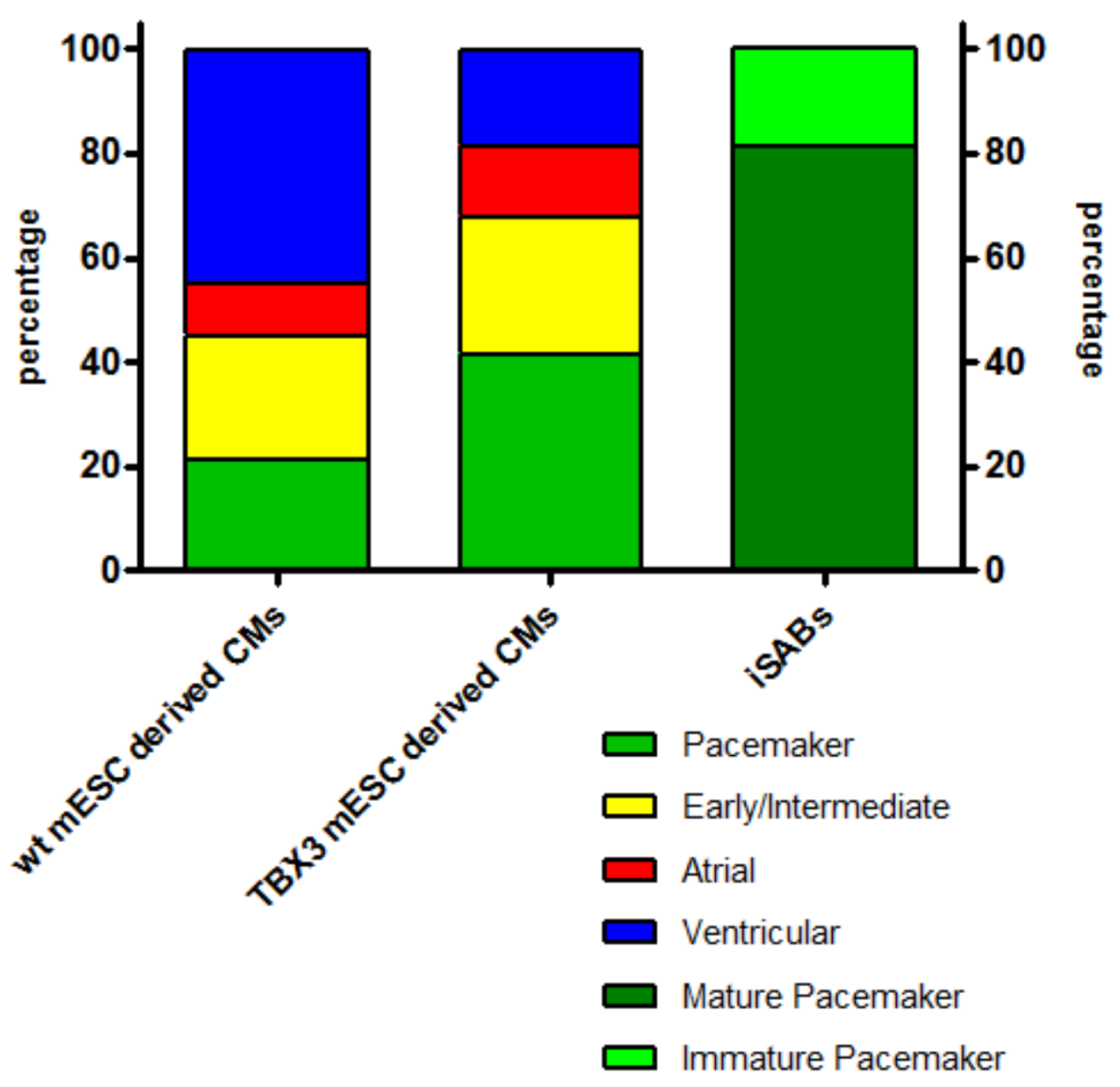

B

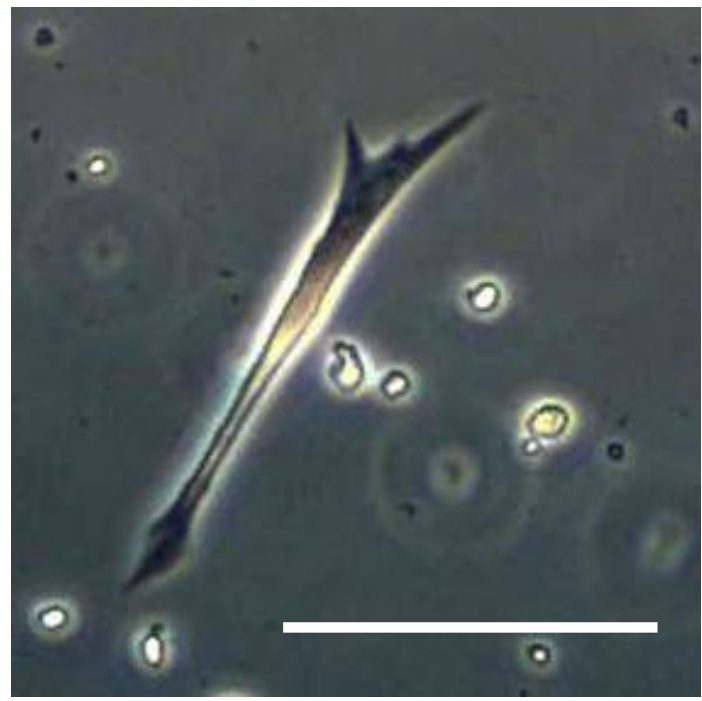

C

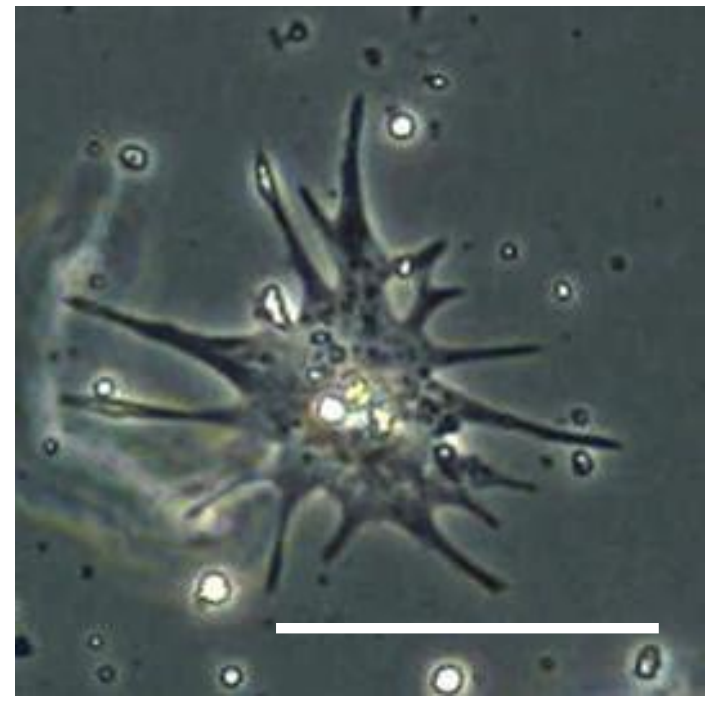


Click here to download high resolution image
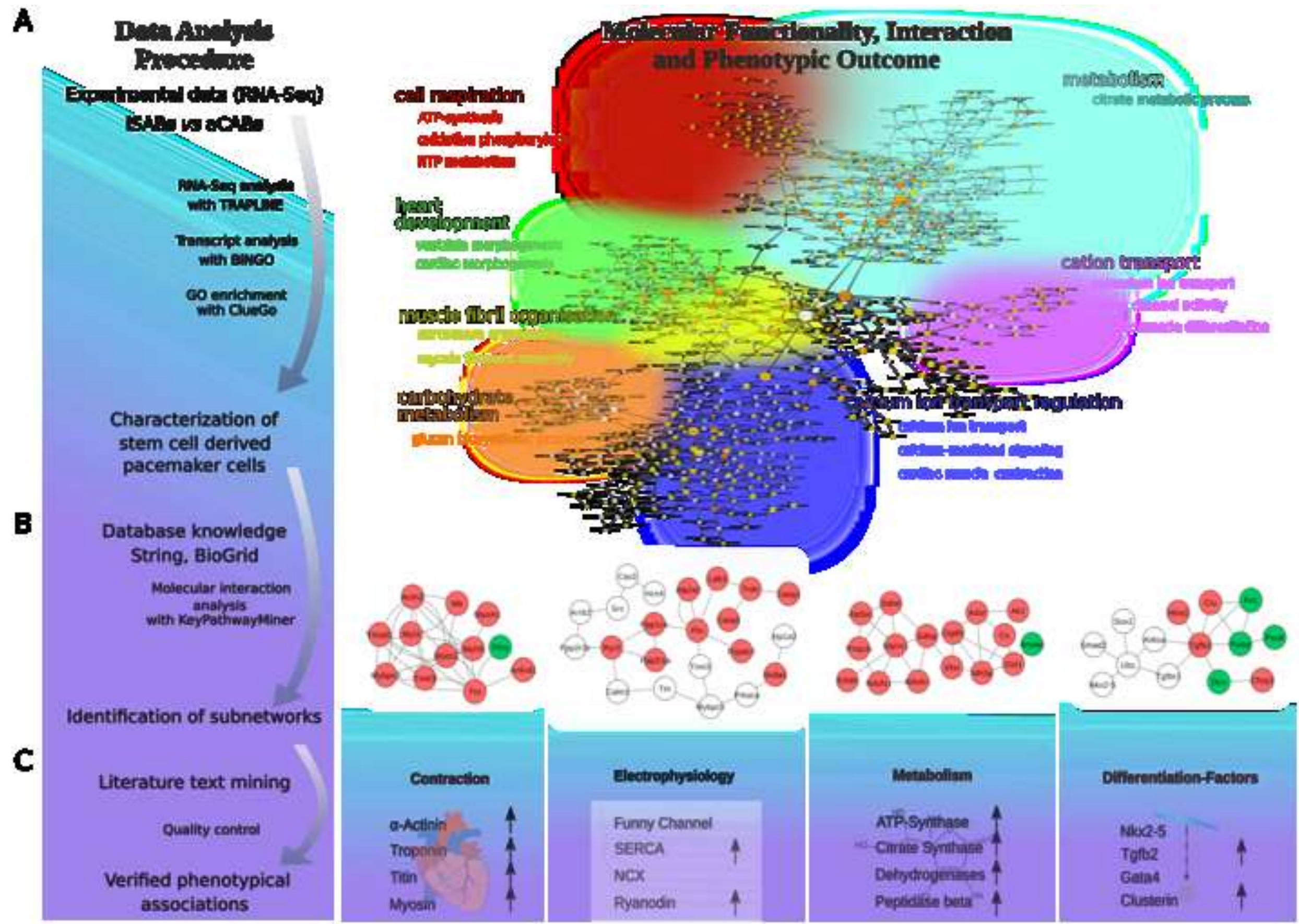


\section{List of abbreviations}

\begin{tabular}{|c|c|}
\hline ADSC & adipose tissue-derived mesenchymal stem cell \\
\hline Alcam & activated leukocyte cell adhesion molecule \\
\hline AMI & acute myocardial infarction \\
\hline ANF & natriuretic factor \\
\hline AP & action potential \\
\hline ASC & adult stem cell \\
\hline AV & atrioventricular \\
\hline AVB & atrioventricular bundle \\
\hline AVN & atrioventricular node \\
\hline BB & bundle branch \\
\hline BCT & bioartificial cardiac tissue \\
\hline bHLH & basic helix-loop-helix \\
\hline Bry & Brachyury \\
\hline CABG & coronary artery bypass graft \\
\hline $\mathrm{Ca}_{\mathrm{v}} 1.3$ & calcium voltage-gated channel subunit alpha1 D \\
\hline $\mathrm{Ca}_{\mathrm{v}} 3.1$ & calcium voltage-gated channel subunit alpha1 G \\
\hline CCS & cardiac conduction system \\
\hline CF & cardiac fibroblast \\
\hline CHD & congenital heart disease \\
\hline CM & cardiomyocyte \\
\hline CMPC & cardiomyocyte progenitor cell \\
\hline CMVEC & cardiac microvascular endothelial cell \\
\hline CPC & cardiac progenitor cell \\
\hline CS & conduction system \\
\hline CV & cardiovascular \\
\hline CVD & cardiovascular disease \\
\hline Cx30.2 & connexin 30.2 \\
\hline Cx40 & connexin40 \\
\hline Cx43 & connexin43 \\
\hline Cx45 & connexin45 \\
\hline ECG & electrocardiogram \\
\hline EMILIN2 & elastin microfibril interface 2 \\
\hline EPC & endothelial progenitor cell \\
\hline EPCS & electric-pulse current stimulation \\
\hline ESC & embryonic stem cell \\
\hline FDA & Food and Drug Administration \\
\hline FGF & fibroblast growth factor \\
\hline FHF & first (primary) heart field \\
\hline GF & growth factor \\
\hline GFP & green fluorescence protein \\
\hline GO & gene ontology \\
\hline HCN4 & hyperpolarization-activated cyclic nucleotide-gated cation channel 4 \\
\hline hPSCreg & Human Pluripotent Stem Cell registry \\
\hline
\end{tabular}




\begin{tabular}{|c|c|}
\hline HTS & high-throughput sequencing \\
\hline iCM & induced cardiomyocyte \\
\hline iPSC & induced pluripotent stem cell \\
\hline iSAB & induced sino-atrial body \\
\hline Is|1 & ISL LIM homeobox 1 \\
\hline JNK & c-Jun N-terminal kinase \\
\hline LVEF & left ventricular ejection fraction \\
\hline MAPK & mitogen-activated protein kinase \\
\hline MB & molecular beacons \\
\hline MEA & multi-electrode-array \\
\hline Mlc2v & myosin, light polypeptide 2 , regulatory, cardiac, slow \\
\hline MSC & mesenchymal stem cell \\
\hline MYH6 & myosin, heavy chain 6 , cardiac muscle, alpha \\
\hline Myh7 & myosin, heavy polypeptide 7 , cardiac muscle, beta \\
\hline $\mathrm{Na}_{\mathrm{v}} 1.5$ & sodium voltage-gated channel alpha subunit 5 \\
\hline Nkx2-5 & NK2 homeobox 5 \\
\hline Nppa & natriuretic peptide $A$ \\
\hline ODE & ordinary differential equation \\
\hline PA & polyacrylate \\
\hline PDMS & polydimethylsiloxane \\
\hline PLGA & polylactide-co-glycolide \\
\hline PMC & pacemaker cell \\
\hline PPT & protein-protein interaction \\
\hline PSC & pluripotent stem cell \\
\hline Rarg & retinoic acid receptor, gamma \\
\hline ROCK & rho-associated, coiled-coil containing protein kinase \\
\hline Rxra & retinoid $\mathrm{X}$ receptor, alpha \\
\hline SA & sino-atrial \\
\hline SAN & sinoatrial node \\
\hline SCD & sudden cardiac death \\
\hline SCN5A & sodium channel, voltage-gated, type $\mathrm{V}$, alpha subunit \\
\hline SHF & second heart field \\
\hline Shox2 & short stature homeobox 2 \\
\hline SIRPA & signal-reduced protein alpha \\
\hline SSS & sick sinus syndrome \\
\hline Tbx18 & T-box 18 \\
\hline Tbx3 & T-box 3 \\
\hline TF & transcription factor \\
\hline THF & tertiary heart field \\
\hline VCAM1 & vascular cell adhesion molecule 1 \\
\hline VCS & ventricular conduction system \\
\hline VEGF & vascular endothelial growth factor \\
\hline wt & wild-type \\
\hline
\end{tabular}


Table 1: Overview of recently published programming strategies of ASCs toward diverse cardiovascular subtypes

\begin{tabular}{|c|c|c|c|c|c|c|c|}
\hline Cell origin & Host & $\begin{array}{l}\text { Delivery } \\
\text { system }\end{array}$ & $\begin{array}{l}\text { in vivo/ } \\
\text { in vitro }\end{array}$ & Factor / Substances & $\begin{array}{l}\text { Target } \\
\text { cell type }\end{array}$ & Special features & Literature \\
\hline CMPC & human & $\begin{array}{l}\text { synthetic } \\
\text { nucleoside } \\
\text { protein }\end{array}$ & in vitro & $\begin{array}{l}5 \mu \mathrm{mol} / \mathrm{L} 5-A Z A \\
\text { following } \\
1 \mathrm{ng} / \mathrm{mL} \text { TGF- } \beta 1\end{array}$ & CM-like & $\begin{array}{l}\text { spontaneously beating myocytes; gap- } \\
\text { junctional communication and action } \\
\text { potentials of maturing cardiomyocytes }\end{array}$ & $\begin{array}{l}\text { Goumans et al., } \\
2007 \text { [117] }\end{array}$ \\
\hline ADSC & rat & protein & in vitro & $10 \mathrm{ng} / \mathrm{mL}$ TGF- $\beta 1$ & CM-like & Actin, cMhc & $\begin{array}{l}\text { Gwak et al., } \\
2009 \text { [107] }\end{array}$ \\
\hline ADSC & human & $\begin{array}{l}\text { synthetic } \\
\text { nucleoside }\end{array}$ & in vitro & $\begin{array}{l}10 \mu \mathrm{mol} / \mathrm{L} 5-A Z A \\
\text { or } \\
100 \mathrm{ng} / \mathrm{mL} \text { TSA } \\
\text { or } \\
\text { Co-culture with RNCM } \\
\text { or } \\
\text { modified cardiomyogenic } \\
\text { medium }\end{array}$ & CM-like & $\begin{array}{l}\text { Highest expression in direct contact co- } \\
\text { culture with RNCM: } \\
\text { Actin, Gata4, Nkx2.5, cTnT } \\
\text { spontaneous contractions } \\
\text { synchronous } \mathrm{Ca}^{2+} \text { transient }\end{array}$ & $\begin{array}{l}\text { Choi et al., } 2010 \\
{[109]}\end{array}$ \\
\hline CMPC & human & miRNA & in vitro & miR-1 and miR-499 & CM-like & $\begin{array}{l}\text { Repression of HDAC4 and Sox6 } \\
\text { Enhanced cardiomyogenesis }\end{array}$ & $\begin{array}{l}\text { Sluijter et al., } \\
2010 \text { [118] }\end{array}$ \\
\hline CMPC & human & miRNA & $\begin{array}{l}\text { in vitro / } \\
\text { in vivo }\end{array}$ & miR-499 & CM-like & $\begin{array}{l}\text { Repression of Sox } 6 \text { and Rod } 1 \\
\text { Enhanced cardiomyogenesis }\end{array}$ & $\begin{array}{l}\text { Hosoda et al., } \\
2011[116]\end{array}$ \\
\hline ADSC & rat & $\begin{array}{l}\text { synthetic } \\
\text { nucleoside }\end{array}$ & in vitro & $\begin{array}{l}\text { Planat-Bérnard } \\
\text { or } \\
5 \mu \mathrm{mol} / \mathrm{L} 5-\mathrm{AZA}\end{array}$ & CM-like & $\begin{array}{l}\text { no spontaneous contraction } \\
\text { Actn } 2, C x-43\end{array}$ & $\begin{array}{l}\text { Carvalho et al., } \\
2012 \text { [105] }\end{array}$ \\
\hline BMSC & mouse & $\begin{array}{l}\text { miRNA } \\
\text { (Lentiviral) }\end{array}$ & in vitro & miR-1 & CM-like & $\begin{array}{l}\text { downregulation of Hes-1 } \\
\text { expression of: Nkx2.5, GATA-4, CTnT, and } \\
\text { Cx43 }\end{array}$ & $\begin{array}{l}\text { Huang et al., } \\
2013 \text { [102] }\end{array}$ \\
\hline BMSC & human & $\begin{array}{l}\text { synthetic } \\
\text { nucleoside }\end{array}$ & in vitro & $\begin{array}{l}6 \mu \mathrm{mol} / \mathrm{L} 5-A Z A \\
\text { or } \\
10 \mathrm{ng} / \mathrm{mL} \text { TGF- } \beta 1\end{array}$ & CM-like & $\begin{array}{l}\text { Expression of: GATA-4, Nkx2.5, Mlc-2a, actin } \\
\text { Higher expression in AZA-group to control: } \\
\text { MIc-2a, Mlc-2v, cTnT }\end{array}$ & $\begin{array}{l}\text { Mohanty et al., } \\
2013[100]\end{array}$ \\
\hline EPC & human & $\begin{array}{l}\text { synthetic } \\
\text { nucleoside }\end{array}$ & in vitro & 5-AZA & CM-like & $\begin{array}{l}\text { expression of: Actn2, cTnT, cTnl and } \\
\text { desmin }\end{array}$ & $\begin{array}{l}\text { López-Ruiz et } \\
\text { al., 2014 [112] }\end{array}$ \\
\hline BMSC & pig & synthetic & in vitro & $10 \mu \mathrm{mol} / \mathrm{L} \mathrm{5}-\mathrm{AZA}$ & CM-like & Expression of: GATA-4, Nkx2.5, $\beta$-MHC and & Li et al., 2015 \\
\hline
\end{tabular}




\begin{tabular}{|c|c|c|c|c|c|c|c|}
\hline & & $\begin{array}{l}\text { nucleoside } \\
\text { lentiviral }\end{array}$ & & IGF-1 & & MEF2c & [99] \\
\hline BMSC & rabbit & DNA Plasmid & $\begin{array}{l}\text { in vitro / } \\
\text { in vivo }\end{array}$ & $\begin{array}{l}\text { GATA4, Nkx2.5 } \\
\text { extracellular environment } \\
\text { co-culture with RNCM }\end{array}$ & CM-like & $\begin{array}{l}\text { In combination with co-culture: } \\
\text { significantly effective and enhance the } \\
\text { ability to repair MI }\end{array}$ & $\begin{array}{l}\text { Li and Zhang, } \\
2015 \text { [98] }\end{array}$ \\
\hline BMSC & mouse & $\begin{array}{l}\text { specific } \\
\text { culture and } \\
\text { substrate } \\
\text { conditions }\end{array}$ & in vitro & $0.3 \mathrm{~mm}$-thick hcECM & CM-like & no evidence of $\mathrm{CM}$ differentiation & $\begin{array}{l}\text { Oberwallner et } \\
\text { al., } 2015 \text { [119] }\end{array}$ \\
\hline BAT & mouse & $\begin{array}{l}\text { specific } \\
\text { culture } \\
\text { conditions }\end{array}$ & $\begin{array}{l}\text { in vitro / } \\
\text { in vivo }\end{array}$ & $\begin{array}{l}1 \% \text { methylcellulose/ } \\
\text { Iscove's Modified } \\
\text { Dulbecco's Medium } \\
\text { containing hematopoietic } \\
\text { cytokines }\end{array}$ & CCS-like & $\begin{array}{l}\text { regular beating } \\
\text { expression of: } \\
\text { Nkx2.5, } \\
\text { GATA6, } \\
\text { Mef2c, } \\
\text { ANF, } \alpha-M H C \text {, } \\
\beta-M H C \text {, } \\
\text { MLC2a, } \\
\text { MLC2v, but not GATA4 }\end{array}$ & $\begin{array}{l}\text { Takahashi et al., } \\
2015 \text { [110] }\end{array}$ \\
\hline BMSC & rat & $\begin{array}{l}\text { synthetic } \\
\text { nucleoside }\end{array}$ & $\begin{array}{l}\text { in vitro / } \\
\text { in vivo }\end{array}$ & $10 \mu \mathrm{mol} / \mathrm{L} \mathrm{5}-\mathrm{AZA}$ & CM-like & Expression of: desmin, actin and cTnT & $\begin{array}{l}\text { Yang et al., } \\
2015 \text { [97] }\end{array}$ \\
\hline BMSC & canine & lentiviral & in vitro & $\begin{array}{l}\text { Shox2 } \\
\text { Co-culture with RNCMs }\end{array}$ & SAN-like & $\begin{array}{l}\text { High levels of: Tbx3, HCN4, Cx45 } \\
\text { Low levels of: Nkx2.5, Cx43 } \\
\text { Able to pace RNCMs with a faster rate }\end{array}$ & $\begin{array}{l}\text { Feng et al., } \\
2016[101]\end{array}$ \\
\hline $\begin{array}{l}\text { SC-ADSC } \\
\text { VL-ADSC } \\
\text { CA-ADSC } \\
\text { SS-ADSC }\end{array}$ & mouse & $\begin{array}{l}\text { specific } \\
\text { culture } \\
\text { conditions }\end{array}$ & $\begin{array}{l}\text { in vitro / } \\
\text { in vivo }\end{array}$ & $\begin{array}{l}\text { Medium suppl. with: } \\
\text { - for vascular smooth } \\
\text { muscle cell differentiation: } \\
\text { TGF- } \beta \\
\text { - for endothelial } \\
\text { differentiation: } \\
\text { hFGF, hVEGF, hIGF, AA, } \\
\text { hEGF } \\
\text { - for cardio- } \\
\text { myocyte differentiation: }\end{array}$ & $\begin{array}{l}\text { CM-like, } \\
\text { endotheli } \\
\text { al cells, } \\
\text { vascular } \\
\text { smooth } \\
\text { muscle } \\
\text { cells }\end{array}$ & Highest potential with: CA-ADSC & $\begin{array}{l}\text { Nagata et al., } \\
2016 \text { [108] }\end{array}$ \\
\hline
\end{tabular}




\begin{tabular}{|c|c|c|c|c|c|c|c|}
\hline & & & & PMA & & & \\
\hline DFC & human & $\begin{array}{l}\text { small } \\
\text { molecule }\end{array}$ & $\begin{array}{l}\text { in vitro / } \\
\text { in vivo }\end{array}$ & $\begin{array}{l}10 \mu \mathrm{M} \text { SAHA in ADMEM } \\
\text { media; } \\
\text { following continuous } \\
\text { culture in media containing } \\
1 \mu \mathrm{M} \text { of SAHA }\end{array}$ & CM-like & $\begin{array}{l}\text { in vitro: } \\
\text { expression of: } \alpha \text {-SMA, TnnT2, desmin, } \\
\text { Actc1 } \\
\text { in vivo homing: } \\
5.6 \pm 1.0 \% \text { heart } \\
3.6 \pm 1.1 \% \text { liver } \\
11.6 \pm 2.7 \% \text { kidney } \\
\text { With differences in IL-2 and IL-10 }\end{array}$ & $\begin{array}{l}\text { Sung et al., } \\
2016[111]\end{array}$ \\
\hline $\begin{array}{l}\text { E-ADSC } \\
\text { P-ADSC } \\
\text { O-ADSC }\end{array}$ & human & $\begin{array}{l}\text { synthetic } \\
\text { nucleoside } \\
\text { retroviral }\end{array}$ & in vitro & $\begin{array}{l}10 \mu \mathrm{mol} / \mathrm{L} 5-A Z A \\
\text { or } \\
\text { ESRRG, GATA4, MEF2C, } \\
\text { MESP1, MYOCD, TBX5, } \\
\text { ZFPM2 }\end{array}$ & CM-like & $\begin{array}{l}\text { 5-AZA: } \\
\text { no increased expression of Actn2 or cTnT } \\
\text { 7-factor-group: } \\
\text { E-ADSC: increased Actn2 and cTnT }\end{array}$ & $\begin{array}{l}\text { Wystrychowski } \\
\text { et al., } 2016 \\
{[106]}\end{array}$ \\
\hline BMSC & human & $\begin{array}{l}\text { synthetic } \\
\text { nucleoside }\end{array}$ & in vitro & $10 \mu \mathrm{mol} / \mathrm{L}$ 5-AZA & CM-like & $\begin{array}{l}\text { Upregulation of: Notch1, Gata4, Nkx2.5, } \alpha- \\
\text { actin, cTnT }\end{array}$ & $\begin{array}{l}\text { Yu et al., } 2016 \\
{[103]}\end{array}$ \\
\hline BMSC & mouse & IncRNA & in vitro & $\begin{array}{l}10 \mu \mathrm{mol} / \mathrm{L} 5-\mathrm{AZA} \\
\text { Braveheart } \\
\text { hypoxia/reoxygenation } \\
\text { treatment }\end{array}$ & CM-like & $\begin{array}{l}\text { Expressions of: } \alpha \text {-actin, cTnT, Nkx2.5, } \\
\text { Gata4, Gata6, Isl-1, EMT-associated genes } \\
\text { (Snail, Twist, N-cadherin) }\end{array}$ & $\begin{array}{l}\text { Hou et al., } 2017 \\
{[104]}\end{array}$ \\
\hline
\end{tabular}

AA: ascorbic acid; Actc1: cardiac muscle alpha actin; Actn2: sarcomeric alpha-actinin; ADSC: adipose tissue-derived mesenchymal stem cells (E: epicardium, P: pericardium, O: omentum, SC: subcutaneous white adipose tissue, VL: visceral white adipose tissue; CA: cardiac brown adipose tissue, SS: subscapular brown adipose tissue); $\alpha$-SMA: alpha-smooth muscle actin; BAT: brown adipose tissue derived stem cells from interscapular area; BMSC: bone marrow mesenchymal stem cells; CCS: cardiac conduction system; CM: cardiomyocyte; CMPC: cardiomyocyte progenitor cells; CPC: cardiac progenitor cells; cTnT: cardiac Troponin T; Cx43/45: Connexin43/45; DFC: dental follicle-derived mesenchymal stem cells; hcECM: human cardiac extracellular matrix; HDAC4: Histone deacetylase 4; hEGF: human epidermal growth factor; hFGF: human fibroblast growth factor; hIGF: human insulin-like growth factor; hVEGF: human vascular endothelial growth factor; IL-2/10: interleukin-2/10; IncRNA: long noncoding RNA; miR: microRNA; Mlc: myosin light chain; PMA: phorbol myristate acetate; RNCM: rat neonatale cardiomyocytes; SAHA: suberoylanilide hydroxamic acid; TGF- $\beta$ : transforming growth factor- $\beta$; TnnT2: cardiac muscle troponin T; TSA: trichostatin A; 5-AZA: 5-azacytidine 
Table 1: Overview of recently published programming strategies of ESCs toward diverse cardiovascular subtypes

\begin{tabular}{|c|c|c|c|c|c|c|c|}
\hline Cell origin & Host & $\begin{array}{l}\text { Delivery } \\
\text { system }\end{array}$ & $\begin{array}{l}\text { in vivo/ } \\
\text { in vitro }\end{array}$ & Factor / Substances & $\begin{array}{l}\text { Target } \\
\text { cell type }\end{array}$ & Special features & Literature \\
\hline $\begin{array}{l}\text { ESC(HES-2, } \\
\mathrm{H} 1, \mathrm{H} 9)\end{array}$ & human & $\begin{array}{l}\text { specific } \\
\text { culture } \\
\text { conditions }\end{array}$ & in vitro & $\begin{array}{l}\text { day 0-1: } 0.5 \mathrm{ng} / \mathrm{mL} \text { of BMP- } \\
4 \\
\text { day 1-4: } 10 \mathrm{ng} / \mathrm{mL} \text { BMP-4, } \\
5 \mathrm{ng} / \mathrm{mL} \text { human bFGF, and } \\
6 \mathrm{ng} / \mathrm{mL} \text { Activin A } \\
\text { day 4-8: basal medium } \\
\text { containing } 10 \mathrm{ng} / \mathrm{mL} \text { VEGF, } \\
150 \mathrm{ng} / \mathrm{mL} \text { Dkk-1 } \\
\text { day } 8 \text {-end: basal medium } \\
\text { with } 10 \mathrm{ng} / \mathrm{mL} \text { VEGF, } \\
10 \mathrm{ng} / \mathrm{mL} \text { human bFGF } \\
\text { MEF-free and serum-free } \\
\text { hESC adherent culture } \\
\text { under cGMP and cGLP } \\
\text { conditions }\end{array}$ & CM-like & $\begin{array}{l}27 \% \mathrm{cTnT}^{+} \\
\text {expression of: sMHC, } \beta M H C, \text { Isl-1, Nkx2.5, } \\
\text { MYH6, Tnnt2, Myl2, and Myl7 }\end{array}$ & $\begin{array}{l}\text { Chen et al., } \\
2012 \text { [163] }\end{array}$ \\
\hline ESC (H7) & human & $\begin{array}{l}\text { specific } \\
\text { culture } \\
\text { conditions }\end{array}$ & in vitro & $\begin{array}{l}\text { 1) MEF and SNL feeder cell } \\
\text { layers + conventional SC } \\
\text { culture medium containing } \\
\text { ko-SR } \\
\text { 2) bFGF } \\
\text { 3) Matrigel matrix + } \\
\text { commercial } \\
\text { mTeSR1 medium }\end{array}$ & CM-like & $\begin{array}{l}\text { most efficient protocol: MEF and SNL } \\
\text { feeder cell layers + conventional SC culture } \\
\text { medium containing ko-SR } \\
\text { least efficient protocol: Matrigel matrix + } \\
\text { commercial mTeSR1 medium; neural } \\
\text { lineage induction }\end{array}$ & $\begin{array}{l}\text { Ojala et al., } \\
2012 \text { [190] }\end{array}$ \\
\hline $\begin{array}{l}\text { ESC (m: J1; } \\
h: H 1)\end{array}$ & $\begin{array}{l}\text { mouse } \\
\text { / } \\
\text { human }\end{array}$ & $\begin{array}{l}\text { specific } \\
\text { purification } \\
\text { method }\end{array}$ & $\begin{array}{l}\text { in vitro / } \\
\text { in vivo }\end{array}$ & CM-specific MBs & CM-like & $\begin{array}{l}\text { in vitro: myosin heavy chain-MB: } 97 \% \\
\text { cTnT }{ }^{+} \text {cells } \\
\text { in vivo: improved cardiac function, without } \\
\text { tumor formation after } 4 \text { weeks }\end{array}$ & $\begin{array}{l}\text { Ban et al., } 2013 \\
\text { [174] }\end{array}$ \\
\hline ESC & mouse & $\begin{array}{l}\text { specific } \\
\text { culture }\end{array}$ & in vitro & $\begin{array}{l}\text { GSK3 inhibitor } \\
\text { P38 MAPK inhibitors }\end{array}$ & CM-like & $\begin{array}{l}\text { ERK activators, CaMKII inhibitors: } \\
\text { proliferative effects only on CMs in early }\end{array}$ & $\begin{array}{l}\text { Uosaki et al., } \\
2013[168]\end{array}$ \\
\hline
\end{tabular}




\begin{tabular}{|c|c|c|c|c|c|c|c|}
\hline & & conditions & & $\begin{array}{l}\text { CaMKII inhibitors } \\
\text { ERK activators }\end{array}$ & & $\begin{array}{l}\text { developmental stage } \\
\text { GSK3 inhibitor (BIO, CHIR), ERK activator } \\
(5 \mu \mathrm{M} \text { SU1498), CaMKII inhibitor ( } 5 \mu \mathrm{M} \\
\text { KN93): induced cell cycle progression in } \\
\text { CM, resulting in CM proliferation }\end{array}$ & \\
\hline ESC & mouse & $\begin{array}{l}\text { specific } \\
\text { culture } \\
\text { conditions }\end{array}$ & in vitro & $\begin{array}{l}44 \text { cytokines/signaling } \\
\text { molecules on day } 3 \text { of diff }\end{array}$ & 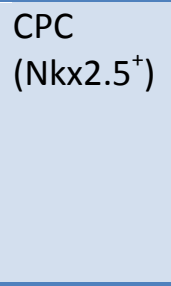 & $\begin{array}{l}\text { IGF1, IGF2, insulin, Wnt3a: significantly } \\
\text { increase CPC formation } \\
\text { IGF, insulin: promote Bry }{ }^{+} \text {mesodermal cell } \\
\text { proliferation } \\
\text { Activin A, BMP2 or BMP4: decrease CPC } \\
\text { formation }\end{array}$ & $\begin{array}{l}\text { Engels et al., } \\
2014 \text { [162] }\end{array}$ \\
\hline ESC & mouse & $\begin{array}{l}\text { specific } \\
\text { culture } \\
\text { conditions }\end{array}$ & in vitro & $\begin{array}{l}2 \% \mathrm{O}_{2} \text { preconditioning ( } 3 \\
\text { passages) of ESCs } \\
\text { diff as EBs in } 20 \% \mathrm{O}_{2}\end{array}$ & CM-like & $\begin{array}{l}\text { significant increased expression of early } \\
\text { differentiation markers FGF5, Eomes } \\
\text { increased gene expression of Eomes, } \\
\text { Goosecoid, Bry, AFP, Sox17, FoxA2, and } \\
\text { protein expression of Bry, Eomes, Sox17, } \\
\text { FoxA2 - diff into mesodermal and } \\
\text { endodermal lineages }\end{array}$ & $\begin{array}{l}\text { Fynes et al., } \\
2014 \text { [185] }\end{array}$ \\
\hline ESC & human & $\begin{array}{l}\text { specific } \\
\text { culture } \\
\text { conditions }\end{array}$ & in vitro & $\begin{array}{l}2 \% \mathrm{O}_{2} \text { preconditioning ( } 3 \\
\text { passages) of ESCs } \\
\text { diff as EBs in } 20 \% \mathrm{O}_{2}\end{array}$ & CM-like & $\begin{array}{l}\text { decreased expression of early } \\
\text { differentiation markers FGF5, Eomes } \\
\text { increased gene expression Nestin, } \beta 3 \text { - } \\
\text { tubulin - diff into ectodermal lineage }\end{array}$ & $\begin{array}{l}\text { Fynes et al., } \\
2014 \text { [185] }\end{array}$ \\
\hline ESC (H9) & human & $\begin{array}{l}\text { specific } \\
\text { substrate } \\
\text { mechanics }\end{array}$ & in vitro & $\begin{array}{l}\text { 1) TCPS } \\
\text { 2) PA hydrogel substrate }\end{array}$ & CM-like & $\begin{array}{l}\text { intermediate stiffness of PA hydrogel } \\
\text { yielded slightly higher } \mathrm{CTnT}^{+} \text {cells without } \\
\text { significant difference to TCPS }\end{array}$ & $\begin{array}{l}\text { Hazeltine et al., } \\
2014 \text { [188] }\end{array}$ \\
\hline ESC (GSES) & mouse & $\begin{array}{l}\text { DNA-Plasmid } \\
\text { specific } \\
\text { purification } \\
\text { method }\end{array}$ & in vitro & $\begin{array}{l}\text { Tbx3 } \\
\text { Myh6-promoter-based } \\
\text { antibiotic selection }\end{array}$ & SAN-like & $\begin{array}{l}>80 \% \text { physiologically and } \\
\text { pharmacologically functional pacemaker } \\
\text { cells with highly increased beating rates } \\
(300-400 \mathrm{bpm})\end{array}$ & $\begin{array}{l}\text { Jung et al., } \\
2014 \text { [89] } \\
\text { Rimmbach et } \\
\text { al., } 2015 \text { [90] }\end{array}$ \\
\hline ESC & mouse & lentiviral & in vitro & Fndc5 & CM-like & $\begin{array}{l}\text { sign. expression of: Flk1, Isl1, Nkx2.5, } \\
\text { Gata4, Mef2C, } \alpha-M H C, c T n T, \alpha \text {-actinin, } \\
\text { SM22 } \alpha, \alpha-S M A\end{array}$ & $\begin{array}{l}\text { Rabiee et al., } \\
2014 \text { [152] }\end{array}$ \\
\hline
\end{tabular}




\begin{tabular}{|c|c|c|c|c|c|c|c|}
\hline $\begin{array}{l}\text { ESC (H7, ESI- } \\
017)\end{array}$ & human & $\begin{array}{l}\text { specific } \\
\text { culture and } \\
\text { substrate } \\
\text { conditions }\end{array}$ & in vitro & $\begin{array}{l}\text { matrix-free, scalable, } \\
\text { and GMP-compliant process } \\
\text { culture: including first CHIR } \\
\text { and second IWP-4 induction }\end{array}$ & CM-like & $\begin{array}{l}>90 \% \text { pure } \mathrm{CM} ; 1.5 \text { to } 2 \times 10^{9} \mathrm{CM} / \mathrm{L} \text { (up to } \\
1 \mathrm{~L} \text { spinner flasks) } \\
\text { ESI-017: } 6 \mu \mathrm{M} \text { CHIR - } 91 \% \mathrm{cTnT}^{+} \\
\text {H7: } 12 \mu \mathrm{M} \text { CHIR - } 92 \% \mathrm{cTnT}^{+}\end{array}$ & $\begin{array}{l}\text { Chen et al., } \\
2015 \text { [157] }\end{array}$ \\
\hline ESC & mouse & lentiviral & $\begin{array}{l}\text { in vitro / } \\
\text { in vivo }\end{array}$ & $\begin{array}{l}\text { Nkx2.5 } \\
\text { Isl1 }\end{array}$ & $\begin{array}{l}\text { CM-like } \\
\text { SAN-like }\end{array}$ & $\begin{array}{l}\text { Overexpression of Nkx2.5: inhibition of Isl1 } \\
\text { expression } \\
\text { Overexpression of Isl1: enhanced } \\
\text { specification of cardiac progenitors, earlier } \\
\text { cardiac differentiation, and increased } \\
\text { cardiomyocyte number, upregulation of } \\
\text { nodal-specific genes (e.g. Hcn4), } \\
\text { downregulation of transcripts of working } \\
\text { myocardium }\end{array}$ & $\begin{array}{l}\text { Dorn et al., } \\
2015 \text { [155] }\end{array}$ \\
\hline ESC (R1) & mouse & adenoviral & in vitro & Shox2 & SAN-like & $\begin{array}{l}\text { increase in Cx45, decrease in Cx43, Nkx2.5 } \\
\text { SHOX2-EBs beat spontaneously }(83 \pm 7 \% \\
\text { versus } 15 \pm 6 \%) \\
\text { pacemaker-like AP profile ( } 62 \%)\end{array}$ & $\begin{array}{l}\text { lonta et al., } \\
2015 \text { [154] }\end{array}$ \\
\hline $\begin{array}{l}\text { ESC (CGR8, } \\
\alpha \mathrm{PIG} 44)\end{array}$ & mouse & $\begin{array}{l}\text { specific } \\
\text { culture } \\
\text { conditions }\end{array}$ & in vitro & $100 \mu \mathrm{M} \mathrm{AA}$ & CM-like & $\begin{array}{l}\text { AA application from day } 0-2 \text { increases } \\
\text { cardiogenesis } 2-4 \text {-fold } \\
\text { day } 5 \text { : increased expression of genes } \\
\text { associated with angiogenesis, blood } \\
\text { vessel development, hematopoiesis/ } \\
\text { erythropoiesis, Bry, Mef2c, Myl7 }\end{array}$ & $\begin{array}{l}\text { Ivanyuk et al., } \\
2015 \text { [169] }\end{array}$ \\
\hline ESC (H7) & human & $\begin{array}{l}\text { specific } \\
\text { purification } \\
\text { method }\end{array}$ & in vitro & CM-specific MBs & CM-like & NPPA-MB: $92 \% \alpha$-actinin ${ }^{+}$cells & $\begin{array}{l}\text { Jha et al., } 2015 \\
\text { [175] }\end{array}$ \\
\hline ESC $(\alpha-P I G)$ & mouse & $\begin{array}{l}\text { specific } \\
\text { culture and } \\
\text { substrate } \\
\text { conditions }\end{array}$ & in vitro & $0.3 \mathrm{~mm}$-thick hcECM & CM-like & $\begin{array}{l}\text { hcECM supported proliferation } \\
\text { significantly increased expression of: Myh6, } \\
\text { Tnnt2, Nkx2.5 } \\
\text { Matrigel or Geltrex use did not induce } \\
\text { cardiac-specific markers }\end{array}$ & $\begin{array}{l}\text { Oberwallner et } \\
\text { al., } 2015 \text { [119] }\end{array}$ \\
\hline
\end{tabular}




\begin{tabular}{|c|c|c|c|c|c|c|c|}
\hline $\begin{array}{l}\text { ESC (derived } \\
\text { from } \\
\text { C57BL/6 } \\
\text { mouse } \\
\text { strain) }\end{array}$ & mouse & $\begin{array}{l}\text { specific } \\
\text { culture } \\
\text { conditions }\end{array}$ & in vitro & $10 \mu \mathrm{M}$ resveratrol & CM-like & $\begin{array}{l}\text { promotes mESC differentiation towards } \\
\text { CM } \\
\text { enhanced beating properties of EBs } \\
\text { significantly higher expression of: Nkx2.5, } \\
\text { Mef2c, Tbx5, dHand2, aMHC, Cx43, cTnC1 }\end{array}$ & $\begin{array}{l}\text { Ding et al., } \\
2016 \text { [202] }\end{array}$ \\
\hline ESC & mouse & DNA-Plasmid & in vitro & CIBZ & CM-like & $\begin{array}{l}\text { CIBZ depletion: induced expression of Bry, } \\
\text { MesP1, Gata6, Sox17 } \\
\text { CIBZ overexpression: decreased expression } \\
\text { of Bry, MesP1, Flk1 IsI1, Gata4, Mhc, cTnl; } \\
\text { Significant suppression of beating EBs }\end{array}$ & $\begin{array}{l}\text { Kotoku et al., } \\
2016[151]\end{array}$ \\
\hline $\begin{array}{l}\text { ESC (in- } \\
\text { house and } \\
\text { E14tg2a) }\end{array}$ & mouse & $\begin{array}{l}\text { specific } \\
\text { culture } \\
\text { conditions }\end{array}$ & in vitro & $\begin{array}{l}\text { monolayer culture without } \\
\text { feeder cells } \\
\text { day 0-1: IMDM/Ham's F12, } \\
\text { N2 supplement } \\
\text { B27 supplement, } \\
0.5 \mathrm{mM} \mathrm{AA,} 4.5 \times 10^{-4} \mathrm{M} \mathrm{MTG} \\
\text { day 1-3: } 8 \mathrm{ng} / \mathrm{mL} \text { Activin A, } \\
0.5 \mathrm{ng} / \mathrm{mL} \text { BMP4, } 5 \mathrm{ng} / \mathrm{mL} \\
\text { hVEGF } \\
\text { day 3-13: StemPro-34 SF } \\
\text { medium, } 0.5 \mathrm{mM} \mathrm{AA,} \\
5 \mathrm{ng} / \mathrm{mL} \text { hVEGF, } 10 \mathrm{ng} / \mathrm{mL} \\
\text { bFGF, } 50 \mathrm{ng} / \mathrm{mL} \text { hFGF10 }\end{array}$ & CM-like & $\begin{array}{l}60 \% \mathrm{CM} \\
35-40 \% \mathrm{cTnT}^{+} / \mathrm{MF}^{+} 0^{+} \\
\text {E14tg2a: more efficient CM-like cell yield } \\
\text { with } 5 \mathrm{ng} / \mathrm{mL} \text { Activin A }\end{array}$ & $\begin{array}{l}\text { Kokkinopoulos } \\
\text { et al., } 2016 \\
\text { [165] }\end{array}$ \\
\hline ESC & mouse & $\begin{array}{l}\text { specific } \\
\text { culture } \\
\text { conditions }\end{array}$ & $\begin{array}{l}\text { in vitro / } \\
\text { in vivo }\end{array}$ & $\begin{array}{l}25 \mathrm{ng} / \mathrm{ml} \text { Activin, } 20 \mathrm{ng} / \mathrm{ml} \\
\text { BMP2, } 20 \mathrm{ng} / \mathrm{ml} \text { BMP4, } \\
100 \mathrm{ng} / \mathrm{ml} \text { DLL1, } 10 \mathrm{ng} / \mathrm{ml} \\
\mathrm{bFGF}, 10 \mathrm{ng} / \mathrm{ml} \text { FGF8, } \\
20 \mathrm{ng} / \mathrm{ml} \text { Tgfb, } 100 \mathrm{ng} / \mathrm{ml} \\
\text { Wnt3a, } 5 \mu \mathrm{M} \text { IWR1, } 5 \mu \mathrm{M} \\
\text { SB431542 }\end{array}$ & $\begin{array}{l}\text { MesP1- } \\
\text { CPC }\end{array}$ & $\begin{array}{l}\text { BMP4 exposure: day 0-4 highest } \\
\text { improvement of MesP }{ }^{+} \text {cells }(29.6 \%) \\
\left.\text { BMP4 + IWR1: MesP }{ }^{+} \text {cells ( } 13.8 \%\right) \\
\text { however differentiate more efficiently into } \\
\text { cardiac myocytes } \\
\text { In vivo: injection of day } 5 \text { MesP1-CPCs led } \\
\text { to improved survival of MI mice and } \\
\text { decreased scar formation }\end{array}$ & $\begin{array}{l}\text { Liu et al., } 2016 \\
\text { [144] }\end{array}$ \\
\hline ESC (E14T) & mouse & $\begin{array}{l}\text { specific } \\
\text { purification }\end{array}$ & $\begin{array}{l}\text { in vitro / } \\
\text { in vivo }\end{array}$ & $\begin{array}{l}\text { selection based on VE- } \\
\text { cadherin promoter }\end{array}$ & CEDP & $\begin{array}{l}\text { Differentiation into: } \sim 47 \% \mathrm{cTnT}^{+} \text {and } \\
\sim 28 \% \text { VE-cadherin }{ }^{+} \text {cells }\end{array}$ & $\begin{array}{l}\text { Maltabe et al., } \\
2016[173]\end{array}$ \\
\hline
\end{tabular}




\begin{tabular}{|c|c|c|c|c|c|c|c|}
\hline & & method & & & & & \\
\hline $\begin{array}{l}\text { ESC (H7 and } \\
\text { H9) }\end{array}$ & human & $\begin{array}{l}\text { specific } \\
\text { culture } \\
\text { conditions }\end{array}$ & in vitro & $\begin{array}{l}\text { 1) day 0-1.5: BMP4, FGF2, } \\
\text { Activing A, LY294002 } \\
\text { day 1.5-5: BMP4, FGF2, RA, } \\
\text { IWR1/IWP2 } \\
\text { day 5-9: BMP4, FGF2 } \\
\text { 2) day 0-2: CHIR99021, day } \\
\text { 2-4: IWP2 }\end{array}$ & CM-like & $\begin{array}{l}\text { WNT3, WNT8: regulation of Bry expression } \\
\text { and mesoderm induction (via FZD7 + } \\
\text { canonical Wnt signaling) } \\
\text { WNT5A/5B: regulation of MesP1 } \\
\text { expression and cardiovascular } \\
\text { development (via ROR2 + noncanonical } \\
\text { Wnt signaling) } \\
\text { WNT2, WNT5A/5B, WNT11: regulation of } \\
\text { late functional CM diff (via FZD4, FZD6 + } \\
\text { noncanonical Wnt signaling) }\end{array}$ & $\begin{array}{l}\text { Mazzotta et al., } \\
2016 \text { [161] }\end{array}$ \\
\hline ESC (5) & mouse & DNA-Plasmid & in vitro & CITED2 & CM-like & $\begin{array}{l}\text { Cited2 depletion: significantly decreased } \\
\text { expression of Brachyury, Mesp1, Isl1, } \\
\text { Gata4, Tbx5 } \\
\text { Cited2 overexpression: stimulation of } \\
\text { Brachyury, Mesp1, Isl1, Gata4, Tbx5, Myh6, } \\
\text { cTnT; protein interaction with Isl1 }\end{array}$ & $\begin{array}{l}\text { Pacheco-Leyva } \\
\text { et al., } 2016 \\
{[150]}\end{array}$ \\
\hline ESC & mouse & $\begin{array}{l}\text { miRNA } \\
\text { lentiviral }\end{array}$ & in vitro & miR-322/-503 & CM-like & $\begin{array}{l}\text { Highest enriched miRNA in Mesp1 lineage } \\
\text { (miR-322/-503) } \\
\text { Celf1 is a direct target of miR-322/-503 } \\
\text { miR-322/-503 selectively inhibits } \\
\text { neuroectoderm differentiation }\end{array}$ & $\begin{array}{l}\text { Shen et al., } \\
2016 \text { [145] }\end{array}$ \\
\hline ESC & human & $\begin{array}{l}\text { specific } \\
\text { culture } \\
\text { conditions }\end{array}$ & in vitro & $\begin{array}{l}\text { monolayer-directed } \\
\text { differentiation protocol } \\
\text { different concentrations of } \\
\text { activin A and BMP4 }\end{array}$ & $\begin{array}{l}\text { CM-like } \\
\text { EC-like }\end{array}$ & $\begin{array}{l}\text { generation of distinct CVP populations } \\
\text { following derivation of cardiogenic versus } \\
\text { hemogenic mesoderm } \\
>90 \% \mathrm{CD} 31^{+} / \text {VE-cadherin }{ }^{+} \mathrm{ECs}\end{array}$ & $\begin{array}{l}\text { Palpant et al., } \\
2017 \text { [164] }\end{array}$ \\
\hline $\begin{array}{l}\text { ESC (HES3- } \\
N k \times 2.5^{g f / w} \\
\text { HES2) }\end{array}$ & human & $\begin{array}{l}\text { specific } \\
\text { culture } \\
\text { conditions }\end{array}$ & $\begin{array}{l}\text { in vitro / } \\
\text { in vivo }\end{array}$ & $\begin{array}{l}\text { EB formation, } 5 \% \mathrm{O}_{2}(\mathrm{~d} 0-12) \\
\text { Generation of VLCMs: } \\
\text { day 0-3: } 10 \mathrm{ng} / \mathrm{mL} \mathrm{rhBMP} 4 \\
6 \mathrm{ng} / \mathrm{mL} \text { rhActivinA, } 5 \mathrm{ng} / \mathrm{mL} \\
\mathrm{rhbFGF} \\
\text { day 3-5: } 0.5 \mu \mathrm{M} \text { IWP2, } \\
10 \mathrm{ng} / \mathrm{mL} \mathrm{rhVEGF}\end{array}$ & $\begin{array}{l}\text { CM-like } \\
\text { SAN-like }\end{array}$ & $\begin{array}{l}\text { FGF pathway blocks the development of } \\
\text { NKX2- } 5^{+} \text {CM } \\
\text { Marker expression of the SAN lineage } \\
\text { (TBX18, SHOX2, TBX3), typical pacemaker } \\
\text { action potentials }(90 \%) \text {, ion current } \\
\text { profiles and chronotropic response }\end{array}$ & $\begin{array}{l}\text { Protze et al., } \\
2017 \text { [159] }\end{array}$ \\
\hline
\end{tabular}




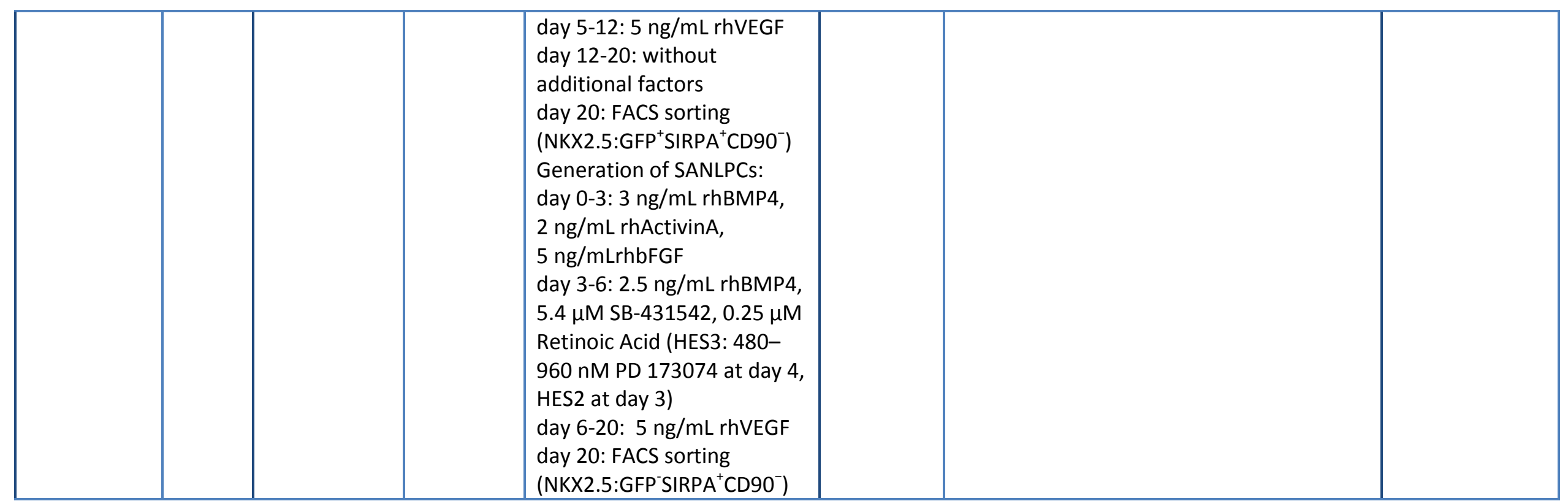

AA: ascorbic acid; $\beta$ MHC: $\beta$ myosin heavy chain; bFGF: basic fibroblast growth factor; BMP: bone morphogenetic protein; bpm: beats per minute; Bry: Brachyury; CAMKII: $\mathrm{Ca}^{2+} /$ calmodulin-dependent protein kinase II; CEDP: cardiac and endothelial dual-progenitor population; CHIR: CHIR99021, Wnt activator; CIBZ: BTB domain-containing zinc finger protein; CM: cardiomyocytes; CPC: cardiac progenitor cell; CTnC1: cardiac troponin C1; CVP: cardiovascular progenitor cell; diff: differentiation; EB: embryoid bodies; EC: endothelial cell; ERK: extracellular signal-regulated kinase; ESC: embryonic stem cells; Fndc5: Fibronectin type III domain-containing 5 protein (also known as: peroxisomal protein (PEP)); GSK3: glycogen synthase kinase-3; hcECM: human cardiac extracellular matrix; IWP: WNT inhibitor; ko-SR: knockout serum replacement; LY294002: phosphoinositide 3-kinase inhibitor; MAPK: p38 mitogen-activated protein kinase; MB: molecular beacon; MTG: monothioglycerol; PA: polyacrylamide; PD 173074: FGF signaling inhibitor; SAN: sinoatrial node; SB-431542: Activin/Nodal/TGF $\beta$ signaling inhibitor; sMHC: sarcomeric myosin heavy chain; TCPS: tissue culture polystyrene; Tnnt2: cardiac troponin T2; VEGF: vascular endothelial growth factor; (x): number of cell lines used. 
Table 1: Overview of recently published programming strategies of iPSCs toward diverse cardiovascular subtypes

\begin{tabular}{|c|c|c|c|c|c|c|c|}
\hline Cell origin & Host & $\begin{array}{l}\text { Delivery } \\
\text { system }\end{array}$ & $\begin{array}{l}\text { in vivo/ } \\
\text { in vitro }\end{array}$ & Factor / Substances & $\begin{array}{l}\text { Target } \\
\text { cell type }\end{array}$ & Special features & Literature \\
\hline iPSC & $\begin{array}{l}\text { mouse } \\
\text { and } \\
\text { human }\end{array}$ & $\begin{array}{l}\text { specific } \\
\text { culture } \\
\text { conditions }\end{array}$ & in vitro & $\begin{array}{l}16 \text { cytokines and chemical } \\
\text { components }\end{array}$ & CM-like & $\begin{array}{l}\text { AA: CM enhancement in } 11 \text { lines } \\
\text { Application of } 50 \mu \mathrm{g} / \mathrm{mL} \text { AA during day 2-6: } \\
7.3 \text {-fold (miPSC) and } 30.2 \text {-fold (hiPSC) } \\
\text { enhanced yield through specific increase in } \\
\text { the proliferation of CPCs via the MEK- } \\
\text { ERK1/2 pathway }\end{array}$ & $\begin{array}{l}\text { Cao et al., } 2012 \\
\text { [203] }\end{array}$ \\
\hline $\begin{array}{l}\text { iPSC } \\
\text { (UTA.00112. } \\
\text { hFF, } \\
\text { UTA.04602. } \\
\text { WT, } \\
\text { UTA.00525.L } \\
\text { QT2, } \\
\text { UTA.00106.h } \\
\text { FF) }\end{array}$ & human & $\begin{array}{l}\text { specific } \\
\text { culture } \\
\text { conditions }\end{array}$ & in vitro & $\begin{array}{l}\text { 1) MEF and SNL feeder cell } \\
\text { layers + conventional SC } \\
\text { culture medium containing } \\
\text { ko-SR } \\
\text { 2) bFGF } \\
\text { 3) Matrigel matrix + } \\
\text { commercial } \\
\text { mTeSR1 medium }\end{array}$ & CM-like & $\begin{array}{l}\text { most efficient protocol: MEF and SNL } \\
\text { feeder cell layers + conventional SC culture } \\
\text { medium containing ko-SR } \\
\text { least efficient protocol: Matrigel matrix + } \\
\text { commercial mTeSR1 medium; neural } \\
\text { lineage induction } \\
\text { exception: UTA.04602.WT line - highest } \\
\text { amount of beating areas on Matrigel in } \\
\text { mTeSR1 }\end{array}$ & $\begin{array}{l}\text { Ojala et al., } \\
2012 \text { [190] }\end{array}$ \\
\hline $\begin{array}{l}\text { iPSC (BJ1- } \\
\text { iPS10) }\end{array}$ & human & $\begin{array}{l}\text { specific } \\
\text { selection } \\
\text { method }\end{array}$ & $\begin{array}{l}\text { in vitro / } \\
\text { in vivo }\end{array}$ & CM-specific MBs & CM-like & $\begin{array}{l}\text { in vitro: myosin heavy chain-MB: } 97 \% \\
\text { cTnT }^{+} \text {cells } \\
\text { in vivo: improved cardiac function, without } \\
\text { tumor formation after } 4 \text { weeks }\end{array}$ & $\begin{array}{l}\text { Ban et al., } 2013 \\
\text { [174] }\end{array}$ \\
\hline iPSC & human & $\begin{array}{l}\text { long-term } \\
\text { culture }\end{array}$ & in vitro & $\begin{array}{l}\text { EB-formation } \\
360 \text { day culture }\end{array}$ & CM-like & $\begin{array}{l}\text { day 14: immature high-density Z-bands } \\
\text { day 180: mature Z-, } A-, \mathrm{H}-\text {-, and I-bands } \\
\text { day 360: } \mathrm{M-}, \mathrm{Z}-, \mathrm{A}-\mathrm{H}-\text {-, and I-bands }\end{array}$ & $\begin{array}{l}\text { Kamakura et al. } \\
2013 \text { [204] }\end{array}$ \\
\hline iPSC & $\begin{array}{l}\text { mouse } \\
\text { and } \\
\text { human }\end{array}$ & $\begin{array}{l}\text { specific } \\
\text { culture } \\
\text { conditions } \\
\text { antibiotic } \\
\text { selection }\end{array}$ & in vitro & $\begin{array}{l}\alpha \mathrm{MHC} \text {-antibiotic resistance } \\
\text { gene } \\
\text { EB formation } \\
\mathrm{BCT} \text { (cells + liquid collagen } \\
\text { type I and Matrigel) } \\
\text { AA } \\
\text { static stretch }\end{array}$ & CM-like & $\begin{array}{l}\text { structurally and functionally homogenous } \\
\text { syncytium } \\
\text { enhanced the contractility of murine and } \\
\text { human BCTs (active tension of } \\
4.4 \mathrm{mN} / \mathrm{mm}^{2} \text { ) }\end{array}$ & $\begin{array}{l}\text { Kensah et al., } \\
2013 \text { [171] }\end{array}$ \\
\hline
\end{tabular}




\begin{tabular}{|c|c|c|c|c|c|c|c|}
\hline $\begin{array}{l}\text { iPSC (from: } \\
\text { skeletal } \\
\text { muscle PC, } \\
\text { skeletal } \\
\text { muscle } \\
\text { fibroblasts) }\end{array}$ & mouse & $\begin{array}{l}\text { retroviral } \\
\text { specific } \\
\text { culture } \\
\text { conditions }\end{array}$ & in vitro & $\begin{array}{l}16 \mathrm{~h} \text { after EB seeding onto } \\
\text { gelatin: exposure to hypoxia } \\
\left(3 \% \mathrm{O}_{2}\right) \text { for } 24 \mathrm{~h}\end{array}$ & CM-like & $\begin{array}{l}\text { EBs normoxic conditions: } 59 \% \text { beating } \\
\text { EBs hypoxic conditions: abolished beating, } \\
\text { significant increased expression of Bry and } \\
\text { Isl1, HIF-1 } \alpha \text {; accumulation of HIF-1 } \alpha \text { and } \beta \text { - } \\
\text { catenin in nuclear protein extracts, } \\
\text { suggesting involvement of } \\
\text { the Wnt/beta-catenin pathway }\end{array}$ & $\begin{array}{l}\text { Medley et al., } \\
2013 \text { [205] }\end{array}$ \\
\hline ¡PSC & human & $\begin{array}{l}\text { specific } \\
\text { culture } \\
\text { conditions }\end{array}$ & in vitro & $\begin{array}{l}\text { day 0-1: } 6 \mu \mathrm{M} \text { CHIR } \\
\text { day 2-3: diff medium } \\
\text { day 4-5: } 5 \mu \mathrm{M} \text { IWR-1 } \\
\text { day 6-7: diff medium } \\
\text { day 8-end: diff medium + } \\
\text { insulin }\end{array}$ & CM-like & $\begin{array}{l}\text { expression of: IRX4, MLC2v, MLC2a, TNNI3, } \\
\text { and TNNT2 }\end{array}$ & $\begin{array}{l}\text { Bhattacharya et } \\
\text { al., } 2014 \text { [156] }\end{array}$ \\
\hline $\begin{array}{l}\text { iPSC (from } \\
\text { BJ } \\
\text { fibroblasts) }\end{array}$ & human & $\begin{array}{l}\text { mRNA } \\
\text { reprogrammi } \\
\text { ng } \\
\text { specific } \\
\text { culture } \\
\text { conditions }\end{array}$ & in vitro & $\begin{array}{l}\text { day 0-8: EBs in low adhesion } \\
\text { culture dished, } 5 \mu \mathrm{M} \\
\text { SB203580 } \\
\text { day 9-week 8: EBs plated on } \\
0.1 \% \text { gelatin coated dishes, } \\
\text { without SB203580 }\end{array}$ & CM-like & $\begin{array}{l}\text { day 11-14 until day 50-60: rhythmically } \\
\text { contracting areas (55-75 \%) } \\
\text { day 6: expression of Isl1, Kdr, Mef2C, } \\
\text { NKx2.5, Gata4, Tbx3/5/20 } \\
\text { day 8, 14: expression of Tnni2, Mlc2a/v, } \\
\text { Myh7, Myl3/4, Ca } 1.3, \mathrm{Hcn} 4, \text { Serca2a, Ryr2 } \\
\text { specific response to pharmacological } \\
\text { substance administration }\end{array}$ & $\begin{array}{l}\text { Mehta et al., } \\
2014 \text { [133] }\end{array}$ \\
\hline iPSC (IMR90) & human & $\begin{array}{l}\text { specific } \\
\text { culture } \\
\text { conditions }\end{array}$ & in vitro & day 20-27: 20 ng/mL T3 & CM-like & $\begin{array}{l}\text { increased cardiomyocyte size, anisotropy, } \\
\text { and sarcomere length } \\
\text { 2-fold higher force per-beat }\end{array}$ & $\begin{array}{l}\text { Yang et al., } \\
2014[206]\end{array}$ \\
\hline $\begin{array}{l}\text { iPSC (from } \\
\text { Dr. Joseph } \\
\text { Wu, } \\
\text { Stanford) }\end{array}$ & human & $\begin{array}{l}\text { specific } \\
\text { culture and } \\
\text { substrate } \\
\text { conditions }\end{array}$ & in vitro & $\begin{array}{l}\text { matrix-free, scalable, } \\
\text { and GMP-compliant process } \\
\text { culture: including first CHIR } \\
\text { and second IWP-4 induction }\end{array}$ & CM-like & $\begin{array}{l}>90 \% \text { pure } \mathrm{CM} ; 1.5 \text { to } 2 \times 10^{9} \mathrm{CM} / \mathrm{L} \text { (up to } \\
1 \mathrm{~L} \text { spinner flasks) } \\
\text { relationship between } \\
\text { aggregate size and } \mathrm{CHIR} \text { concentration } \\
6 \mu \mathrm{M} \mathrm{CHIR} 94 \% \mathrm{CTnT}^{+}\end{array}$ & $\begin{array}{l}\text { Chen et al., } \\
2015 \text { [157] }\end{array}$ \\
\hline $\begin{array}{l}\text { iPSC (from } \\
\text { activated T } \\
\text { cells, } \\
\text { hPBMC) }\end{array}$ & human & $\begin{array}{l}\text { retroviral } \\
\text { specific } \\
\text { culture } \\
\text { conditions }\end{array}$ & in vitro & $\begin{array}{l}\text { day 1-13: } 5 \% \mathrm{O}_{2} \text { and } 7 \% \\
\mathrm{CO}_{2} \\
\text { day 1-2: } 50 \% \text { mTeSR, } 45 \% \\
\text { DMEM (low }\end{array}$ & CM-like & $\begin{array}{l}\text { before selection: } 30-45 \% \mathrm{CM} \text {, expression } \\
\text { of cTnT and MLC2v } \\
\text { after lactate selection: } 90 \% \mathrm{CM} \text {, } \\
\text { electrophysiological characterization: }\end{array}$ & $\begin{array}{l}\text { Fuerstenau- } \\
\text { Sharp et al., } \\
2015 \text { [158] }\end{array}$ \\
\hline
\end{tabular}




\begin{tabular}{|c|c|c|c|c|c|c|c|}
\hline & & $\begin{array}{l}\text { metabolic } \\
\text { selection } \\
\text { (lactate) }\end{array}$ & & $\begin{array}{l}\text { glucose), } 5 \% \mathrm{FBS}, 1 \mu \mathrm{M} \\
\mathrm{H} 1152,100 \mathrm{ng} / \mathrm{mL} \text { bFGF } \\
\text { day 2: } 2 / 3 \text { medium change } \\
\text { to: DMEM (low glucose), } \\
10 \% \mathrm{FBS}, 50 \mathrm{ng} / \mathrm{mL} \text { bFGF } \\
\text { day 3-7: DMEM (low } \\
\text { glucose), } 10 \% \mathrm{FBS} \text {, } \\
50 \mathrm{ng} / \mathrm{mL} \text { bFGF, } 6 \mathrm{ng} / \mathrm{mL} \\
\text { activing A, } 10 \mathrm{ng} / \mathrm{mL} \mathrm{BMP4} \\
\text { day 8-13: DMEM (low } \\
\text { glucose), } 10 \% \mathrm{FBS} \\
\text { day } 14-e n d: 20 \% \mathrm{O}_{2} \text { and } \\
7 \% \mathrm{CO}_{2} \\
\text { day } 16-18: \text { DMEM (no } \\
\text { glucose), } 1 \% \text { sodium DL- } \\
\text { lactate solution }\end{array}$ & & $\begin{array}{l}\text { ventricular, atrial and nodal-like action } \\
\text { potentials }\end{array}$ & \\
\hline iPSC & mouse & $\begin{array}{l}\text { specific } \\
\text { culture } \\
\text { conditions }\end{array}$ & $\begin{array}{l}\text { in vitro / } \\
\text { in vivo }\end{array}$ & $\begin{array}{l}\text { aMHC-GFP } \\
\text { EB formation } \\
\text { diff. after EB: } 1 \text { week } \\
\text { treatment with } 1 \% \text { DMSO } \\
\text { and/or } 100 \mathrm{ng} / \mathrm{mL} \mathrm{NRG-1 \beta}\end{array}$ & CM-like & $\begin{array}{l}\text { significantly higher expression of: Gata4, } \\
\text { Gata6, aMhc, Myhl7, Myl3, cTnnc1, Ryr2, } \\
\text { Serca2a } \\
\text { ventricular-like AP } \\
\text { preserves cardiac function in mouse model }\end{array}$ & $\begin{array}{l}\text { Iglesias-García } \\
\text { et al., } 2015 \\
\text { [207] }\end{array}$ \\
\hline $\begin{array}{l}\text { iPSC (TiB7.4, } \\
\text { AT25) }\end{array}$ & mouse & $\begin{array}{l}\text { specific } \\
\text { culture } \\
\text { conditions }\end{array}$ & in vitro & $100 \mu \mathrm{M}$ AA & CM-like & $\begin{array}{l}\text { AA application from day } 0-2 \text { increases } \\
\text { cardiogenesis } 2-4 \text {-fold }\end{array}$ & $\begin{array}{l}\text { Ivanyuk et al., } \\
2015 \text { [169] }\end{array}$ \\
\hline $\begin{array}{l}\text { iPSC (DF19-9 } \\
-11 T . H)\end{array}$ & human & RNA & in vitro & $\begin{array}{l}\text { EB-formation } \\
\text { diff after EB: transfection } \\
\text { with CIR RNA }\end{array}$ & CM-like & $\begin{array}{l}\text { spindle-shaped cells with characteristic } \\
\text { expression of: cTnT, tropomyosin, } \alpha \text {-actinin }\end{array}$ & $\begin{array}{l}\text { Kochegarov et } \\
\text { al., } 2015[208]\end{array}$ \\
\hline iPSC (AT25) & mouse & $\begin{array}{l}\text { specific } \\
\text { culture and } \\
\text { substrate } \\
\text { conditions }\end{array}$ & in vitro & $0.3 \mathrm{~mm}$-thick hcECM & CM-like & $\begin{array}{l}\text { hcECM supported the proliferation } \\
\text { significantly increased expression of: Myh6, } \\
\text { Tnnt2, Nkx2.5 } \\
\text { Matrigel, Geltrex: did not induce cardiac- } \\
\text { specific markers }\end{array}$ & $\begin{array}{l}\text { Oberwallner et } \\
\text { al., } 2015 \text { [119] }\end{array}$ \\
\hline iPSC & mouse & lentiviral & in vitro & telomerase-competent cell & CM-like & iPSCs $^{\text {highTRF1 }}:$ differentiate earlier and more & Aguado et al., \\
\hline
\end{tabular}




\begin{tabular}{|c|c|c|c|c|c|c|c|}
\hline & & & & $\begin{array}{l}\text { lines (TRF1 expression) } \\
\text { AA }\end{array}$ & & $\begin{array}{l}\text { efficiently into CMs } \\
\text { iPSC }^{\text {lowTRF1 }} \text { : differentiate very efficiently to } \\
\text { the ectoderm lineage } \\
\text { AA: increase CM yield with iPSC } C^{\text {highTRF1 }}\end{array}$ & 2016 [170] \\
\hline $\begin{array}{l}\text { ¡PSC } \\
\text { (Duanqing } \\
\text { Pei, Chinese } \\
\text { Academy of } \\
\text { Sciences) }\end{array}$ & mouse & $\begin{array}{l}\text { specific } \\
\text { selection } \\
\text { method }\end{array}$ & in vitro & $\begin{array}{l}0.001-0.2 \mu \mathrm{mol} / \mathrm{L} \text { EPI } \\
10 \mu \mathrm{mol} / \mathrm{L} \text { phentolamine } \\
5 \mu \mathrm{mol} / \mathrm{L} \text { propranolol } \\
10 \mu \mathrm{mol} / \mathrm{L} \text { phenylephrine } \\
10 \mu \mathrm{mol} / \mathrm{L} \text { clonidine } \\
1 \mu \mathrm{mol} / \mathrm{L} \text { isoproterenol } \\
10 \mu \mathrm{mol} / \mathrm{L} \text { PD } 98059\end{array}$ & CM-like & $\begin{array}{l}\text { EPI and activation of } \alpha 1-A R \text { : enhancement } \\
\text { of CM differentiation via MEK-ERK1/2 } \\
\text { signaling }\end{array}$ & $\begin{array}{l}\text { Li et al., } 2016 \\
\text { [167] }\end{array}$ \\
\hline $\begin{array}{l}\text { iPSC (from: } \\
\text { MEFs) }\end{array}$ & mouse & $\begin{array}{l}\text { retroviral } \\
\text { specific } \\
\text { culture } \\
\text { conditions }\end{array}$ & in vitro & $\begin{array}{l}\text { EB formation } \\
\text { medium containing: DMEM, } \\
15 \% \text { fetal } \\
\text { bovine serum, } 0.2 \mathrm{mmol} / \mathrm{I} \mathrm{L}- \\
\text { glutamine, } 0.1 \mathrm{mmol} / / \mathrm{I} \\
\text { nonessential amino } \\
\text { acids, and } 0.1 \mathrm{mmol} / \mathrm{l} \beta- \\
\text { mercaptoethanol }\end{array}$ & CM-like & $\begin{array}{l}\text { After EB formation: expression of Flk1, } \alpha- \\
\text { actinin, } \alpha-M H C, c T n T, C \times 43, N k x 2.5 \\
\text { active beating: } 360 \mathrm{bpm} \\
\text { incompletely differentiated iPS cells: } \\
\text { teratoma formation after transplantation } \\
\text { into a SCID mouse model of } \mathrm{MI}\end{array}$ & $\begin{array}{l}\text { Wang et al., } \\
2016 \text { [209] }\end{array}$ \\
\hline $\begin{array}{l}\text { iPSC (from } \\
\text { foreskin } \\
\text { tissue) }\end{array}$ & human & $\begin{array}{l}\text { specific } \\
\text { culture } \\
\text { conditions } \\
\text { metabolic } \\
\text { selection } \\
\text { (lactate) }\end{array}$ & in vitro & $\begin{array}{l}\text { chemical-defined and } \\
\text { albumin-free medium } \\
\text { day 0-1: S12 without insulin } \\
\text { medium, } 4-8 \mu \mathrm{M} \text { CHIR } \\
\text { day 1-3: S12 without insulin } \\
\text { medium } \\
\text { day 3-5: S12 without insulin } \\
\text { medium, } 5 \mu \mathrm{M} \text { IWR-1 } \\
\text { day 5-end: S12 with insulin } \\
\text { medium, atrial diff: } 1 \mu \mathrm{M} \\
\text { RA, ventricular diff: } 1 \mu \mathrm{M} \\
\text { BMS493 }\end{array}$ & $\begin{array}{l}\text { CM-like } \\
\text { Atrial-like }\end{array}$ & $\begin{array}{l}\text { highly homogenous atrial and ventricular } \\
\text { myocytes in a scalable fashion with normal } \\
\text { electrophysiological properties }\end{array}$ & $\begin{array}{l}\text { Pei et al., } 2017 \\
\text { [160] }\end{array}$ \\
\hline
\end{tabular}

AA: ascorbic acid; AP: action potential; AR: adrenergic receptor; BCT: bioartificial cardiac tissue; bpm: beats per minute; BMS493: RA inhibitor; Bry: Brachyury; CHIR: CHIR99021 (GSK-3 inhibitor, Wht activator); CIR: specific fetal cardiac-inducing RNA (fragment of N-sulfoglucosaminesulfohydrolase and the caspase 
recruitment domain family member 14 precursor); Cx43: connexin 43; clonidine: selective a2-AR agonist; cTnT: cardiac troponin T; DMSO: dimethyl sulfoxide; EPI: epinephrine; hcECM: human cardiac extracellular matrix; hPBMC: human peripheral blood mononuclear cells; H1152: Rho-kinase (ROCK) inhibitor; IRX4: iroquois-class homeodomain protein IRX-4; isoproterenol: $\beta$-AR agonist; IWP-4: WNT inhibitor; IWR-1: WNT inhibitor; MEF: mouse embryonic fibroblast; MLC2a: myosin regulatory light chain 2, atrial isoform; MLC2v: myosin regulatory light chain 2, ventricular/cardiac muscle is oform; NRG-1B: Neuregulin-1 3 ; PC: progenitor cells; PD98059: MEK1/2 inhibitor; MI: myocardial infarction; phenylephrine: selective $\alpha 1$-AR agonist; phentolamine: $\alpha$-AR antagonist; propranolol: $\beta$-AR antagonist; RA: retinoic acid; SB203580: MAPK signaling inhibitor; SCID: severe combined immunodeficiency; TNNI3: cardiac troponin I; Tnnt2: cardiac troponin T2; TRF1: shelterin-complex protein; T3: Tri-iodo-L-thyronine. 
Table 1: Overview of recently published direct reprogramming strategies of somatic cells toward diverse cardiovascular subtypes

\begin{tabular}{|c|c|c|c|c|c|c|c|}
\hline Cell origin & Host & $\begin{array}{l}\text { Delivery } \\
\text { system }\end{array}$ & $\begin{array}{l}\text { in vivo/ } \\
\text { in vitro }\end{array}$ & Factor / Substances & $\begin{array}{l}\text { Target } \\
\text { cell type }\end{array}$ & Special features & Literature \\
\hline $\begin{array}{l}\text { neonatal } \\
\text { cardiac } \\
\text { fibroblasts }\end{array}$ & mouse & $\begin{array}{l}\text { retroviral or } \\
\text { lentiviral }\end{array}$ & $\begin{array}{l}\text { in vitro / } \\
\text { in vivo }\end{array}$ & Gata4, Mef2c, Tbx5 & CM-like & $\begin{array}{l}30 \% \mathrm{cTnT}^{+} \text {cells (to a lesser extent in tail- } \\
\text { tip fibroblasts) } \\
\text { Upregulation of: Myh6, Actc1, Actn2, Nppa }\end{array}$ & $\begin{array}{l}\text { leda et al., } 2010 \\
\text { [227] }\end{array}$ \\
\hline $\begin{array}{l}\text { neonatal } \\
\text { cardiac } \\
\text { fibroblasts }\end{array}$ & mouse & $\begin{array}{l}\text { lentiviral } \\
\text { microRNA } \\
\text { specific } \\
\text { culture } \\
\text { conditions }\end{array}$ & $\begin{array}{l}\text { in vitro / } \\
\text { in vivo }\end{array}$ & $\begin{array}{l}\text { miR-1/-122/-208/499 } \\
\text { JAK inhibitor I }\end{array}$ & CM-like & $\begin{array}{l}\text { day 3: } 2 \text { - to } 3 \text {-fold upregulation of Mef2c, } \\
\text { Tbx5, Hand2, Nkx2.5, Gata4 } \\
\text { day 6: expression of cTnT, cTnl, sarcomeric } \\
\text { actinin } \\
\text { reprogramming efficiency: } 1.13-5.28 \% \text { in } \\
\text { non-JAK inhibitor I-treated cells } \\
\text { with JAK inhibitor I: } 28 \% \text { aMHC cells } \\
\text { enhanced cardiac function in mouse model }\end{array}$ & $\begin{array}{l}\text { Jayawardena et } \\
\text { al., } 2012 \text { and } \\
2014[235,236]\end{array}$ \\
\hline $\begin{array}{l}\text { fibroblasts } \\
\text { (from hESCs; } \\
\text { H9) }\end{array}$ & human & retroviral & in vitro & $\begin{array}{l}\text { EGFP, ESRRG, GATA4, } \\
\text { MEF2C, MESP1, TBX5, } \\
\text { MYOCD, ZFPM2 } \\
\text { SIS3 }\end{array}$ & CM-like & $\begin{array}{l}20 \% \text { functional } \mathrm{Ca}^{2+} \text { transients } \\
\text { cardiac marker expression of: cTnT, } \alpha- \\
\text { Actinin, ACTC1, ACTN2, MYH6, MYL2, } \\
\text { MYL7, TNNT2, NPPA, } \\
\text { PLN, and RYR2 } \\
\text { SIS3 significantly decreases } \alpha \mathrm{MHC}^{+} \text {cells }\end{array}$ & $\begin{array}{l}\text { Fu et al., } 2013 \\
\text { [221] }\end{array}$ \\
\hline $\begin{array}{l}\text { tail tip and } \\
\text { embryonic } \\
\text { fibroblasts } \\
\text { (B6;129S4) }\end{array}$ & mouse & retroviral & in vitro & $\begin{array}{l}\text { M3 domain of mouse MyoD } \\
\text { fused on carboxy-terminus } \\
\text { of Mef2c, Gata4, Hand2, } \\
\text { Tbx5 } \\
\text { GSK126 (day 1-4), UNC0638 } \\
\text { (day 3-7) }\end{array}$ & CM-like & $\begin{array}{l}\text { Reprogramming efficiency: } \\
\mathrm{MM}_{3}-\mathrm{GHT} \text { : } 3.5 \% \text { (> 15-fold increase) } \\
\mathrm{MM}_{3}-\mathrm{GHT}+\mathrm{GSK} 126 \text { : further increase to } \\
\text { control 2.1-fold (most efficient } \\
\text { combination) } \\
\mathrm{MM}_{3}-\mathrm{GHT}+\text { UNC0638: further increase to } \\
\text { control 2-fold }\end{array}$ & $\begin{array}{l}\text { Hirai et al., } \\
2013[219] \text { and } \\
2014[220]\end{array}$ \\
\hline NRVM & rat & adenoviral & $\begin{array}{l}\text { in vitro / } \\
\text { in vivo }\end{array}$ & Tbx18 & SAN-like & $\begin{array}{l}\text { downregulation of } \mathrm{Cx} 43 \\
\text { pacemaker-like AP profile }(9.2 \%)\end{array}$ & $\begin{array}{l}\text { Kapoor et al., } \\
2013 \text { [242] }\end{array}$ \\
\hline $\begin{array}{l}\text { neonatal } \\
\text { foreskin and }\end{array}$ & human & retroviral & in vitro & $\begin{array}{l}\text { Gata4, Hand2, Tbx5, } \\
\text { myocardin, miR-1/-133 }\end{array}$ & CM-like & $\begin{array}{l}\sim 35 \% \text { tropomyosin }^{+} \text {cells } \\
\sim 20 \% \text { cTnT }^{+} \text {cells }\end{array}$ & $\begin{array}{l}\text { Nam et al., } \\
2013[222]\end{array}$ \\
\hline
\end{tabular}




\begin{tabular}{|c|c|c|c|c|c|c|c|}
\hline $\begin{array}{l}\text { adult } \\
\text { fibroblasts }\end{array}$ & & & & Culture time: 4-11 weeks & & & \\
\hline $\mathrm{CM}$ & pig & adenoviral & $\begin{array}{l}\text { in vitro / } \\
\text { in vivo }\end{array}$ & Tbx18 & SAN-like & $\begin{array}{l}\text { mean HR was higher in TBX18-transduced } \\
\text { animals } \\
\text { sympathetic predominance in the } \\
\text { TBX18-transduced group } \\
\text { TBX18-transduced animals had persistent } \\
\text { and stable activity }\end{array}$ & $\begin{array}{l}\text { Hu et al., } 2014 \\
{[243]}\end{array}$ \\
\hline $\begin{array}{l}\text { embryonic } \\
\text { fibroblasts } \\
\text { (C57BL/6) }\end{array}$ & mouse & $\begin{array}{l}\text { chemical } \\
\text { cocktail }\end{array}$ & in vitro & 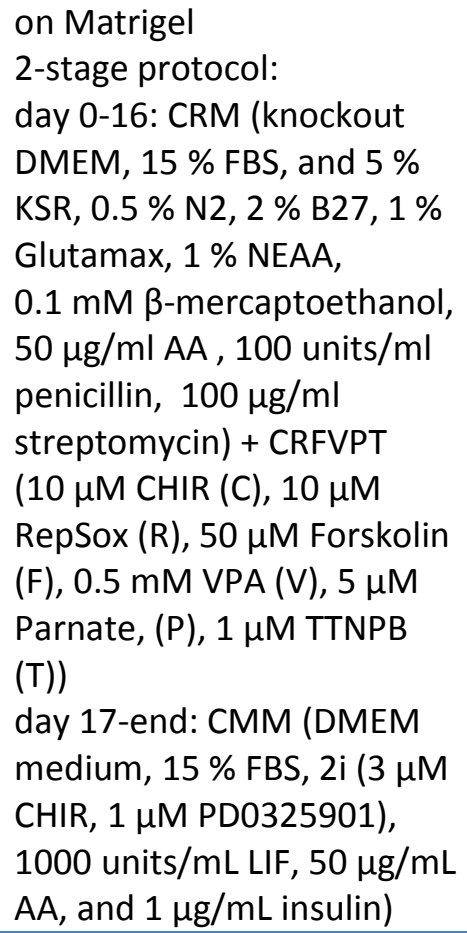 & CM-like & $\begin{array}{l}\text { morphology: spindle shape, rod shape or } \\
\text { round shape } \\
\text { spontaneously beating activity: increases } \\
\text { from day } 8 \\
\text { cardiac marker expression of: Mef2c, } \alpha \text { - } \\
\text { Actinin, Gata4, cTnT, Nkx2.5, } \alpha-\mathrm{MHC}, \mathrm{N}- \\
\text { cadherin, Cx43, cTnl } \\
\text { action potential of atrial- and ventricular- } \\
\text { like CMs }\end{array}$ & $\begin{array}{l}\text { Fu et al., } 2015 \\
\text { [218] }\end{array}$ \\
\hline $\begin{array}{l}\text { cardiac } \\
\text { fibroblasts }\end{array}$ & mouse & $\begin{array}{l}\text { retroviral } \\
\text { antibiotic } \\
\text { selection }\end{array}$ & in vitro & Gata4, Mef2c, Tbx5 & CM-like & $\begin{array}{l}\text { stoichiometry of } \mathrm{G}, \mathrm{M}, \mathrm{T} \text { protein expression } \\
\text { influences reprogramming efficiency } \\
\text { high Mef2c and low Gata4, Tbx } 5 \text { most } \\
\text { efficient }\end{array}$ & $\begin{array}{l}\text { Wang et al., } \\
2015 \text { [228] }\end{array}$ \\
\hline embryonic & mouse & retroviral & in vitro & Gata4, Hand2, Mef2c, Tbx5, & CM-like & spontaneously beating activity without & Zhao et al., \\
\hline
\end{tabular}




\begin{tabular}{|c|c|c|c|c|c|c|c|}
\hline fibroblasts & & & & $\begin{array}{l}\text { miR-1/-133, Y-27632, } \\
\text { Thiazovivin, SR-3677, A83- } \\
01\end{array}$ & & $\begin{array}{l}\text { signaling inhibitors: GHMT > day } 21 \text {, } \\
\text { GHMT+miR-1/-133 > day } 8 \\
\text { ROCK inhibitors enhance reprogramming of } \\
\text { MEFs } \\
\text { TGF- } \beta \text { inhibitors enhance reprogramming } \\
\text { of MEFs most efficiently }\end{array}$ & 2015 [217] \\
\hline $\begin{array}{l}\text { embryonic, } \\
\text { adult } \\
\text { cardiac, tail } \\
\text { tip }\end{array}$ & mouse & retroviral & in vitro & $\begin{array}{l}\text { Gata4, Hand2, Mef2c, Tbx5, } \\
\text { Akt1 }\end{array}$ & CM-like & $\begin{array}{l}\text { spontaneously beating activity: MEFs }>\text { day } \\
7(50 \%>\text { day } 21), C F s>\text { day } 14, \text { TTFs }>\text { day } \\
21 ; \\
\text { responsive to } \beta \text {-adrenoreceptor } \\
\text { pharmacologic modulation, polynucleated, } \\
\text { and hypertrophic }\end{array}$ & $\begin{array}{l}\text { Zhou et al., } \\
2015 \text { [216] }\end{array}$ \\
\hline $\begin{array}{l}\text { neonatal } \\
\text { cardiac } \\
\text { fibroblasts }\end{array}$ & mouse & $\begin{array}{l}\text { retroviral } \\
\text { (TFs) and } \\
\text { lentiviral } \\
\text { (shRNA) }\end{array}$ & in vitro & $\begin{array}{l}\text { Gata4, Mef2c, Tbx5 } \\
\text { shRNA of } 35 \text { selected } \\
\text { components of chromatin } \\
\text { modifying or remodeling } \\
\text { complexes }\end{array}$ & CM-like & $\begin{array}{l}\text { Bm1 downregulation significantly } \\
\text { enhanced } \mathrm{CM} \text { generation }\end{array}$ & $\begin{array}{l}\text { Zhou et al., } \\
2016[231]\end{array}$ \\
\hline $\begin{array}{l}\text { neonatal } \\
\text { cardiac } \\
\text { fibroblasts }\end{array}$ & mouse & $\begin{array}{l}\text { TFs } \\
\text { specific } \\
\text { culture } \\
\text { conditions }\end{array}$ & $\begin{array}{l}\text { in vitro / } \\
\text { in vivo }\end{array}$ & $\begin{array}{l}\text { Gata4, Mef2c, Tbx5 } \\
\text { SB431542 } \\
\text { XAV939 }\end{array}$ & CM-like & $\begin{array}{l}\text { 8-fold increased reprogramming efficiency } \\
\text { beating cells } 1 \text { week after reprogramming } \\
\text { enhanced cardiac function in mouse model }\end{array}$ & $\begin{array}{l}\text { Mohamed et } \\
\text { al., } 2017 \text { [230] }\end{array}$ \\
\hline
\end{tabular}

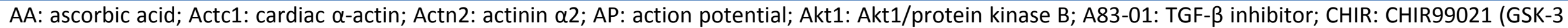

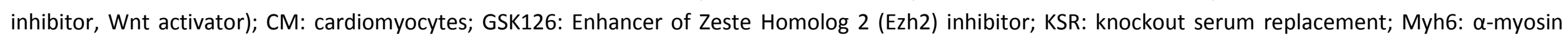

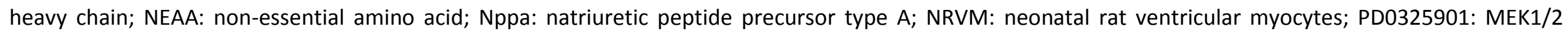

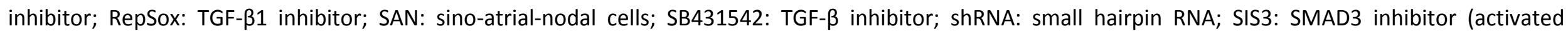

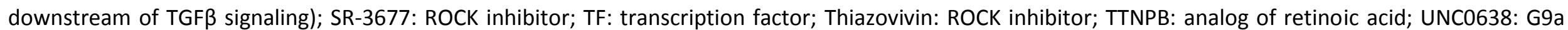
and GLP inhibitor; VPA: valproic acid (histone deacetylase inhibitor); XAV939: WNT inhibitor; Y-27632: ROCK inhibitor. 